\title{
A comparison between the homocyclic aromatic metabolic pathways from plant-derived compounds by bacteria and fungi
}

Lubbers, Ronnie J. M.

2019-11-15

Lubbers, R J M , Dilokpimol , A, Visser , J, Makela, M R , Hilden, K S \& de Vries, R P 2019 , ' A comparison between the homocyclic aromatic metabolic pathways from plant-derived compounds by bacteria and fungi ' , Biotechnology Advances, vol. 37 , no. 7 , 107396 . https://doi.org/10.1016/j.biotechadv.2019.05.002

http://hdl.handle.net/10138/327458

https://doi.org/10.1016/j.biotechadv.2019.05.002

cc_by_nc_nd

acceptedVersion

Downloaded from Helda, University of Helsinki institutional repository.

This is an electronic reprint of the original article.

This reprint may differ from the original in pagination and typographic detail.

Please cite the original version. 
A comparison between the homocyclic aromatic metabolic pathways from plant-derived compounds by bacteria and fungi

Ronnie J. M. Lubbers ${ }^{a}$, Adiphol Dilokpimola , Jaap Vissera, Miia R. Mäkelä ${ }^{b}$, Kristiina S. Hildén ${ }^{b}$, and Ronald P. de Vries ${ }^{\mathrm{a}, \mathrm{b} *}$

${ }^{\text {a}}$ Fungal Physiology, Westerdijk Fungal Biodiversity Institute \& Fungal Molecular Physiology, Utrecht

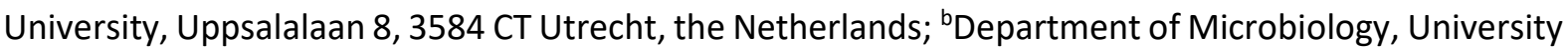
of Helsinki, Viikinkaari 9, Helsinki, Finland.

*Corresponding author: r.devries@westerdijkinstitute.nl

E-mail addresses other authors:

Ronnie Lubbers: r.lubbers@westerdiikinstitute.nl

Adiphol Dilokpimol: a.dilokpimol@westerdijkinstitute.nl

Jaap Visser: j.visser@westerdijkinstitute.nl

Miia Mäkelä: miia.r.makela@helsinki.fi

Kristiina Hildén: kristiina.s.hilden@helsinki.fi 


\begin{abstract}
Aromatic compounds derived from lignin are of great interest for renewable biotechnical applications. They can serve in many industries e.g. as biochemical building blocks for bioplastics or biofuels, or as antioxidants, flavor agents or food preservatives. In nature, lignin is degraded by microorganisms, which results in the release of homocyclic aromatic compounds. Homocyclic aromatic compounds can also be linked to polysaccharides, tannins and even found freely in plant biomass. As these compounds are often toxic to microbes already at low concentrations, they need to be degraded or converted to less toxic forms. Prior to ring cleavage, the plant- and lignin-derived aromatic compounds are converted to seven central ring-fission intermediates, i.e. catechol, protocatechuic acid, hydroxyquinol, hydroquinone, gentisic acid, gallic acid and pyrogallol through complex aromatic metabolic pathways and used as energy source in the tricarboxylic acid cycle. Over the decades, bacterial aromatic metabolism has been described in great detail. However, the studies on fungal aromatic pathways are scattered over different pathways and species, complicating a comprehensive view of fungal aromatic metabolism. In this review, we depicted the similarities and differences of the reported aromatic metabolic pathways in fungi and bacteria. Although both microorganisms share the main conversion routes, many alternative pathways are observed in fungi. Understanding the microbial aromatic metabolic pathways could lead to metabolic engineering for strain improvement and promote valorization of lignin and related aromatic compounds.
\end{abstract}

\title{
Keywords
}

Aromatic metabolism, fungus, lignin, platform chemicals, plant-derived homocyclic aromatic compounds 


\begin{tabular}{|c|c|}
\hline Abbreviations & \\
\hline Acar & Aryl carboxylic acid reductase \\
\hline AroY & Protocatechuate decarboxylase \\
\hline BadA & Benzoate-CoA ligase \\
\hline BadDEFG & Benzoate-CoA reductase subunits $D, E, F$ and $G$ \\
\hline Bagl & Gentisate 1,2-dioxygenase \\
\hline BagL & L-cysteine-dependent maleylpyruvate isomerase \\
\hline BagK & Fumarylpyruvate hydrolase \\
\hline BclA & Benzoate-CoA ligase \\
\hline BenABC & Benzoate 1,2-dioxygenase subunits $A, B$ and $C$ \\
\hline BenD & Benzoate 1,2-dioxygenase subunit D \\
\hline BphA & Benzoate 4-monooxygenase \\
\hline BsdBCD & Phenolic acid decarboxylase subunits B, C and D \\
\hline BzuA & Benzoate 4-monooxygenase \\
\hline CalA & Coniferyl alcohol dehydrogenase \\
\hline CalB & Coniferyl aldehyde dehydrogenase \\
\hline CatA1 & Catechol 1,2-dioxygenase 1 \\
\hline CatA2 & Catechol 1,2-dioxygenase 2 \\
\hline CatB & Muconate cycloisomerase \\
\hline CatC & Muconolactone Delta-isomerase \\
\hline CatD & 3-oxoadipate enol-lactonase 2 \\
\hline Catl & 3-oxoadipate CoA-transferase subunit $A$ \\
\hline CatJ & 3-oxoadipate CoA-transferase subunit B \\
\hline ChqB & Hydroxyquinol 1,2-dioxygenase \\
\hline CMLE & 3-carboxy-cis, cis-muconate lactonizing enzyme \\
\hline Coul & $p$-Hydroxycinnamoyl-CoA synthetase \\
\hline CouM & p-Hydroxycinnamoyl-CoA hydratase \\
\hline CouN & $p$-Hydroxyphenoxy- $\beta$-hydroxyacyl-CoA dehydrogenase \\
\hline $\mathrm{CouO}$ & $p$-Hydroxyphenoxy- $\beta$-ketoacyl-CoA hydrolase \\
\hline CprA & Cytochrome $\mathrm{P} 450$ reductase \\
\hline Cso2 & Isoeugenol oxygenase 2 \\
\hline DesA & Syringate $o$-demethylase \\
\hline DesB & Gallate dioxygenase \\
\hline DesV & Aldehyde dehydrogenase \\
\hline DesZ & 3-o-methylgallate 3,4-dioxygenase \\
\hline DhbA & 2,3-dihydroxybenzoic acid 3,4-dioxygenase \\
\hline DmpB & Catechol 2,3-dioxygenase \\
\hline DmpC & 2-hydroxymuconic semialdehyde dehydrogenase \\
\hline DmpD & 2-hydroxymuconate semialdehyde hydrolase \\
\hline DmpE & 2-oxopent-4-enoate hydratase \\
\hline DmpF & Acetaldehyde dehydrogenase \\
\hline DmpG & 4-hydroxy-2-oxovalerate aldolase \\
\hline $\mathrm{DmpH}$ & 4-oxalocrotonate decarboxylase \\
\hline Dmpl & 2-hydroxymuconate tautomerase \\
\hline DmpLMNOP & Phenol hydroxylase components $\mathrm{L}, \mathrm{M}, \mathrm{N}, \mathrm{O}$ and $\mathrm{P}$ \\
\hline Ech & Enoyl-CoA hydratase/aldolase \\
\hline EhyA & Eugenol hydroxylase alpha-subunit \\
\hline EhyB & Eugenol hydroxylase beta-subunit \\
\hline EugO & Eugenol oxidase \\
\hline FCS & Feruloyl-CoA synthase \\
\hline Fdc1 & Ferulic acid decarboxylase \\
\hline
\end{tabular}




\begin{tabular}{|c|c|}
\hline FerA & Feruloyl-CoA synthase \\
\hline FerB & Enoyl-CoA hydratase/aldolase \\
\hline Fph1 & Fumarylpyruvate dioxygenase \\
\hline GalA & Gallate dioxygenase \\
\hline GalB & 4-oxalmesaconate hydratase \\
\hline GalC & 4-carboxy-4-hydroxy-2-oxoadipic acid aldolase \\
\hline GalD & 4-oxalomesaconate tautomerase \\
\hline Gdc & Gallic acid decarboxylase \\
\hline Gdx1 & Gentisate dioxygenase \\
\hline $\mathrm{HbaA}$ & 4-hydroxybenzoate-CoA ligase \\
\hline $\mathrm{HbaBCD}$ & 4-hydroxybenzoyl-CoA reductase subunits B, C and D \\
\hline HcaB & Dihydrodiol dehydrogenase \\
\hline HcaEFCD & 3-phenylpropionate/cinnamic acid dioxygenase subunits $E, F, C$ and $D$ \\
\hline HcrBCD & 4-hydroxybenzoyl-CoA reductase subunits $B, C$ and D \\
\hline Hdq1 & Hydroxyquinol dioxygenase \\
\hline Hdq2 & Catechol 1,2-dioxygenase \\
\hline $\mathrm{Hdx1}$ & Hydroxyquinol dioxygenase \\
\hline HMPHP-SCOA & 4-hydroxy-3-methoxyphenyl- $\beta$-hydroxypropionyl-CoA \\
\hline HMPKP-SCOA & 4-hydroxy-3-methoxyphenyl- $\beta$-ketopropionic acid-CoA \\
\hline Нрав & 4-hydroxyphenylacetate 3-hydroxylase monooxygenase B \\
\hline HраC & 4-hydroxyphenylacetate 3-hydroxylase oxidoreductase C \\
\hline HPHP-SCOA & 3-hydroxy-3-( $p$-hydroxyphenyl) propyl-CoA \\
\hline IvaA & Isovanillic acid demethylase \\
\hline IvaB & Isovanillic acid demethylase reductase \\
\hline LigAB & Protocatechuate 4,5-dioxygenases alpha chain and beta chain \\
\hline LigC & 4-carboxy-2-hydroxymuconate-6-semialdehyde dehydrogenase \\
\hline Ligl & 2-pyrone-4,6-dicarboxylate hydrolase \\
\hline LigJ & 4-oxalmesaconate hydratase \\
\hline LigK & 4-carboxy-4-hydroxy-2-oxoadipate aldolase \\
\hline LigM & Vanillate/3-o-methylgallate $o$-demethylase \\
\hline LigU & 4-oxalomesaconate tautomerase \\
\hline LinE & Chlorohydroquinone 1,2-dioxygenase \\
\hline $\operatorname{LinF}$ & Maleylacetate reductase \\
\hline LpdC & Gallate decarboxylase \\
\hline Mci1 & Cis, cis-muconate cycloisomerase \\
\hline MhpB & 2,3-dihydroxicinnamic acid 1,2-dioxygenase \\
\hline Mli1 & Muconolactone isomerase \\
\hline Mnx1 & 4-hydroxybenzoate 1-hydroxylase \\
\hline $\operatorname{Mnx} 2$ & 3-hydroxybenzoate 6-hydroxylase \\
\hline Mnx3 & Phenol 2-monooxygenase \\
\hline MobA & 3-hydroxybenzoate-4-monooxygenase \\
\hline NagG & Salicylate 5-hydroxylase large oxygenase component \\
\hline $\mathrm{NagH}$ & Salicylate 5-hydroxylase, small oxygenase component \\
\hline NahG & Salicylate hydroxylase (decarboxylating) \\
\hline Oel1 & 3-oxoadipate enol-lactonase \\
\hline Osc1 & 3-oxoadipate CoA-transferase \\
\hline Pad & Phenolic acid decarboxylase \\
\hline Pad1 & Flavin prenyltransferase \\
\hline PadC & Phenolic acid decarboxylase \\
\hline PcaB & 3-carboxy-cis, cis-muconate cycloisomerase \\
\hline PcaC & 4-carboxymuconolactone decarboxylase \\
\hline
\end{tabular}




$\begin{array}{ll}\text { PcaD } & \text { 3-oxoadipate enol-lactonase 1 } \\ \text { PcaF } & \text { Beta-ketoadipyl-CoA thiolase } \\ \text { PcaGH } & \text { Protocatechuate 3,4-dioxygenases alpha chain and beta chain } \\ \text { Pcal } & \text { 3-oxoadipate CoA-transferase subunit A } \\ \text { PcaJ } & \text { 3-oxoadipate CoA-transferase subunit B } \\ \text { PhgA } & \text { p-hydroxybenzoyl-CoA hydroxylase } \\ \text { PhgB } & \text { Gentisyl-CoA thioesterase } \\ \text { PhgC } & \text { p-hydroxybenzoyl-CoA ligase } \\ \text { PhhY } & \text { Phenol 2-hydroxylase } \\ \text { PobA } & \text { 4-hydroxybenzoate-3-hydroxylase } \\ \text { PraA } & \text { Protocatechuate 2,3-dioxygenase } \\ \text { PraB } & \text { 2-hydroxymuconate-6-semialdehyde dehydrogenase } \\ \text { PraC } & \text { 2-hydroxymuconate tautomerase } \\ \text { PraD } & \text { 4-oxalocrotonate decarboxylase } \\ \text { PraE } & \text { 2-hydroxypenta-2,4-dienoate hydratase } \\ \text { PraF } & \text { 4-hydroxy-2-oxovalerate aldolase } \\ \text { PraG } & \text { Acetaldehyde dehydrogenase } \\ \text { PraH } & \text { 5-carboxy-2-hydroxymuconate-6-semialdehyde decarboxylase } \\ \text { Pral } & \text { 4-hydroxybenzoate-3-hydroxylase } \\ \text { Sam5 } & \text { 4-coumarate 3-hydroxylase } \\ \text { Sdc } & \text { Salicylic acid decarboxylase } \\ \text { SdgA } & \text { Salicylyl-AMP ligase } \\ \text { SdgB } & \text { Salicylyl-CoA synthetase } \\ \text { SdgC } & \text { Salicylyl-CoA 5-hydroxylase } \\ \text { SdgD } & \text { Gentisate 1,2-dioxygenase } \\ \text { Sdo } & \text { Salicylate 1,2-dioxygenase } \\ \text { StyA } & \text { Styrene-monooxygenase A } \\ \text { StyB } & \text { Styrene-monooxygenase B } \\ \text { StyC } & \text { Styrene-oxide isomerase } \\ \text { StyD } & \text { Phenylacetaldehyde dehydrogenase } \\ \text { TCA } & \text { Tricarboxylic acid cycle } \\ \text { VanA } & \text { Vanillate o-demethylase oxygenase subunit } \\ \text { VanB } & \text { Vanillate o-demethylase oxidoreductase } \\ \text { VaO } & \text { Vanillyl-alcohol oxidase } \\ \text { VdcC } & \text { Vanillate decarboxylase } \\ \text { Vdh } & \text { Vanillin dehydrogenase } \\ \text { VerA } & \text { Veratric acid o-demethylase } \\ \text { VerB } & \text { Veratric acid o-demethylase oxidoreductase } \\ \text { VprA } & \text { Vinylphenol reductase } \\ \text { XInD } & \text { 3-hydroxybenzoate 6-hydroxylase } \\ \text { XylE } & \text { Catechol 2,3-dioxygenase } \\ \text { XylF } & \text { 2-hydroxymuconate semialdehyde hydrolase } \\ \text { XylG } & \text { 2-hydroxymuconic semialdehyde dehydrogenase } \\ \text { XylK } & \text { 4-hydroxy-2-oxovalerate aldolase } \\ \text { YfmT } & \text { Benzaldehyde dehydrogenase } \\ & \end{array}$




\section{Introduction}

The growing global human population creates an increasing demand for alternative energy and renewable raw material resources. Lignin is the most complex and one of the most abundant polymers on earth. It consists of the aromatic monolignols coniferyl alcohol, $p$-coumaryl alcohol and sinapyl alcohol that form guaiacyl, p-hydroxyphenyl and syringyl (G, $H$ and $S$ ) units in lignin (Fig. 1), respectively (Freudenberg, 1965; Humphreys and Chapple, 2002). Thus, it is a rich resource of renewable aromatic compounds that could be used as a basis for biotechnological applications. In plant biomass, aromatic compounds are also found in tannins, linked to polysaccharides and are even found freely (Mäkelä et al., 2015; Mcleod, 1974; Newby et al., 1980). Microbial degradation of lignin results in the release of aromatic compounds, such as ferulic acid and vanillin, which are toxic already at low concentrations for most microorganisms (Adeboye et al., 2014; Friedman et al., 2003; Guiraud et al., 1995; Lima et al., 2017). In order to survive this toxicity, the aromatic compounds need to be degraded or converted to non- or less toxic compounds by the microorganism. This is usually followed by the cleavage of the aromatic ring to eliminate toxicity, resulting in compounds that can be used as a carbon source. Lignin degradation and modification by basidiomycete white-rot and brown-rot fungi has been studied for decades and most of the resulting products are funnelled to the central (ringfission) intermediates (Mäkelä et al., 2015). Less is known about the role of bacteria in this process, eventhough bacteria that are able to convert or degrade small lignin-derived aromatic compounds have been described previously (Bugg et al., 2011a, Brown and Chang, 2014). Currently, much research is performed in the degradation of small lignin-derived aromatic compounds, especially for the alpha-proteobacterium Sphingomonas paucimobilis SYK-6, which was later classified as Sphingobium sp. strain SYK-6 (Kamimura et al., 2017; Sonoki et al., 2009).

Plant- and lignin-derived aromatic compounds have great industrial and commercial potential since they can be used for many applications, such as biochemical building blocks for biorefineries, plastics, drugs and cosmetics, and as food additives, such as flavor agents, preservatives or antioxidants (Arif, 2015; Kaur and Chakraborty, 2013; McKenna et al., 2013; Tsuge et al., 2016). The need for plastics increases each year, and plastics derived from renewable aromatic compounds are a sustainable way to supply this increasing demand. Styrene is an example of an aromatic compound, which can be used as a precursor to produce plastics such as acrylonitrile butadiene styrene (ABS), polystyrene and styrene acrylonitrile resin (SAN). Styrene is chemically synthesized from phenylalanine however, in nature styrene can also obtained through the decarboxylation of cinnamic acid (Plumridge et al., 2008, Plumridge et al., 2010, Richard et al., 2015). Another promising industrial niche is the increasing consumer demand for "naturally" produced aromatic compounds. For example, vanillin is one of the most important flavor and fragrance compounds in food and cosmetics. Less than $1 \%$ of the produced vanillin derives from natural sources, while the majority is produced from guaiacol by chemical synthesis (Gallage and Møller, 2018; Krings and Berger, 1998; Walton et al., 2003). To efficiently produce aromatic compounds such as vanillin or styrene, microorganisms have been genetically modified to produce desired compounds from glucose through the shikimate pathway (Lee and Wendisch, 2017; McKenna and Nielsen, 2011) or through lignin valorization (Barton et al., 2018; Wu et al., 2017).

In the past decades, many studies aimed to identify the pathways, and enzymes involved in the aromatic metabolism of diverse microorganisms have been reported. Recently, aromatic metabolism of filamentous fungi has been reviewed (Mäkelä et al., 2015), but an extensive comparison between fungal and bacterial aromatic metabolism has not been made. At present, only a few fungal enzymes involved in aromatic metabolism have been identified and characterized, whereas more enzymes have been described in bacteria (Tables S1 and S2). A thorough comparison of aromatic metabolism between the two kingdoms will be of great help in identifying new fungal aromatic metabolic enzymes and pathways. This will also greatly expand the potential of lignin and its aromatic compounds in biotechnological applications. This review focuses on the identified aromatic metabolic enzymes and 
in particular the similarities and differences of conversion pathways between fungi and bacteria. Due to the current interest in biorefinery of lignin-based aromatics, this review has a special focus on industrially relevant compounds derived from lignin and related non-lignin derived homocyclic aromatic compounds released during plant biomass degradation or found ubiquitously in plants. Only plant-derived homocyclic aromatic metabolic pathways are discussed in this review and not other pathways, such as conversion of xylene and toluene. Aromatic metabolic pathways such as the homogentisate or homoprotocatechuate pathway are not included since these are uncommon pathways and are contributing to the recycling of uncommon compounds. For reviews on conversion of lignin-derived oligomeric aromatic compounds, we suggest the following reviews, Bugg et al., 2011b, Mäkelä et al., 2015 and Kamimura et al., 2017.

\section{Aromatic metabolism in bacteria and fungi}

Several possible conversion pathways of homocyclic aromatic compounds are described in fungi and bacteria. However, no complete overview of the various aromatic metabolic pathways has been described for a single fungus (Mäkelä et al., 2015). Here, we discuss the pieces of the puzzle that have already emerged from experimental observations in fungi as compared to bacteria. The review is separated into two main parts. The first part (2.1-2.8) describes the conversion pathways of the homocyclic aromatic compounds that are derived from lignin and closely related compounds, which are released during plant biomass degradation or found ubiquitously in plant biomass (Fig. 1). Enzymes involved in these pathways are summarized in Table S1. The second part (2.9) describes the ring cleavage process through the seven central ring-fission intermediates, catechol, protocatechuic acid, hydroxyquinol, hydroquinone, gentisic acid, gallic acid and pyrogallol, and the significance of this conversion for cellular metabolism (Fig. 1). Enzymes involved in these pathways are summarized in tables S1 and S2. It should be noted that some of the referred microorganisms are unable to use aromatic compounds as a sole carbon source. Their detoxicfication mechanisms do not imply ring cleavage and are therefore likely to use a different mechanism.

\subsection{Coniferyl alcohol and eugenol metabolic pathways}

Coniferyl alcohol is one of the three building blocks found in lignin. The conversion pathway specific to coniferyl alcohol has been characterized in bacteria, but it is not known in fungi (Fig. 2). In the first bacterial pathway, coniferyl alcohol is converted to ferulic acid via the intermediate coniferyl aldehyde. In Pseudomonas sp. strain HR199, the step from coniferyl alcohol to coniferyl aldehyde is catalyzed by coniferyl alcohol dehydrogenase (CalA), after which coniferyl aldehyde is converted to ferulic acid by coniferyl aldehyde dehydrogenase (CalB) (Overhage et al., 1999, Overhage et al., 2003). In Pseudomonas aeruginosa an alternative pathway was observed, in which coniferyl aldehyde is converted to 5-hydroxyconiferylaldehyde by 4-hydroxyphenylacetate 3-hydroxylase consisting of a monooxygenase ( $\mathrm{HpaB}$ ) and an oxidoreductase ( $\mathrm{HpaC}$ ) component (Chakraborty et al., 2009; Furuya and Kino, 2014). In P. aeruginosa and Burkholderia xenovorans, $\mathrm{HpaBC}$ are also able to convert 4hydroxyphenylacetate to homoprotocatechuic acid (Chakraborty et al., 2009; Méndez et al., 2011).

The aromatic compound eugenol is of high industrial interest since it can be used for the production of ferulic acid and vanillin. Eugenol is released from Kraft lignin and low sulfonate lignin during $160^{\circ} \mathrm{C}$ treatment (Varanasi et al., 2013). In addition, high concentrations of eugenol, which is synthesized from coniferyl alcohol, can be extracted from clove oil making it a cheap precursor for the production of ferulic acid and vanillin. In Pseudomonas sp. strain OPS1, eugenol is converted to coniferyl alcohol by eugenol hydroxylases EhyA and EhyB (Brandt et al., 2001), while Rhodococcus sp. strain RHA1 uses eugenol oxidase (EugO) to catalyze the oxidation of eugenol to coniferyl alcohol (Jin et al., 2007). More recently, EugO was shown to have a broad substrate range as it can also convert the aromatic compounds zingerone, raspberry ketone and 5-indanol (Nguyen et al., 2016). The conversion of eugenol to vanillin through the intermediates coniferyl alcohol, coniferyl aldehyde and ferulic acid was also observed in Bacillus safensis (Singh et al., 2018). In addition, Bacillus cereus PN42 has been shown 
to convert eugenol to $p$-vinyl guaiacol in multiple steps without the intermediate ferulic acid (Kadakol and Kamanavalli, 2010), but the enzymes involved in this conversion have not yet been identified.

In fungi, there have been no pathways described in which coniferyl alcohol is converted. However, the basidiomycete Pycnoporus cinnabarinus was reported to be able to reduce ferulic acid to coniferyl aldehyde and coniferyl alcohol (Falconnier et al., 1994). This was also observed for the basidiomycete Trametes sp. and was suggested for the ascomycete Aspergillus japonicus (Nishida and Fukuzumi, 1978; Milstein et al., 1983). In the yeast Saccharomyces cerevisiae, coniferyl aldehyde is directly converted to ferulic acid, but enzymes involved in this conversion are not known (Adeboye et al., 2015). In the ascomycete Penicillium simplicissimum, vanillyl-alcohol oxidase (VaO) catalyzes the hydroxylation of eugenol to coniferyl alcohol (de Jong et al., 1992; Van den Heuvel et al., 2002). The physiological substrate of $\mathrm{VaO}$ has been proposed to be 4-methoxy(methylphenol) and is the only substrate found so far that induces the production of $\mathrm{VaO}$ (Fraaije et al., 1997). The aromatic pathway by which eugenol is converted to $p$-vinyl guaiacol was also observed in the basidiomycete Schizophyllum commune, and the ascomycetes Paecilomyces variotii and Fusarium solani (Ghosh et al., 2005; Nazareth and Mavinkurve, 1986; Rahouti et al., 1989). The enzyme catalyzing this conversion remains unknown in both fungi and bacteria.

In summary, bacteria have been shown to convert the lignin building block coniferyl alcohol into ferulic acid and 5-hydroxyconiferylaldehyde, while in fungi no conversions of coniferyl alcohol have been observed. Despite that coniferyl alcohol is not a mainstream lignin degradation product, it is likely that fungi can convert coniferyl alcohol since both fungi and bacteria can synthesize coniferyl alcohol from eugenol, and conversion pathways for ferulic acid, a derivative of coniferyl alcohol, have been observed. To determine whether a metabolic system for the conversion of coniferyl alcohol exists in fungi, experimental confirmation is needed. Insufficient information is available about the conversion of coniferyl alcohol in fungi however, in bacteria it appears that the main pathway is towards ferulic acid.

\subsection{Ferulic acid metabolic pathways}

Ferulic acid is an aromatic compound derived from the monolignol coniferyl alcohol and is released when lignin is degraded by Bacillus sp., Pseudomonas putida and Rhodococcus jostii (Bugg et al., 2011b; Raj et al., 2007). In addition, ferulic acid is also present in polysaccharides, such as xylan and pectin, and can form crosslinks between them and between polysaccharides and lignin through dimerization of ferulic acid (Dilokpimol et al., 2016; Mäkelä et al., 2015). Ferulic acid has diverse pharmaceutical applications because of its antioxidant, anti-inflammatory, and antimicrobial properties (Ou and Kwok, 2004). In food industry, ferulic acid is mainly used as a precursor for vanillin production. The conversion of ferulic acid to vanillin is a well-studied biotransformation and is described in detail for many bacterial species such as Amycolatopis sp., Bacillus subtilis, Pseudomonas fluorescens, P. putida and R. jostii (Achterholt et al., 2000; Chen et al., 2012; Graf et al., 2016; Narbad and Gasson, 1998; Overhage et al., 1999a; Overhage et al., 1999b; Plaggenborg et al., 2003, Plaggenborg et al., 2006). Seven pathways are described for the conversion of ferulic acid in which two result in vanillin (Fig. 3):

1. The conversion of ferulic acid to feruloyl-SCoA by feruloyl-CoA synthase (Fcs, FerA, Atu1416) or $p$ hydroxycinnamoyl-CoA synthetase (CouL) followed by:

a. Non- $\beta$-oxidative decarboxylation in which feruloyl-SCoA is converted to 4-hydroxy-3methoxyphenyl- $\beta$-hydroxypropionyl-CoA (HMPHP-SCoA) and then to vanillin by Enoyl-CoA hydratase/aldolase (Ech, FerB).

b. $\beta$-oxidative decarboxylation in which feruloyl-SCOA is converted to HMPHP-SCoA and then to 4-hydroxy-3-methoxyphenyl- $\beta$-ketopropionic acid-CoA (HMPKP-SCoA), before conversion to vanillic acid.

2. The non-oxidative decarboxylation of ferulic acid to $p$-vinyl guaiacol followed by:

a. Conversion to vanillin catalyzed by an iron-dependent isoeugenol oxygenase (Cso2). 

b. Conversion to vanillic acid.
c. Oxidation to $p$-hydroxyphenylethanol.
d. Reduction to 4-ethylguaiacol catalyzed by vinylphenol reductase (VprA).
e. Conversion to guaiacol.

Pathway 1a has been described in the bacteria Amycolatopsis sp. ATCC39116, R. jostii RHA1, Streptomyces sp. strain V-1, Sphingobium sp. strain SYK-6, P. fluorescens and P. putida KT2440 (Gasson et al., 1998; Masai et al., 2002; Otani et al., 2014; Priefert et al., 1999; Yang et al., 2013), and in the yeast Debaryomyces hansenii and Rhodotorula rubra (Huang et al., 1993; Mathew et al., 2007). Recently, this pathway was also suggested in Aspergillus luchuensis (Taira et al., 2018). Pathway $1 \mathrm{~b}$ was described in Agrobacterium fabrum and R. jostii (Campillo et al., 2014; Otani et al., 2014). The suggested enzymes CouM, CouN and CouO involved in this pathway are based on transcriptome data (Fig. 3) (Otani et al., 2014). Deletion of the Atu1417, Atu 1415 and Atu1421 in A. fabrum resulted in the accumulation of the intermediates (Fig. 3) (Campillo et al., 2014).

Pathway 2a has been observed in Bacillus coagulans, B. cereus, B. subtilis, P. fluorescens and many other bacterial species (Karmakar et al., 2000; Mishra et al., 2013). In B. subtilis, a phenolic acid decarboxylase (PadC) catalyzes transformation of ferulic acid, caffeic acid and $p$-coumaric acid, but not cinnamic acid to the $p$-vinyl form (Cavin et al., 1997b, Cavin et al., 1998; Tran et al., 2008). Cinnamic acid lacks the $\mathrm{OH}$ group at $\mathrm{C} 4$ of the aromatic ring that is present in the other three compounds, suggesting that this is essential for the action of PadC. Close homologs of PadC, for example ferulic acid decarboxylase (Fdc) from Bacillus pumilus, are also involved in the decarboxylation of ferulic acid and $p$-coumaric acid. However, the PadC homolog $(\mathrm{Pdc})$ from Lactobacillus plantarum was reported to decarboxylate $p$-coumaric acid and caffeic acid, but not ferulic acid (Cavin et al., 1997a; Zago et al., 1995), which suggests differences in substrate specificity despite high sequence homology between these decarboxylases. In the ascomycetes $A$. luchuensis and Isaria farinosa, the phenolic acid decarboxylase (Pad) involved in this conversion was characterized (Linke et al., 2017; Maeda et al., 2018). In the yeast S. cerevisiae, ferulic acid decarboxylase (Fdc1) together with the flavin prenyltransferase (Pad1) can convert ferulic acid to $p$-vinyl guaiacol (Lin et al., 2015; Mukai et al., 2010), while dihydroferulic acid has been suggested to be a conversion intermediate (Adeboye et al., $2015,2017)$. Recently, the iron-dependent oxygenase Cso2 catalyzes the conversion of $p$-vinyl guaiacol to vanillin has been identified in the bacteria Caulobacter segnis (Fig. 3) (Furuya et al., 2014). Expression of CsO2 together with Fdc of B. pumilus in Escherichia coli resulted in the conversion of ferulic acid to $p$-vinyl guaiacol and further to vanillin. Pathway 2 a has been reported for the filamentous fungi S. commune, $P$. variotii and $F$. solani, and the yeasts Brettanomyces anomalus, $D$. hansenii and S. cerevisiae (Edlin et al., 1995; Ghosh et al., 2005; Mathew et al., 2007; Nazareth and Mavinkurve, 1986; Rahouti et al., 1989; Tsujiyama and Ueno, 2008). Pathway $2 \mathrm{~b}$ has been observed in the filamentous ascomycete fungus Myceliophthora thermophila, suggesting the conversion of $p$ vinyl guaiacol to vanillic acid instead of vanillin (Topakas et al., 2003). A similar pathway was also described for the diploid ascomycete fungus Aspergillus niger DAR2, derived from parasexual crosses with two haploid mutants of $A$. niger C28B25 (Baqueiro-Peña et al., 2010; Montiel-González et al., 2002). This pathway was not detected in A. niger C28B25 and was suggested to be due to differential regulation of ferulic acid converting enzymes (Baqueiro-Peña et al., 2010). Pathway 2c has been observed in S. cerevisiae, in which $p$-vinyl guaiacol was not converted to vanillic acid or vanillin, but instead was suggested to be oxidized to $p$-hydroxyphenylethanol, followed by dehydration to phenethyl alcohol (Adeboye et al., 2015). Pathway $2 \mathrm{~d}$ has been observed in the several yeasts, such as Candida species, Dekkera bruxellensis, D. anomala and Pichia guillermondii (Suárez et al., 2007). The biological function of the vinylphenol reductase of $D$. bruxellensis has been demonstrated by heterologous expression in S. cerevisiae (Romano et al., 2017). Recently, this conversion has been described in L. plantarum where it is catalyzed by vinylphenol reductase (VprA) (Santamaria et al., 2018). Pathway 2 e has been observed in S. cerevisiae in which $p$-vinyl guaiacol is directly converted to 
guaiacol (Adeboye et al., 2017). Guaiacol is released from lignin by the bacteria Aneurinibacillus aneurinilyticus, Bacillus sp. and Paenibacillus sp. (Raj et al., 2007). The conversion of ferulic acid to vanillic acid was observed in the oleaginous yeasts, Cryptococcus curavatus, Rhodosporium toruloides and Trichosporon guehoae, however which pathway is used remains unknown (Sànchez i Nogué et al., 2018).

Five alternative pathways in which ferulic acid is transformed to different aromatic compounds have been observed (Fig 3):

3. 5-Hydroxylation of ferulic acid to 5-hydroxyferulic acid by HpaBC.

4. 2-Hydroxylation of ferulic acid to 2-hydroxyferulic acid.

5. Demethylation of ferulic acid to caffeic acid.

6. Demethylation of ferulic acid to $p$-coumaric acid.

7. Reduction of ferulic acid to coniferylaldehyde followed by reduction to coniferyl alcohol.

Pathway 3 showed that $\mathrm{HpaBC}$ of $P$. aeruginosa can catalyze the conversion of ferulic acid to 5hydroxyferulic acid (Furuya and Kino, 2014). This pathway has also been observed in the basidiomycete Lentinula edodes (Crestini and Sermanni, 1994). In addition, 5-hydroxyferulic acid is further converted to 3,4,5-trihydroxycinnamic acid after which the aromatic ring is cleaved. Pathway 4 has been observed in L. edodes in which ferulic acid is converted to 2-hydroxyferulic acid and further to 2,3,4-trihydroxycinnamic acid followed by the cleavage of the aromatic ring (Crestini and Sermanni, 1994). Pathway 5 has been observed in the bacteria Enterobacter cloacae and Streptomyces albogriseolus, and the ascomycete Penicillium rubens, in which ferulic acid is demethylated to caffeic acid and further converted to protocatechuic acid (Buraimoh et al., 2017; Grbić-Galić and La PatPolasko, 1985; Tillett and Walker, 1990). The enzymes catalyzing these reactions have not yet been identified. Pathway 6 was suggested in the yeast S. cerevisiae (Adeboye et al., 2017). Pathway 7 has been observed in the basidiomycete $P$. cinnabarinus, which reduces ferulic acid to coniferyl aldehyde and coniferyl alcohol (Fig. 2, 3) (Falconnier et al., 1994). The enzymes catalyzing these alternative pathways are not known.

In summary, both bacteria and filamentous fungi are able to produce vanillin from ferulic acid while most yeasts are not known to produce vanillin. This is probably because vanillin has a strong toxic effect on yeast (Shen et al., 2014). At this moment, $D$. hansenii is the only yeast reported to produce vanillin from ferulic acid, but only at low concentrations (Mathew et al., 2007). Nevertheless, yeasts are being used to produce vanillin from dihydroshikimic acid through engineered biosynthetic pathways in which genes from Podospora pausiceta, Nocardia sp., E. coli and Homo sapiens are used (Hansen et al., 2009). To avoid the toxicity of vanillin, a glucosylation step was added to produce the less toxic compound vanillin $\beta$-D-glucoside resulting in higher vanillin yields. Interestingly, this strategy to avoid toxicity of vanillin was also observed in A. Iuchuensis (Taira et al., 2018). Low tolerance against the toxicity of vanillin is also a major issue in the production of vanillin in microbial production systems (Fleige and Steinbüchel, 2014; Fleige et al., 2016; Fitzgerald et al., 2003, Kaur and Chakraborty, 2013). Another issue is the rapid detoxification of vanillin in their systems. Therefore, many genetic modifications, such as deletions, are needed to increase the metabolic flux and the production of vanillin from eugenol or ferulic acid (Fleige et al., 2016; Gallage and Møller, 2015, Hansen et al., 2009; Kaur and Chakraborty, 2013; Overhage et al., 2003; Priefert et al., 1999; Priefert et al., 2001). From ferulic acid a yield of $19.2 \mathrm{~g} / \mathrm{I}$ vanillin was obtained while from eugenol around $10 \mathrm{~g} / \mathrm{l}$ vanillin was obtained (Gallage and Møller, 2015). In the plant Vanilla planifolia, ferulic acid is directly converted to vanillin by vanillin synthase (VpVAN) (Gallage et al., 2014), but direct conversion of ferulic acid to vanillin has never been reported for bacteria or fungi. In addition, no homolog of VpVAN was found in fungal genomes, confirming that this conversion is probably not present in fungi. Currently, multiple ferulic acid metabolic pathways have been observed in fungi, but only one enzyme, Pad of $A$. luchuensis and I. farinosa, has been characterized (Linke et al., 2017; Maeda et al., 2018). Many observations of the conversion of ferulic acid to vanillic acid through non- $\beta$-oxidative decarboxylation 
and non-oxidative decarboxylation were made. It is likely that these two pathways are the main ferulic acid metabolic pathways in microorganisms.

\subsection{Vanillin, vanillic acid and related metabolic pathways}

Degradation of spruce wood lignin by $P$. chrysosporium results in the release of vanillin (Chen et al., 1982). Vanillin was also released from kraft lignin by the bacterium Aeromonas formicans and from alkaline lignin by the bacterium Bacillus ligniniphilus (Gupta et al., 2001; Zhu et al., 2017). Due to the high industrial interest, much research has been performed on the vanillin metabolic pathways in bacteria and fungi. Currently, two pathways are known for the conversion of vanillin (Fig. 4):

1. The oxidation of vanillin to vanillic acid by vanillin dehydrogenase (Vdh) or benzaldehyde dehydrogenase (YfmT).

2. The conversion between vanillin to vanillyl alcohol.

In pathway $1, \mathrm{Vdh}$ catalyzes the conversion of vanillin to vanillic acid through NAD-dependent oxidation (Ding et al., 2015; Fleige et al., 2013; Masai et al., 2007b; Priefert et al., 1997). Deletion of $v d h$ in P. fluorescens resulted in complete loss of ferulic acid utilization (Di Gioia et al., 2011), while overexpression of fcs and ech (see previous section), and deletion of $v d h$ in Amycolatopsis sp. ATCC39116 resulted in the accumulation of vanillin (Fleige et al., 2016). The deletion of $v d h$ in Corynebacterium glutamicum revealed delayed growth on vanillin, 3-hydroxybenzaldehyde, $p$ hydroxybenzaldehyde, protocatechuic aldehyde, ferulic acid and caffeic acid, but not on $p$-cresol, cinnamyl aldehyde or syringic aldehyde (Ding et al., 2015). Purified Vdh of C. glutamicum biotransformed protocatechuic aldehyde to protocatechuic acid. This was also observed for the vanillin dehydrogenase ( $\mathrm{Yfmt}$ ) of $B$. subtilis 3NA that can catalyze the conversion of vanillin, isovanillin, p-hydroxybenzaldehyde, 3-hydroxybenzaldehyde, protocatechualdehyde, ethylvanillin, benzaldehyde and salicylaldehyde to the corresponding acids (Graf et al., 2016). Both Vdh and YfmT showed a broad substrate range suggesting an important role of these enzymes in the catabolism of aromatic compounds (Ding et al., 2015; Graf et al., 2016). The conversion of protocatechuic aldehyde to protocatechuic acid has been proposed in the fungus Aspergillus fumigatus (Jones et al., 1993). Pathway 2 was described for Alicyclobacillus acidoterrestris, E. coli and Pseudomonas deceptionensis in which vanillin is converted to vanillyl alcohol (Cai et al., 2015; Kunjapur et al., 2014; Ravi et al., 2018).

Similar to bacteria, two vanillin conversion pathways have been described for fungi. Pathway 1 was reported for several filamentous fungi such as $A$. japonicus, $P$. cinnabarinus and $S$. commune, and the yeasts Coniochaeta mutabilis, B. anomalus, D. hansenii, Exophiala heteromorpha, Trichosporon oleaginosus and Aureobasidium pullulans (Edlin et al., 1995; Falconnier et al., 1994; Henderson, 1961; Krings et al., 2001; Mathew et al., 2007; Milstein et al., 1983; Stentelaire et al., 2000; Tsujiyama and Ueno, 2008; Yaguchi et al., 2017). Pathway 2 in which vanillyl alcohol is oxidized to vanillin was observed for the filamentous fungi $P$. simplicissimum, A. japonicus, S. commune and Sporotrichum pulverulentum (an anamorph of Phanerochaete chrysosporium), and the yeast $D$. hansenii (Ander et al., 1980; de Jong et al., 1992; Mathew et al., 2007; Milstein et al., 1983; Tsujiyama and Ueno, 2008). In $P$. simplicissimum, $\mathrm{VaO}$ is involved in the oxidation of vanillyl alcohol to vanillin (de Jong et al., 1992). $\mathrm{VaO}$ is a homolog of EugO from the bacterium $R$. jostii and is also able to catalyze the oxidation of vanillyl alcohol to vanillin, the oxidative demethylation of 4-(methoxymethyl)phenol, the deamination of vanillyl amine, the dehydroxylation of 4-propylphenol, the dehydrogenation of 4-butylphenol and the enantioselective hydroxylation of 4-ethylphenol (Drijfhout et al., 1998; Fraaije et al., 1997; de Jong et al., 1992; Van den Heuvel et al., 2000, 2002). Recently, it was shown that VaO has a broader substrate specificity than EUGO (Ewing et al., 2018). In fungi and yeast, vanillin was observed to be reduced to vanillyl alcohol (Ander et al., 1980; Edlin et al., 1995; Hatakka, 1985; Henderson, 1961; Tsujiyama and Ueno, 2008). 
Vanillic acid and isovanillic acid were both released during lignin degradation by the bacteria $A$. formicans and B. ligniniphilus and the fungus P. chrysosporium (Chen et al., 1982; Gupta et al., 2001; Zhu et al., 2017). Currently, four vanillic acid conversion pathways have been described for bacteria and fungi (Fig. 4):

3. Demethylation of vanillic acid to protocatechuic acid by the vanillate demethylases VanA and VanB, or LigM.

4. Non-oxidative decarboxylation of vanillic acid to guaiacol by the phenolic acid decarboxylase subunits $B, C$ and $D(B s d B C D)$ or vanillate decarboxylase $C(\mathrm{VdcC})$.

5. Oxidative decarboxylation of vanillic acid to methoxy-hydroquinone by vanillate (decarboxylating) hydroxylase and further to hydroxyquinol.

6. Reduction of vanillic acid to vanillin.

In pathway 3, demethylation of vanillic acid to protocatechuic acid is catalyzed by VanA and VanB of Pseudomonas sp. strain HR199 or LigM of Sphingobium sp. strain SYK-6 (Harada et al., 2017; Priefert et al., 1997; Rosini et al., 2016). VanAB demethylates vanillic acid through a non-heme iron monooxygenase mechanism, while LigM demethylates vanillic acid through a tetrahydrofolatedependent mechanism. The homology of Atu1420 to LigM and the deletion of Atu1420, which resulted in the accumulation of vanillic acid, revealed that this mechanism is also present in $A$. fabrum (Campillo et al., 2014). Pathway 3 has also been reported for Streptomyces spp. (Sutherland et al., 1981, Sutherland et al., 1983), while pathway 4 has been reported for several bacterial species, such as $B$. subtilis, Bacillus megaterium, Clostridium hydroxybenzoicum, E. coli and several Streptomyces sp. strains (Álvarez-Rodrígues et al., 2003; Cai et al., 2015; Chow et al., 1999; Crawford and Olson, 1978; Lupa et al., 2005, Lupa et al., 2008; Pometto et al., 1981). BsdBCD of B. subtilis and VdcC of Streptomyces sp. are involved in the non-oxidative decarboxylation of vanillic acid to guaiacol (Chow et al., 1999; van Duy et al., 2007), which can then be further converted to catechol after which the aromatic ring is cleaved (Fig. 4) (Pometto et al., 1981). Pathway 5 has been reported only once in bacteria, suggesting that it is uncommon, and the enzymes of this pathway are unknown (El-Mansi and Anderson 2004). Pathway 6 was observed in E. coli expressing an aryl carboxylic acid reductase (Acar) of Nocardia iowensis, which catalyzed the conversion of vanillic acid to vanillin (He et al., 2004; Kunjapur et al., 2014).

In fungi, these four pathways have also been described for the biotransformation of vanillic acid. Pathway 3 has been observed for the filamentous fungi $A$. japonicus and $S$. commune (Milstein et al., 1983; Tsujiyama and Ueno, 2008), while pathway 4 was reported for $M$. thermophila, $P$. variotii and several Aspergilli (Crawford and Olson, 1978; Guiraud et al., 1992). Pathway 5 was observed in many fungi, including A. niger and P. chrysosporium (Baqueiro-Peña et al., 2010; Guiraud et al., 1992; Kirk and Lorenz, 1973, Rahouti et al., 1989; Yajima et al., 1979). This reaction is also catalyzed by 4hydroxybenzoate 1-hydroxylase (Mnx1) from Candida parapsilosis (van Berkel et al., 1994; Eppink et al., 1997). Pathway 6 is the reduction of vanillic acid to vanillin, which was observed for several filamentous fungi such as Trichoderma reesei (Guiraud et al., 1992; Hatakka, 1985). The enzymes involved in these conversions are also unknown.

Veratric acid is a compound similar to vanillic acid and it is derived from veratryl alcohol and veratraldehyde, which are considered as monomeric lignin model compounds (Zapanta and Tien, 1997). Veratric acid is a product of lignin when spruce wood is degraded by $P$. chrysosporium (Chen and Chang, 1982). In the bacterium Pseudomonas putida, the ascomycete $P$. simplicissimum and the basidiomycete $P$. chrysosporium, an aromatic pathway in which veratryl alcohol is converted to veratrylaldehyde and further to veratric acid has been observed (de Jong et al., 1990; Leisola et al., 1985; Mohan and Phale, 2017). However, the bacterial and fungal enzymes involved in the conversions 
of veratryl alcohol and veratraldehyde have not yet been identified. Two pathways in which veratric acid is converted are described (Fig. 4):

7. Conversion of veratric acid to:

a. Isovanillic acid through o-demethylation catalyzed by VanAB followed by the demethylation to protocatechuic acid catalyzed by isovanillic acid demethylase (IvaA).

b. Vanillic acid through $p$-demethylation catalyzed by IvaA followed by the $o$-demethylation to protocatechuic acid by VanAB.

8. Reduction of veratric acid to veratrylaldehyde and veratryl alcohol.

Pathway $7 \mathrm{a}$, in which veratric acid is converted to vanillic acid, was observed in Comamonas testosteroni BR6020 and Streptomyces spp. (Providenti et al., 2006; Sutherland et al., 1981), while pathway $7 \mathrm{~b}$ was observed in C. testosteroni (Providenti et al., 2006). VanA or IvaA demethylates the meta- or para-methoxy-group of veratric acid, respectively resulting in the formation of isovanillic or vanillic acid. Isovanillic acid and vanillic acid are then converted to protocatechuic acid by IvaA and VanA, respectively. The reductase component IvaB is involved in the reactions of both IvaA and VanA. Recently, the enzymes catalyzing the conversion of veratric acid to vanillic acid in P. putida CSV86 have been identified (VerA and VerB; Mohan and Phale, 2017). The main difference in this system is that demethylase VerA uses the reductase VerB, while VanA is using a different reductase.

In fungi, pathway 7 , in which veratric acid is converted either to isovanillin or vanillin and further to protocatechuic acid was observed in both $P$. simplicissimum and $P$. cinnabarinus and in the yeast $C$. mutabilis and A. pullulans (Fig. 4) (de Jong et al., 1990; Hatakka, 1985; Henderson, 1961). Interestingly, in $A$. japonicus veratric acid was suggested to be directly converted to protocatechuic acid since no intermediates were detected (Milstein et al., 1983). Pathway 8 was observed in the basidiomycete $P$. cinnabarinus (Hatakka, 1985). Fungal enzymes catalyzing these pathways remain unknown.

In summary, vanillic acid, isovanillic acid, veratric acid and vanillin are important G-unit monolignols since these have been detected during lignin degradation (Chen and Chang, 1982; Gupta et al., 2001). Vanillin can be converted by bacteria, filamentous fungi and yeast with two pathways either to vanillic acid or to vanillyl alcohol (Fig. 4). Vanillic acid is converted towards three main compounds (in reducing order): protocatechuic acid, catechol and hydroxyquinol, after which the ring is cleaved as discussed in section 2.9. The pathway towards hydroxyquinol is common for fungi, but uncommon for bacteria (El-Mansi and Anderson 2004). Therefore, it is likely that vanillic acid pathways 3 and 4 are the main pathways in bacteria and yeast while pathway 5 is the main pathway in filamentous fungi. As mentioned before, vanillyl alcohol was oxidized to vanillin in several fungal species, including $A$. japonicus, S. commune and S. pulverulentum, and the yeast D. hansenii (Ander et al., 1980; Mathew et al., 2007; Tsujiyama and Ueno, 2008). No homolog of VaO were found in the genomes of $A$. japonicus, S. commune, Sporotrichum and Debaryomyces (Gygli et al., 2018), indicating that other enzymes are involved in this conversion in these species. An alternative explanation for low frequency of $\mathrm{VaO}$ candidates was found in phylogenetic analysis of $\mathrm{VaO}$ in fungi and suggested that this gene was possibly obtained from bacteria through horizontal gene transfer (Gygli et al., 2018). Similar to the ferulic acid pathway, multiple vanillic acid pathways have been observed in fungi, but so far, only one fungal enzyme has been characterized.

\subsection{Cinnamic acid and related metabolic pathways}

Cinnamic acid is one of the key building blocks for lignin synthesis in plants since it can be converted to the three monolignols (Humphreys and Chapple, 2002). Breakdown of kraft lignin by Bacillus sp. and Cupriavidus basilensis results in the release of cinnamic acid (Raj et al., 2007; Shi et al., 2013). In addition, cinnamic acid also naturally occurs in plants such as Cinnamomum verum, and is used as a 
flavor agent in cosmetics and pharmaceuticals, and as a precursor for the sweetener aspartame. In fungi and bacteria, four pathways have been described for the conversion of cinnamic acid (Fig. 5):

1. Conversion of cinnamic acid to benzoic acid through:

a. Non- $\beta$-oxidative decarboxylation, in which cinnamic acid is converted to benzaldehyde and then to benzoic acid.

b. $\beta$-oxidative decarboxylation, in which cinnamic acid is converted to cinnamoyl-CoA followed by conversion to $\beta$-ketophenylpropionyl-CoA, $\beta$-hydroxyphenylpropionyl-CoA, benzoyl-CoA and benzoic acid.

2. Reduction of cinnamic acid to cinnamaldehyde and further to cinnamyl alcohol.

3. Conversion of cinnamic acid to cinnamic acid-dihydrodiol by 3-phenylpropionate/cinnamic acid dioxygenase subunits $\mathrm{E}, \mathrm{F}, \mathrm{C}$ and $\mathrm{D}$ (HcaEFCD) and further to 2,3-dihydroxycinnamic acid by the dihydrodiol dehydrogenase (HcaB).

4. Non-oxidative decarboxylation of cinnamic acid to styrene by Fdc1 and Pad1.

Pathway 1 has been observed in A. japonicus (Milstein et al., 1983), but it is unknown if the non $\beta$ oxidative decarboxylation or the $\beta$-oxidative decarboxylation pathway is used (Fig. 5). Bacteria can also transform cinnamic acid through either the non- $\beta$-oxidative or the $\beta$-oxidative pathway to benzoic acid, as observed for Alcanivorax borkumensis, Papillibacter cinnamivorans, Rhodopseudomonas palutris and Streptomyces setonii (Austin et al., 2015; Defnoun et al., 2000; Dutta and Harayama, 2001; Sutherland et al., 1983). Pathway 1a has been observed in S. setonii (Sutherland et al., 1983) while pathway 1b has been observed in Streptomyces maritimus (Noda et al., 2012). Enzymes catalyzing these conversions are still unknown. Pathway 2 was described in A. japonicus and S. commune (Fig. 5) (Milstein et al., 1983; Nimura et al., 2010). In addition, the conversion of cinnamaldehyde through cinnamyl alcohol (Larroy et al., 2002) to hydrocinnamyl alcohol by $S$. commune and the yeast $S$. cerevisiae was reported (Gottardi et al., 2017; Nimura et al., 2010). The overexpression of Acar from Nocardia sp. and a phosphopantetheinyl transferase (EntD) from E. coli expressed in S. cerevisiae also resulted in conversion of cinnamic acid to cinnamaldehyde and further to cinnamyl alcohol by endogenous alcohol dehydrogenases (Gottardi et al., 2017).

Pathway 3 was discovered in E. coli (Díaz et al., 1998) and close homologs of the involved enzymes have been also found in the genus Shigella. 2,3-dihydroxycinnamic acid is converted by 2,3dihydroxycinnamic acid 1,2-dioxygenase (MhpB) to 2-hydroxy-6-ketononatrienedioate (Bugg, 1993) and futher converted towards tricarboxylic acid cycle (TCA). This pathway has not been observed in fungi. Pathway 4 is present in filamentous fungi and yeast (Clausen et al., 1994; Milstein et al., 1983; Plumridge et al., 2008; Shimada et al., 1992). The previously mentioned S. cerevisiae enzyme involved in converting ferulic acid to $p$-vinyl guaiacol, Fdc1, and its coenzyme Pad1 are essential for the decarboxylation of cinnamic acid to styrene in yeast (Mukai et al., 2010; Richard et al., 2015; Tran et al., 2008). S. cerevisiae Fdc1 and Pad1 deletion mutants are unable to convert cinnamic acid. Despite their homology to the bacterial ubiquinone biosynthesis enzymes (UbiX and UbiD), Fdc1 and Pad1 are not involved in ubiquinone biosynthesis in yeast (Mukai et al., 2010). However, it was shown that UbiX could replace Pad1 as a coenzyme for Fdc1 (Lin et al., 2015), which indicates that UbiX and Fdc1 require the same cofactor for enzymatic activation. No direct interaction or complex formation is observed between Fdc1 and Pad1, since Fdc1 is localized in the cytosol while Pad1 is in the mitochondria (Richard et al., 2015). One possible suggestion is that cinnamic acid is converted in two steps. First by Fdc1 and subsequently the formed intermediate passes through the mitochondrial membrane where Pad1 is located but this remains to be proven (Richard et al., 2015). Homologs of Fdc1 and Pad1, ObhA and PadA, were identified in A. niger and are involved in the decarboxylation of cinnamic acid and sorbic acid (Plumridge et al., 2010). Deletion of these genes showed decreased tolerance of $A$. niger to the toxicity of cinnamic acid and sorbic acid. The decarboxylation of cinnamic acid to styrene appears to be specific for fungi. The bacterial decarboxylases Pdc, PadC and Fdc are 
able to convert ferulic acid, $p$-coumaric acid and caffeic acid, but not cinnamic acid to its $p$-vinyl form (Cavin et al., 1997a; Tran et al., 2008; Zago et al., 1995). Even though bacteria are unable to decarboxylate cinnamic acid, the conversion of styrene was observed in bacteria. This is probably because styrene naturally occurs in plants and soil (Steele et al., 1994; Tischler, 2015).

Styrene can be degraded to phenyl-1,2-ethanediol, 2-phenylethanol and benzoic acid by the filamentous basidiomycete Pleurotus ostreatus (Braun-Lüllemann et al., 1997). This was also observed for the filamentous basidiomycetes $P$. chrysosporium and Trametes versicolor, and the filamentous ascomycete Daldinia concentrica, which were able to degrade styrene into 2-phenylethanol, benzoic acid, cyclohexadiene-1,4-dione, butanol and succinic acid (Lee et al., 2006). It was suggested that butanol and succinic acid are the products of ring cleavage. Another pathway for styrene metabolism observed in filamentous fungi is through styrene oxide (2-phenyloxirane), followed by the conversion to styrene glycol, mandelic acid and likely to benzoic acid (Braun-Lüllemann et al., 1997). The yeast Exophiala jeanselmei converts styrene to styrene oxide and then to phenylacetaldehyde and phenylacetic acid (Cox et al., 1993). The enzymes involved in these conversions are unknown. The bacteria $P$. fluorescens and $P$. putida can convert styrene to styrene-oxide with the monooxygenases StyA and StyB (Beltrametti et al., 1997; Otto et al., 2004). Styrene-oxide isomerase (StyC) catalyzes the conversion of styrene-oxide to phenylacetaldehyde that is further converted by phenylacetaldehyde dehydrogenase (StyD) to phenylacetate. In Gordonia rubripertincta, styrene oxide is further converted through S-glutathionylation to (S)-(1-phenyl-2-hydroxyethyl)-glutathione (Heine et al., 2018). In P. putida, phenylacetaldehyde can also be converted to phenylacetic acid and further to phenylacetylCoA (Crabo et al., 2017). Rhodococcus rhodochrous strain NCIMB 13259 grown on styrene together with 3-fluorocatechol to inhibit catechol dioxygenase activity, accumulated 3-vinylcatechol (Warhurst et al., 1994a, 1994b). It was suggested that styrene cis-glycol is the intermediate between styrene and 3-vinylcatechol.

\subsection{Benzoic acid, $p$-hydroxybenzoic acid and related metabolic pathways}

Benzoic acid is an intermediate aromatic compound of many secondary metabolites and is currently used as a food and beverage preservative. Biodegradation of alkaline lignin by B. ligniniphilus results in the release of benzoic acid (Zhu et al., 2017). In bacteria and fungi, five pathways in which benzoic acid is converted are described (Fig. 6):

1. Conversion of benzoic acid to benzoic acid dihydrodiol by the benzoate 1,2-dioxygenase subunits $A, B$ and $C$ (Ben $A B C$ ) while the benzoate 1,2-dioxygenase subunit $D$ (BenD) further catalyzes the reaction of benzoic acid dihydrodiol to catechol.

2. Anaerobic conversion of benzoic acid to benzoyl-SCoA by benzoate-CoA ligase (BadA or BlcA).

3. Reduction of benzoic acid to benzaldehyde by Acar that is further converted to benzyl alcohol.

4. Hydroxylation of benzoic acid to 3-hydroxybenzoic acid followed by:

a. 6-hydroxylation to gentisic acid by 3-hydroxybenzoate 6-hydroxylase (BagX, XInD or Mnx2).

b. $p$-hydroxylation to protocatechuic acid by 3-hydroxybenzoate-4-monooxygenase (MobA).

5. Hydroxylation of benzoic acid to $p$-hydroxybenzoic acid by benzoate 4-monooxygenase (BphA).

Pathway 1 was observed in Acinetobacter calcoaceticus, which converts benzoic acid to benzoic acid dihydrodiol and further to catechol (Neidle et al., 1991). In several Streptomyces and Bacillus species, it has been observed that benzoic acid was slowly converted to catechol (Peng et al., 2003; Sutherland et al., 1981). This slow conversion could be due to the multiple steps required, as was suggested in Streptomyces and Amycolatopsis species (Grund et al., 1990). It is therefore possible that pathway 1 is also used by Bacillus species. Pathway 2 was observed in Pseudomonas sp., Rhodopseudomonas palustris and Thauera aromatica (Austin et al., 2015; Breese and Fuchs; 1998; Gibson et al., 1994), and will be further discussed in the p-hydroxybenzoic acid section. Pathway 3 was observed by overexpressing Acar of $N$. iowensis in $E$. coli resulting in the conversion of benzoic acid to benzaldehyde 
and further to benzyl alcohol by endogenous enzymes (Kunjapur et al., 2014). The formation of benzyl alcohol was also observed in Aspergillus flavus when it was grown on benzoic acid (Palazzolo et al., 2015), indicating that this pathway is also present in nature. Pathway 4a has been described in several Bacilli and Paenibacillus sp. strain NyZ101 where conversion of benzoic acid to 3-hydroxybenzoic acid was observed followed by conversion to gentisic acid by 3-hydroxybenzoate 6-monooxygenase (BagX or XInD) (Crawford, 1975; Liu and Zhou, 2012; Peng et al., 2003). The conversion of 3-hydroxybenzoic acid to gentisic acid is catalyzed by $\mathrm{XInD}$ of Pseudomonas alcaligenes, and this conversion was also detected in Klebsiella pneumoniae and R. jostii (Gao et al., 2005; Jones and Cooper, 1990; Montersino and van Berkel, 2012). Pathway $4 \mathrm{~b}$ was observed in C. testosteroni, which converts benzoic acid to 3hydroxybenzoic acid and further to protocatechuic acid by MobA (Chang and Zylstra, 2008). MobA also has activity on 3-hydroxyanthranilate, $p$-hydroxybenzoic acid and 2,3-dihydroxybenzoic acid. The mutation of amino acid Val257 to Ala resulted in enhanced activity on phenol, resorcinol and hydroquinone (Chang and Zylstra, 2008). Currently, the enzymes involved in the conversion of benzoic acid to 3-hydroxybenzoic acid are unknown.

Pathways 1, 2, 3 and 4 have not been observed in filamentous fungi or yeast except for the conversion of 3-hydroxybenzoic acid by the filamentous fungi $P$. chrysosporium and $A$. japonicus (Fig. 6). In these fungi, 3-hydroxybenzoic acid is converted to protocatechuic acid and/or catechol, which is a part of the 3-oxoadipate pathway (Matsuzaki and Wariishi, 2005; Milstein et al., 1983; Sugumaran et al., 1973). In contrast, in the yeast $C$. parapsilosis, 3-hydroxybenzoic acid is converted to gentisic acid by the 3-hydroxybenzoate 6-hydroxylase (Mnx2) (Holesova et al., 2011). Pathway 5 was observed in fungi and not in bacteria. In A. niger, this reaction is catalyzed by BphA that acts together with a cytochrome P450 reductase (CprA), whereas in $A$. nidulans the corresponding enzymes are benzoate 4monooxygenase (BzuA) and an uncharacterized reductase (AN0595, homolog of CprA) (Fraser et al., 2002; Martins et al., 2015; van der Brink et al., 1996; van Gorcom et al., 1990). This conversion by a cytochrome P450 monooxygenase was also reported for Cochliobolus lunatus, $P$. chrysosporium and the yeast Rhodotorula minuta (Fukuda et al., 1996; Korošec et al., 2014; Lah et al., 2011; Matsuzaki and Wariishi, 2005).

Breakdown of kraft lignin by the bacterium $A$. formicans and the fungus $P$. chrysosporium results in the release of $p$-hydroxybenzoic acid (Chen and Chang, 1982; Gupta et al., 2001). In bacteria and fungi, six pathways for $p$-hydroxybenzoic acid conversion have been described (Fig. 7):

6. Hydroxylation of p-hydroxybenzoic acid to protocatechuic acid by 3-hydroxybenzoate-4hydroxylase (PobA or Pral).

7. Decarboxylation of $p$-hydroxybenzoic acid to phenol by BsdBCD and further to catechol by HpaBC or by the phenol hydroxylase components $\mathrm{L}, \mathrm{M}, \mathrm{N}, \mathrm{O}$ and $\mathrm{P}$ (DmpLMNOP).

8. Conversion of $p$-hydroxybenzoic acid to gentisic acid through:

a. Conversion to $p$-hydroxybenzoyl-CoA by $p$-hydroxybenzoyl-CoA ligase (PhgC) followed by the conversion to gentisyl-CoA by $p$-hydroxybenzoyl-CoA hydroxylase (PhgA) and gentisic acid by gentisyl-CoA thioesterase (PhgB).

b. Conversion to salicylic acid followed by the conversion to gentisic acid.

9. Anaerobic conversion of $p$-hydroxybenzoic acid to $p$-hydroxybenzoyl-CoA by 4-hydroxybenzoateCoA ligase ( $\mathrm{HbaA})$ and then to benzoyl-CoA by 4-hydroxybenzoyl-CoA reductase subunits $B, C$ and D (HbaBCD or HrcBCD).

10. Conversion of $p$-hydroxybenzoic acid to phenylacetic acid followed by conversion to tyrosol and benzenethanol.

11. Decarboxylation of o-hydroxybenzoic acid to hydroquinone by Mnx1 and further to hydroxyquinol by phenol 2-monooxygenase (Mnx3). 
Pathway 6 was observed in the bacteria P. aeruginosa, P. desmolytica, P. fluorescens, P. putida and Paenibacillus sp. (Entsch et al., 1988; Howell et al., 1972; Hosokawa and Stanier, 1966; Kasai et al., 2009), and the filamentous fungi $A$. flavus, A. niger, A. nidulans, C. lunatus, S. commune and several Penicillia, and the yeast T. oleaginosus (Halsall et al., 1969; lyayi and Dart, 1982; Lah et al., 2011; Martins et al., 2015; Yaguchi et al., 2017). Currently, many bacterial sequences for 3-hydroxybenzoate4-hydroxylase have been annotated (Westphal et al., 2018).

The fungal enzymes involved in this conversion are unknown, but in A. nidulans, a monooxygenase and NADPH flavin reductase have been suggested to catalyze this reaction (Martins et al., 2015). In C. lunatus, CYP53A15, the ortholog of BphA, with its reductase partners CPR1 and CPR2 catalyzes both steps of the $p$-hydroxybenzoic acid to protocatechuic acid pathway (Lah et al., 2011). Pathway 7 has been observed in B. subtilis (Lupa et al., 2005, 2008). In E. coli, Rhodococcus opacus, Pseudomonas sp. CF600 and $P$. aeruginosa, phenol is converted to catechol and is catalyzed by HpaBC or DmpLMNOP (Furuya and Kino, 2014; Powlowski and Shingler, 1994; Xun and Sandvik, 2000; van Duy et al., 2007; Yoneda et al., 2016). The ring cleavage of catechol is further discussed in section 2.9.1. The conversion of $p$-hydroxybenzoic acid to phenol has not been described for fungi, but the conversion of phenol to catechol was observed in Candida albicans and Trichosporon cutaneum (Gérecová et al., 2015; Kälin et al., 1992). The phenol hydroxylase PhhY of $T$. cutaneum catalyzes this reaction (Kälin et al., 1992).

Pathway 8 has been observed in several Bacilli and suggested to be a direct conversion (Peng et al., 2003). In principle, this conversion can be catalyzed by one enzyme through an intramolecular migration (NIH shift) of the carboxyl group, however it was never demonstrated for $p$-hydroxybenzoic acid. Pathway 8a was recently demonstrated in the bacterium Brevibacillus laterosporus that $p$ hydroxybenzoic acid converted to gentisic acid involving the three enzymes, $p$-hydroxybenzoyl-CoA ligase, $p$-hydroxybenzoyl-CoA hydroxylase and gentisyl-CoA thioesterase (Zhao et al., 2018). Pathway $8 \mathrm{~b}$ was suggested in Rhizobium sp. (Muthukumar et al., 1982). It was also suggested that salicylic acid could be the intermediate between $p$-hydroxybenzoic acid and catechol (Seo et al., 2009). The enzymes involved in this pathway have not been identified. The salicylic acid pathway is further discussed in section 2.7 .

Pathway 9 has been described in R. palustris and T. aromatica and continues through the benzoyl-CoA pathway to 1,5-diene-cyclohexanoyl-CoA and 1-ene-cyclohexanoyl, both catalyzed by benzoate-CoA reductase subunits D, E, F and G (BadDEFG) (Austin et al., 2015; Breese and Fuchs, 1998). Deletion of BadE resulted in the accumulation of benzoic acid when R. palustris was grown on ammonia fibre expansion (AFEX)-pretreated cornstover hydrolysate. The deletion of $\mathrm{HbaB}$ resulted in the accumulation of $p$-hydroxybenzoic acid but did not block the benzoyl pathway. Pathway 10 has been observed in S. cerevisiae in which $p$-hydroxybenzoic acid is converted to phenylacetic acid followed by the conversion to tyrosol and benzenethanol (Adeboye et al., 2017). Pathway 11 has been described in the yeast C. parapsilosis (Eppink et al., 1997, 2000; Holesova et al., 2011). In the fungi A. fumigatus, hydroquinone is converted to hydroxyquinol (Jones et al., 1994). Hydroxyquinol is further processed through ring cleavage, which is discussed in section 2.9.3. Mnx1 is also able to catalyze the conversion of protocatechuic acid to hydroxyquinol (Anderson and Dagley, 1980; Eppink et al., 1997; Holesova et al., 2011).

Currently, only one pathway was described for the conversion of benzoic acid by filamentous fungi, whereas several pathways have been described for bacteria excluding the conversion of benzoic acid to $p$-hydroxybenzoic acid (Fig. 6, 7). It is likely that bacteria prefer the conversion of benzoic acid to 3hydroxybenzoic acid or benzoic acid to benzoic acid dihydrodiol, while fungi prefer the conversion to $p$-hydroxybenzoic acid. However, bacteria are able to convert $p$-hydroxybenzoic acid, probably through the $p$-coumaric acid pathway in which $p$-hydroxybenzoic acid is the conversion product as discussed in section 2.6. Because of many observations in filamentous fungi, this indicates that the hydroxylation of benzoic acid to $p$-hydroxybenzoic acid continued to protocatechuic acid is the main 
metabolic pathway. For bacteria, it is likely that either pathway 1 or 4 is the main benzoic acid metabolic pathway.

\section{6 $p$-Coumaric acid metabolic pathways}

$p$-Coumaric acid is released during lignin breakdown by the bacteria $A$. formicans, $C$. basilensis and $R$. toruloides (Gupta et al., 2001; Shi et al., 2013; Yaegashi et al., 2017). In addition, p-coumaric acid, similar to ferulic acid, can be linked to polysaccharides (Mäkelä et al., 2015). Lignin synthesis in plants converts cinnamic acid to $p$-coumaric acid (Humphreys and Chapple, 2002). $p$-Coumaric acid, a derivative from the monolignol $p$-coumaryl alcohol, has antioxidant and antimicrobial properties (Pei et al., 2016). In the filamentous fungi $A$. flavus, the monolignol $p$-coumaryl alcohol is converted to $p$ coumaryl aldehyde followed by conversion to $p$-coumaric acid (lyayi and Dart, 1982). Five pathways are described for bacteria and fungi, in which $p$-coumaric acid is mainly converted to $p$-hydroxybenzoic acid or caffeic acid through (Fig. 8):

1. Non-oxidative decarboxylation in which $p$-coumaric acid is converted to $p$-vinylphenol by PadC, Fdc1 or Pad and is followed by;

a. The conversion to $p$-hydroxybenzaldehyde and then to $p$-hydroxybenzoic acid by YfmT.

b. The reduction to 4-ethylphenol by VprA

2. Conversion of $p$-coumaric acid to $p$-coumaryl-CoA by Fcs or CouL followed by:

a. CoA-dependent $\beta$-oxidation to 3-hydroxy-3-(p-hydroxyphenyl) propyl-CoA (HPHP-SCoA) and then to $p$-hydroxybenzaldehyde, both catalyzed by Ech.

b. CoA-dependent non- $\beta$-oxidation in which $p$-coumaric acid is first converted to $p$-coumarylSCoA by Fcs and then to $p$-hydroxybenzaldehyde and $p$-hydroxybenzoic acid by YfmT.

3. Conversion of $p$-coumaric acid to $\beta$-hydroxy-( $p$-hydroxyphenyl)-propionic acid followed by ( $p$ hydroxybenzoyl)-acetic acid and $p$-hydroxybenzoic acid.

4. Conversion of $p$-coumaric acid to 3-(p-hydroxyphenyl)-propionic acid followed by 3-(phydroxyphenyl)-propyl aldehyde to 3-( $p$-hydroxyphenyl)-propanol and to $p$-hydroxybenzoic acid.

5. Hydroxylation of $p$-coumaric acid to caffeic acid by HpaBC or 4-coumarate 3-hydroxylase (Sam5).

Pathway 1a was observed for several Bacillus species (Jung et al., 2013; Torres and Rosazza et al., $2001 ;)$. It has been proposed that $p$-vinylphenol is converted to $p$-hydroxybenzaldehyde and then to $p$-hydroxybenzoic acid (Monisha et al., 2017). In fungi, this pathway was described for $P$. variotii and F. solani (Nazareth and Mavinkurve, 1986; Sachan et al., 2006). The pathway was also reported for $S$. commune, but $p$-vinylphenol was not detected (Sachan et al., 2010). Fdc1 of S. cerevisiae and Pad of A. luchuensis and I. farinosa can catalyze the conversion of $p$-coumaric acid to $p$-vinylphenol (Linke et al., 2017; Maeda et al., 2018; Mukai et al., 2010). Pathway 1b has been observed in the wine spoilage yeasts of the genera Brettanomyces and Dekkera (Suárez et al., 2007). Recently, this pathway has also been observed in the bacterium L. plantarum where it is catalyzed by VprA (Santamaría et al., 2018). In the bacterium $P$. putidia, $p$-vinylethyl is further converted to hydroquinone through the intermediates 1-(4-hydroxyphenyl)ethanol, 4-hydroxyacetophenone and 4-hydroxyphenylacetate, respectively (Darby et al., 1987). Hydroquinone is further processed through ring cleavage (see section 2.9.3). The same pathway has also been suggested for $A$. fumigatus which further hydroxylates hydroquinone to hydroxyquinol (Jones et al., 1994), even though the conversion of $p$-vinylphenol to $p$-ethylphenol was not observed. Pathway 2 was observed in P. putida, R. jostii and R. palustris (Austin et al., 2015; Hirakawa et al., 2012; Otani et al., 2014; Ravi et al., 2017). While R. palustris uses both pathways, only pathway 2b was observed in P. putida (Austin et al., 2015; Hirakawa et al., 2012; Ravi et al., 2017). The conversion of $p$-hydroxybenzaldehyde is catalyzed by Yfmt and is probably also catalyzed by Vdh since the deletion of Vdh in C. glutamicum resulted in reduced growth on $p$ hydroxybenzaldehyde (Ding et al., 2015; Jung et al., 2016; Graf et al., 2016 Ravi et al., 2017). In S. setonii, $p$-coumaric acid is converted to $p$-hydroxybenzaldehyde, followed by the conversion to $p$ hydroxybenzoic acid, but it is unclear if one of the CoA-dependent pathways is used (Sutherland et al., 
1983). Bacillus sp. strain B1, P. deceptionensis and $S$. caeruleus are able to convert $p$-coumaric acid to $p$-hydroxybenzoic acid, but it is not known if the described or an alternative pathway is used (Peng et al., 2003; Ravi et al., 2018; Sachan et al., 2005). Pathway 3 was only observed in the fungus A. flavus (Iyayi and Dart, 1982), but the enzymes catalyzing this pathway remain unknown. Pathway 4 has also been described for filamentous fungi. The basidiomycete $P$. cinnabarinus converts $p$-coumaric acid to 3 -( $p$-hydroxyphenyl)-propanoic acid and then to $p$-hydroxybenzoic acid or 3 -( $p$-hydroxyphenyl)propanol (Alvarado et al., 2001), while in S. commune, $\beta$-hydroxy-( $p$-hydroxyphenyl)-propionic acid has been suggested to be first converted to 3-( $p$-hydroxyphenyl)-propyl aldehyde and 3-( $p$ hydroxyphenyl)-propanol before it is converted to $p$-hydroxybenzoic acid (Nimura et al., 2010). Interestingly, the Bacillus sp. strain B1 can convert 3-( $p$-hydroxyphenyl)-propanoic acid to $p$-coumaric acid, and it has been suggested that it is followed by conversion to $p$-hydroxybenzoic acid (Peng et al., 2003). Pathway 5 was observed in bacteria and is catalyzed by HpaBC of $P$. fluorescens and Sam 5 of Saccharothrix espanaensis (Furuya and Kino, 2014; Heo et al., 2017). Comparison of these protein sequences to all available fungal genomes by BlastP (www.ncbi.nlm.nih.gov) results in a few hits with low homology indicating that these enzymes are unique for bacteria. However, the transformation of $p$-coumaric acid to caffeic acid is observed for the basidiomycete $P$. cinnabarinus and the ascomycetes Gliocladium deliquescens and several Aspergilli (Alvarado et al., 2003; Torres and Rosazza, 2001), indicating that this transformation is probably catalyzed by different enzymes in fungi.

Multiple conversion pathways of $p$-coumaric acid in bacteria and filamentous fungi towards $p$ hydroxybenzoic acid have been described (Fig. 8). However, in yeast the conversion of $p$-coumaric acid to $p$-hydroxybenzoic acid has not been observed (Adeboye et al., 2015). Despite the many observations of $p$-coumaric acid being converted to $p$-hydroxybenzoic acid in filamentous fungi, no enzymes have been characterized. Because of many observations, it is possible that the non-oxidative decarboxylation of $p$-coumaric acid is likely the main metabolic pathway of microorganisms.

\subsection{Salicylic acid metabolic pathway}

Salicylic acid can be converted through $p$-hydroxybenzoic acid (Fig. 7), which can be derived from the monolignols $p$-coumaryl alcohol and $p$-coumaric acid (Fig. 8). Salicylic acid is an important aromatic compound, because it has activity against bacterial plant pathogens and an important role in the signaling cascade of the plant immune system (Shah, 2003; Vernooij et al., 1994). In addition, In the pharmaceutical industry, salicylic acid is used as a peeling agent to treat various skin disorders such as acne, melasma and psoriasis (Arif, 2015). In bacteria and fungi, the metabolism of salicylic acid is well studied and six pathways have been described (Fig. 9):

1. Conversion of salicylic acid towards catechol through:

a. Direct conversion to catechol by salicylate hydroxylase (NahG).

b. Hydroxylation of salicylic acid to 2,3-dihyroxybenzoic acid and further to catechol by salicylic acid decarboxylase (Sdc).

2. Conversion of salicylic acid to gentisic acid by the salicylate 5-hydroxylase components NagG and $\mathrm{NagH}$.

3. Decarboxylation of salicylic acid to phenol by BsdBCD or Sdc.

4. Conversion of salicylic acid to salicylyl-AMP by salicylyl-AMP ligase (SdgA).

5. Extradiol cleavage of salicylic acid to 2-oxohepta-3,5-dienedioic acid by salicylate 1,2-dioxygenase (Sdo).

6. Reduction of salicylic acid to salicylicaldehyde and further to salicyl alcohol.

Pathway 1a has been observed in P. putida, Amycolatopsis spp. and Streptomyces spp., where salicylic acid is converted to catechol (Grund et al., 1990). The reaction is catalyzed by NahG of $P$. putida (Grund et al., 1990; Katagiri et al., 1965; Suzuki et al., 1991). In the filamentous fungi Sclerotinia sclerotiorum and several Aspergilli, salicylic acid pathway $1 \mathrm{a}$ and $1 \mathrm{~b}$ have been reported (Kuswandi and Roberts, 
1992; Martins et al., 2015; Milstein et al., 1983; Penn and Daniel, 2013). Both pathways have also been observed in the yeasts Trichosporon cutaneum and T. moniliiforme (Anderson and Dagley, 1980; Kirimura et al., 2010). Sdc of $T$. moniliiforme and 2,3-dihydroxybenzoate decarboxylase of $A$. niger have been shown to catalyze the decarboxylation of 2,3-dihydroxybenzoic acid to catechol (Kirimura et al., 2010; Santha et al., 1995). In addition, Sdc can also convert 2,4-dihydroxybenzoic acid to resorcinol. In Pseudomonas reinekei, $P$. putida and $P$. fluorescens, extradiol cleavage of 2,3 dihydroxybenzoic acid has been observed, which is catalyzed by the 2,3-dihydroxybenzoic acid 3,4dioxygenase DhbA (Marín et al., 2012). Pathway 2 has been observed in Ralstonia sp. and is catalyzed by NagG and NagH to gentisic acid, after which the aromatic ring is cleaved (Fuenmayor et al., 1998; Zhou et al., 2001). This pathway was also suggested in Streptomyces umbrinus (Grund et al., 1990), but has not been observed in fungi.

Pathway 3 is observed in the bacterium B. subtilis catalyzed by BsdBCD and in the yeast $T$. moniliiforme catalyzed by Sdc (Fig. 9) (Kirimura et al., 2010; Lupa et al., 2008). This pathway has also not been observed in filamentous fungi. In pathway 4, Streptomyces sp. strain WA46 converts salicylic acid to salicylyl-AMP by salicylyl-AMP ligase (SdgA) (Ishiyama et al., 2004). Subsequently, salicylyl-AMP is converted to salicylyl-SCoA by SdgA and/or salicylyl-CoA synthetase (SdgB) and then to gentisate-SCoA by salicylyl-CoA 5-hydroxylase ( $\mathrm{SdgC}$ ), followed by conversion to gentisic acid. Pathway 5 has been observed in Pseudaminobacter salicylatoxidans, revealing an extradiol ring cleavage of salicylic acid catalyzed by salicylate 1,2-dioxygenase (Sdo) (Hintner et al., 2001; Matera et al., 2008). Pathway 6 has been observed in the ascomycete Neurospora crassa (Bachman et al., 1960). The enzymes catalyzing these conversions remain unidentified. This pathway has not been observed in bacteria.

Salicylic acid can be produced from $p$-hydroxybenzoic acid in bacteria (Fig. 7), whereas in fungi no pathway leads to the production of salicylic acid. The reason to have a salicylic acid metabolic pathway can be explained by the fact that salicylic acid is an important signaling compound in disease resistance in plants and the conversion of salicylic acid is a strategy to suppress the corresponding plant defenses (Loake and Grant, 2007). In addition, salicylic acid can be found freely in plants and functions as an important plant hormone involved in many developmental processes (Jayakannan et al., 2015; Klessig et al., 2016). In filamentous fungi, the enzymes involved in the salicylic acid metabolic pathways are mostly unknown, but suggestions have been made (Martins et al., 2015). Salicylic acid is converted to catechol in fungi and bacteria or to gentisic acid in bacteria after which the ring is cleaved. Due to many observations, it is likely that pathway 1 a to catechol is the main salicylic acid metabolic pathway in microorganisms.

\subsection{Sinapic acid, syringic acid and related compounds}

Less is known about the aromatic metabolic pathways of sinapic acid, a derivative of the monolignol sinapyl alcohol. Sinapic acid was observed to form a dehydrodimer and sinapate-ferulate heterodimers and therefore has a role in cross-linking polysaccharides in cereal grains (Bunzel et al., 2003). No release of sinapic acid during lignin degradation was detected, but the related compound syringic acid was identified (Gupta et al., 2001). In the fungus $P$. variotii, sinapic acid is converted to syringaldehyde followed by conversion to syringic acid (Mukherjee et al., 2006). The conversion of syringaldehyde to syringic acid has been observed in many ascomycete soil fungi (Henderson and Farmer, 1955). It is unclear, whether this is a direct conversion or that a $\beta$-oxidative decarboxylation, a non- $\beta$-oxidative decarboxylation or a non-oxidative decarboxylation pathway is used. A similar pathway has been observed in the yeast Rhodotorula glutinis, but the intermediate syringaldehyde was not observed (Gupta et al., 1986). Since no syringaldehyde was detected, it is likely that this yeast is using a non-oxidative decarboxylation pathway forming $p$-vinylsyringol as intermediate. However, this intermediate was also not detected. In the yeast Brettanomyces, sinapic acid is degraded to $p$ vinylsyringol and $p$-ethylsyringol, but the conversion to syringic acid was not observed (Heresztyn, 1986). Up to now, no sinapic acid conversions have been detected in bacteria. However, Sphingobium 
sp. strain SYK-6 converts syringaldehyde to syringic acid by the aldehyde dehydrogenase DesV (Kamimura et al., 2017). This conversion was also observed in B. subtilis and is catalysed by $\mathrm{YfmT}$ (Graf et al., 2016). Currently, four syringic acid metabolic pathways have been described (Fig. 10):

1. Demethylation of syringic acid to 3-o-methylgallic acid (5-hydroxyvanillic acid) by syringate odemethylase (DesA) followed by:

a. Demethylation of 3-o-methylgallic acid to gallic acid by LigM.

b. Intradiol ring cleavage of 3-o-methylgallic acid to 2-pyrone-4,6-dicarboxylic acid by the 3-omethylgallate 3,4-dioxygenase (DesZ).

2. Methylation of syringic acid to 3,4,5-trimethoxybenzoic acid.

3. Decarboxylation and hydroxylation of syringic acid to 2,6-dimethoxy-1,4-hydroquinone followed by the conversion to 2,6-dimethoxy-1,4-benzoquinone.

4. Decarboxylation of syringic acid to 2,6-dimethoxyphenol.

Pathway 1 has been observed in the bacteria Sphingobium sp. strain SYK-6 and P. putida (Donnelly and Dagley, 1980, Masai et al., 2004), the filamentous fungi $P$. variotii, $P$. chrysosporium and $S$. pulverulentum (Eriksson et al., 1984; Higuchi, 1986; Mukherjee et al., 2006) and the yeast $R$. glutinis (Gupta et al., 1986). Pathway 1a is the most described conversion and is well studied in the bacterium Sphingobium sp. strain SYK-6 in which it is catalyzed by LigM (Abe et al., 2005; Harada et al., 2017). This pathway has also been observed in the yeast $R$. glutinis (Mukherjee et al., 2006). The formation of gallic acid was suggested in S. pulverulentum, altrough no gallic acid was observed (Eriksson et al., 1984). Pathway 1b has been described in the bacterium Sphingobium sp. strain SYK-6 (Kasai et al., 2007). Pathway 2 has been observed in the fungi S. pulverulentum, Petriellidium boydii and Phialophora mutabilis (Eriksson et al., 1984). 3,4,5-Trimethoxybenzoic acid is further demethylated towards 3-hydroxy-4,5-methoxybenzoic acid followed by another demethylation to 3-o-methyl gallic acid. In P. putida and Eubacterium limosum, 3,4,5-trimethoxybenzoic acid is oxidized to syringic acid (Cocaign et al., 1991; Donnelly and Dagley, 1980). Pathway 3 has been observed in the fungus $P$. ostreatus and the yeast $R$. glutinis (Gupta et al., 1986; Shin, 1995), while pathway 4 has been described for the fungus $P$. ostreatus and is catalysed by an extracellular peroxidase (Shin, 1995). No fungal enzymes have been characterized for these pathways.

Gallic acid is the observed conversion product of pathways 1a and 2, and the aromatic ring can be cleaved (discussed in section 2.9.5). The direct conversion of gallic acid to pyrogallol was observed in the bacteria Entrobacter spp., Klebsiella aerogenes, Pelobacter acidigallici and L. plantarum, and is catalyzed by the gallate decarboxylase (LpdC) (Brune and Schink, 1992; Grant and Patel, 1969; Jiménez et al., 2013; Sonia et al., 2017). This conversion has also been observed in the fungus $A$. oryzea and in the yeast Arxula adeninivorans (Guo et al., 2014; Meier et al., 2017). A. adeninivorans converts gallic acid to pyrogallol (trihydroxybenzene) by gallic acid decarboxylase (Gdc) followed by an intradiol cleavage (Meier et al., 2017). Two additional gallic acid conversions were reported in $A$. oryzea and $R$. glutinis resulting in the formation of progallin $A$ and methyl gallate which can be converted to pyrogallol (Guo et al., 2014; Gupta et al., 1986).

Despite the low amount of observations, it appears that in microorganisms, the main syringic acid metabolic pathway is the conversion to 3-o-methylgallic acid followed by the demethylation to gallic acid. Nevertheless, more research is needed in order to fully understand the metabolic pathway and to discover possible alternative pathways such as the CoA-dependent $\beta$-oxidation and CoA-dependent non- $\beta$-oxidation of sinapic acid.

\subsection{Ring cleavage of aromatic compounds}

The ring cleavage pathways are very important for microorganism to detoxify aromatic compounds and to use these as a carbon source (Vaillancourt et al., 2006). The cleaved ring is then converted in 
multiple steps to pyruvate, fumarate, succinate, oxaloacetate or acetyl-CoA and finally entering the TCA cycle. Prior to entering ring cleavage pathways, most aromatic compounds are converted to seven central ring-fission intermediates, i.e. catechol, protocatechuic acid, hydroxyquinol, hydroquinone, gentisic acid, gallic acid and pyrogallol (Fig. 11). In this section, we discuss the ring cleavage pathways through the seven central ring-fission intermediates. Since ring cleavage pathways are quite conserved and currently only intradiol cleavage is observed in fungi, we summarized their differences and similarities in Table S3 and in section 2.10.

\subsubsection{Catechol ring cleavage}

Catechol derives from several aromatic compounds such as benzoic, salicylic and vanillic acids, which are derived from coniferyl and $p$-coumaryl alcohols (Fig. 4, 6, 9). Catechol is one of the many industrial and commercially interesting aromatic compounds, which can be used as a precursor for artificial flavors and fragrances, and which also has antimicrobial activity (Kocaçalışkan et al., 2006). In bacteria, there are two pathways for the cleavage of catechol (Fig. 11). In the intradiol cleavage (ortho-cleavage) pathway, the catechol 1,2-dioxygenase 1 and 2 (CatA1 and CatA2) of Acinetobacter iwoffii cleave the catechol forming cis, cis-muconic acid (Kim et al., 1997). Interestingly, cis, cis-muconic acid is a platform chemical used as a precursor for bioplastics (Curran et al., 2013; Sun et al., 2013; Xie et al., 2014). Deletion of these dioxygenases resulted in accumulation of catechol. Neither CatA1 nor CatA2 has activity on protocatechuic acid. Cis,cis-muconic acid is further converted to muconolactone and then to 3-oxoadipate enol-lactone by the $P$. putida muconate cycloisomerase 1 (CatB) and muconolactone Delta-isomerase (CatC), respectively (Ornston, 1966, Parsek et al., 1992). 3-Oxoadipate enol-lactone is further converted to 3-oxoadipate by CatD. 3-oxoadipate is converted 3-oxoadipate-SCoA which is converted to acetyl-CoA and succinate before entering the TCA cycle. The enzymes 3-oxoadipate CoAtransferase subunit A and B (Catl and CatJ or Pcal and PcaJ) of $P$. putida and $\beta$-ketoadipyl-CoA thiolase (PcaF) of Pseudomonas knackmussii catalyze these conversions (Kaschabek et al., 2002). This pathway was also observed in $R$. opacus and candidate enzymes were identified with transcriptome analysis (Yoneda et al., 2016).

The extradiol cleavage (meta-cleavage) pathway, in which catechol is converted to 2-oxoadipate, has been observed for several Pseudomonas species (Cao et al., 2008; Hamzah and Al-Baharna, 1994; Kukor and Olsen, 1991). The first step is the conversion of catechol to 2-hydroxymuconate semialdehyde by catechol 2,3-dioxygenase (XyIE in P. putidia) or by metapyrocatechase (DmpB in Pseudomonas sp. strain CF600) (Shingler et al., 1992; Shu et al., 1995). 2-hydroxymuconate semialdehyde is then converted to 2-oxopent-4-enoate and formate by 2-hydroxymuconate semialdehyde hydrolase (DmpD) or XylF in P. putida (Duggleby and Williams, 1986; Shingler et al., 1992). An additional pathway was observed in which 2-hydroxymuconate semialdehyde is converted to 2-hydroxymuconate by 2-hydroxymuconic semialdehyde dehydrogenase ( $\mathrm{DmpC}$ ) or XylG in $P$. putida, then to 4-oxalocrotonate (keto form) by 2-hydroxymuconate tautomerase (Dmpl), and finally to 2-oxopent-4-enoate by 4-oxalocrotonate decarboxylase ( $\mathrm{DmpH}$ ) (Duggleby and Williams, 1986; Inoue et al., 1995; Shingler et al., 1992). 2-Oxopent-4-enoate is then converted to 4-hydroxy-2oxovalerate by 2-oxopent-4-enoate hydratase (DmpE), and further to pyruvate and acetaldehyde by 4-hydroxy-2-oxovalerate aldolase (DmpG) or XylK in P. putida (Duggleby and Williams, 1986; Shingler et al., 1992). Acetaldehyde is further converted to acetyl-CoA by acetaldehyde dehydrogenase (DmpF) (Shingler et al., 1992).

In fungi, the intradiol cleavage pathway cleaves catechol to cis,cis-muconic acid, followed by the conversion to muconolactone (Fig. 11). The yeast C. albicans uses the catechol 1,2-dioxygenase (Hqd2) to cleave the aromatic ring of catechol (Tsai and Li, 2007). This enzyme is substrate specific and has no activity towards hydroxyquinol and catechol-related compounds. Transcriptome data of $A$. nidulans revealed induction of a catechol 1,2-dioxygenase (AN4532) during growth on salicylic acid (Martins et al., 2015). Cis,cis-muconic acid is converted to muconolactone, catalysed by cis,cis- 
muconate cycloisomerase. Deletion of AN3895, encoding for an cis, cis-muconate cycloisomerase, in A. nidulans, resulted in accumulation of cis,cis-muconic acid (Martins et al., 2015). Muconolactone is further converted by muconolactone isomerase. Deletion of AN4061, encoding for a muconolactone isomerase, in $A$. nidulans, resulted in accumulation of muconolactone when grown on salicylic acid (Martins et al., 2015). Muconolactone is further converted to 3-oxoadipate-enol lactone by 3oxoadipate enol-lactone hydrolase, encoded by AN4531. Deletion of AN4531 in A. nidulans resulted in accumulation of 3-oxoadipate-enol lactone. 3-oxoadipate-enol lactone is converted to 3-oxoadipate by and 3-oxoadipate-SCoA by 3-oxoadipate CoA-transferase (Osc1) and further to acetyl-CoA and succinate that enters the TCA cycle. Based on homology of AN3895, AN4061 and AN4531 and gene expression data of $C$. albicans, putative cis,cis-muconate cycloisomerase (Mci1), muconolactone isomerase (Mli1) and 3-oxoadipate enol-lactone hydrolase (Oel1) were suggested (Gérecová et al., 2015).

\subsubsection{Protocatechuic acid ring cleavage}

Protocatechuic acid derives from the aromatic compounds $p$-hydroxybenzoic acid and vanillic acid, the conversion products of $p$-coumaric acid and ferulic acid, respectively (Fig. 4, 7). Protocatechuic acid is the second aromatic compound where most aromatic pathways end. In bacteria, the aromatic ring of protocatechuic acid can be cleaved at the 2,3-, 3,4- and 4,5-side (Fig. 11). The most observed pathway in this group is the protocatechuic acid intradiol $(3,4-)$ cleavage pathway, by which the ring of protocatechuic acid is cleaved to form 3-carboxy-cis,cis-muconic acid (Harwood and Parales, 1996). This cleavage is catalyzed by protocatechuate 3,4-dioxygenases (PcaGH) of P. putida (Harwood et al., 1994). 3-Carboxy-cis,cis-muconic acid is converted to $y$-carboxymuconolactone by 3-carboxy-cis,cismuconate cycloisomerase (PcaB), which is converted to 3-oxoadipate enol-lactone by 4carboxymuconolactone decarboxylase (PcaC) (Buchan et al., 2000). Subsequently, 3-oxoadipate enollactone is converted to 3-oxoadipate by 3-oxoadipate enol-lactonase 1 (PcaD) and is further converted to 3-oxodipate-SCoA by PcaF.

Two protocatechuic acid extradiol cleavage pathways are observed in bacteria. The 4,5-cleavage pathway is observed in Sphingobium sp. strain SYK-6 converts protocatechuic acid to 4-carboxy-2hydroxymuconate-6-semialdehyde by the protocatechuate 4,5-dioxygenase (LigAB), and is further converted through a non-enzymatic reaction to its intramolecular hemiacetal form (Masai et al., 2007a). This compound is hydrated to 2-pyrone-4,6-dicarboxylate by 4-carboxy-2-hydroxymuconate6-semialdehyde dehydrogenase (LigC) (Masai et al., 2000). Interestingly, 2-pyrone-4,6-dicarboxylate is also the 4,5-cleavage product of gallic acid revealing a connection between the ring cleavage pathway of protocatechuic acid and gallic acid (Dennis et al., 1973). 2-Pyrone-4,6-dicarboxylate is further converted to 4-oxalomesaconate (enol form) by 2-pyrone-4,6-dicarboxylate hydrolase (Ligl) (Masai et al., 2007a). 4-oxalomesaconate (enol form) can be converted to either its keto form by the putative 4-oxalomesaconate tautomerase (LigU or GalD) or to 4-carboxy-4-hydroxy-2-oxoadipate by 4-oxalomesaconate hydratase (LigJ or GalB) (Hara et al., 2000, 2003; Hogancamp and Raushel, 2018; Hogancamp et al., 2018; Nogales et al., 2005; Kamimura and Masai, 2014). 4-Carboxy-4-hydroxy-2oxoadipate is cleaved by 4-carboxy-4-hydroxy-2-oxoadipate aldolase (LigK or GalC) to form oxaloacetate and pyruvate (Hara et al., 2003; Masai et al., 2007a; Nogales et al., 2005; 2011). An alternative pathway has been described for Pseudomonas testosteroni in which 4-carboxy-2hydroxymuconate-6-semialdehyde is converted to 4-hydroxy-4-methyl-2-oxoglutarate and then to two pyruvate units by a 4-hydroxy-4-methyl-2-oxoglutarate aldolase (Dennis et al., 1973). The enzymes of this alternative pathway are not characterized.

The second extradiol pathway cleaves protocatechuic acid at the 2,3 side. This pathway has been described for Paenibacillus sp. in which protocatechuate 2,3-dioxygenase (PraA) cleaves protocatechuic acid to form 5-carboxy-2-hydroxymuconate-6-semialdehyde (Crawford et al., 1979, Kasai et al., 2009). This compound is decarboxylated by 5-carboxy-2-hydroxymuconate-6- 
semialdehyde decarboxylase (PraH) to 2-hydroxymuconate-6-semialdehyde, followed by the conversion to 2-hydroxymuconate by 2-hydroxymuconate-6-semialdehyde dehydrogenase (PraB). 2Hydroxymuconate dehydrogenase ( $\mathrm{PraC}$ ) catalyzes the conversion of 2-hydroxymuconate to 4oxalocrotonate which is followed by the formation of 2-hydroxypenta-2,4-dienoate catalyzed by 4oxalocrotonate decarboxylase (PraD). Thereafter, 2-hydroxypenta-2,4-dienoate is converted to 4hydroxy-2-oxovalerate by 2-hydroxypenta-2,4-dienoate hydratase (PraE), which is converted by 4hydroxy-2-oxovalerate aldolase (PraF) to pyruvic acid and acetaldehyde. The latter compound is converted to acetyl-SCoA by acetaldehyde dehydrogenase (PraG). An alternative pathway was observed in $K$. pneumoniae in which protocatechuic acid is converted to catechol by protocatechuate decarboxylase (AroY) and further converted through the catechol pathway (Sonoki et al., 2014).

In fungi, the intradiol cleavage pathway is observed in which protocatechuic acid is cleaved to form 3carboxy-cis,cis-muconic acid (Harwood and Parales, 1996; Mazur et al., 1994). Transcriptome data of A. nidulans revealed induction of a protocatechuate 3,4-dioxygenase (AN8566) during growth on benzoic acid (Martins et al., 2015). After ring cleavage, 3-carboxy-cis,cis-muconic acid is converted to $\beta$-carboxymuconolactone and is catalyzed by 3 -carboxy-cis,cis-muconate lactonizing enzyme (CLME) of $N$. crassa (Kajander et al., 2002). In A. nidulans, the gene assigned to this conversion is AN1151 encoding for carboxy-cis, cis-muconate cyclase, deletion of AN1151 resulted in the accumulation of 3carboxy-cis,cis-muconic acid and abolished growth of A. nidulans on benzoic acid (Martins et al., 2015). 3-Carboxymuconolactone is converted to 3-oxoadipate and 3-oxoadipate-SCoA and is further converted to acetyl-CoA and succinate that enters the TCA cycle. In A. nidulans, the gene AN5232 encoding for 3-carboxymuconolactone hydrolase is predicted to catalyze this conversion. Deletion of AN5232 resulted in abolished growth of $A$. nidulans on benzoic acid and the accumulation of 3carboxymuconolactone acid (Martins et al., 2015), indicating that this fungus has no alternative pathway for this compound. In yeasts, no protocatechuic acid ring cleavage pathways were observed, but protocatechuic acid is converted to catechol by the yeast $A$. adeninivorans and is catalyzed by Gdc (Meier et al., 2017). Another pathway has been described in the yeasts T. cutaneum and C. parapsilosis in which protocatechuic acid is converted to hydroxyquinol by Mnx1 (Anderson and Dagley, 1980; Eppink et al., 1997; Holesova et al., 2011).

\subsubsection{Hydroxyquinol and hydroquinone ring cleavage}

Hydroxyquinol derives from several aromatic compounds such as $p$-hydroxybenzoic and vanillic acids, which are derived from ferulic acid and $p$-coumaric acid (Fig. 4, 7). In bacteria, two hydroxyquinol ring cleavage pathways have been described (Fig. 11). The first pathway converts hydroxyquinol through intradiol ring cleavage to maleylacetate (Chapman and Ribbons, 1976; Daubaras et al., 1996). In Nocardioides simplex, this conversion is catalyzed by hydroxyquinol 1,2-dioxygenase (ChqB) (Travkin et al., 2006). Maleylacetate is then converted to 3-oxoadipate by maleylacetate reductase (LinF), after which it is converted to 3-oxoadipate-SCoA and further to acetyl-CoA and succinate that enters the TCA cycle (Endo et al., 2005).

The second pathway converts hydroxyquinol through extradiol cleavage at the 4,5-side to form 2,4dihydroxymuconic semialdehyde (Chapman and Ribbons, 1976). 2,4-dihydroxymuconic semialdehyde is further converted to acetylpyruvate and formate. Finally, acetylpyruvate is converted to acetate and pyruvate and they are introduced to the TCA cycle. The enzymes catalyzing these reactions are unknown. In the filamentous fungus $S$. pulverulentum ( $P$. chrysosporium), and the yeasts $C$. parapsilosis and $C$. albicans, the intradiol ring cleavage of hydroxyquinol to maleylacetate is observed (Buswell and Eriksson, 1979; Eppink et al., 2000; Gérecová et al., 2015; Rieble et al., 1994). In C. parapsilosis, this conversion is catalyzed by the hydroxyquinol dioxygenase 1 ( $\mathrm{Hdx} 1$ ) (Holesova et al., 2011). Maleyacetate is further converted to 3-oxoadipate and 3-oxoadipate-SCoA. 
Hydroquinone derives from the aromatic compounds 4-hydroxyphenylacetate and $p$-hydroxybenzoic acid (Fig 7,8$)$. In the bacteria P. putida, P. fluorescens ACB and Sphingobium sp. strain SYK-6, hydroquinone is converted through extradiol cleavage to 4-hydroxymuconic semialdehyde and is catalyzed by the chlorohydroquinone 1,2-dioxygenase (LinE or HapCD) (Darby et al., 1987; Endo et al., 2005; Miyauchi et al., 1999; Moonen et al., 2008a, 2008b). In P. fluorescens ACB, hydroquinone is converted by hydroquinone dioxygenase (HapCD) to 4-hydroxymuconic semialdehyde and further degraded through maleylacetate to 3-oxoadipate (Moonen et al., 2008a, 2008b). The conversion of 4hydroxymuconic semialdehyde to maleyacetate was suggested to be catalyzed by 4-hydroxymuconic semialdehyde dehydrogenase (HapE). The reduction of maleylacetate to 3-oxoadipate was suggested to be catalyzed by maleylacetate reductase (HapF). In filamentous fungi and yeast, no ring cleavage of hydroquinone was observed instead it is hydroxylated to hydroxyquinol (Jones et al., 1994; Holesova et al., 2011). In the yeast C. parapsilosis, this conversion is catalyzed by Mnx3 (Eppink et al., 2000).

\subsubsection{Gentisic acid ring cleavage}

Gentisic acid is a conversion product of 3-hydroxybenzoic acid, $p$-hydroxybenzoic acid and salicylic acid (Fig. 6, 7, 9). In the bacteria B. laterosporus, Bacillus spp., Peanibacillus sp. and Stryptomyces spp., gentisic acid is converted through extradiol ring cleavage to maleylpyruvate catalyzed by the gentisate 1,2-dioxygenase (SdgD or Bagl) (Fig. 11) (Clark and Buswell, 1979; Ishiyama et al., 2004; Liu and Zhou et al., 2012; Sutherland et al., 1981; Zhao et al., 2018). Maleylpyruvate is then further converted to fumarylpyruvate by L-cysteine-dependent maleylpyruvate isomerase (BagL) that is further hydrolyzed by fumarylpyruvate hydrolase (BagK) into fumarate and pyruvate that enter the TCA cycle (Evans, 1963; Liu and Zhou et al., 2012). Another pathway was observed in which maleylpyruvate was hydrolyzed by a GSH-independent maleylpyruvate hydrolase to maleic acid and pyruvate (Hopper and Chapman, 1971).

In the yeast $C$. parapsilosis, gentisate dioxygenase ( $\mathrm{Gdx} 1)$ catalyzes the cleavage of the aromatic ring of gentisic acid to maleylpyruvate (Holesova et al., 2011). Maleylpyruvate is converted to fumarylpyruvate that is split into fumarate and pyruvate by fumarylpyruvate dioxygenase 1 (Fph1). Interestingly, in the yeast Trichosporon cutaneum, gentisic acid is converted to hydroxyquinol (Anderson and Dagley, 1980). Trace amounts of catechol were detected when S. sclerotiorum was grown in glucose supplemented with gentisic acid indicating that gentisic acid is converted to catechol (Penn and Daniel, 2013).

\subsubsection{Gallic acid and pyrogallol ring cleavage}

Gallic acid and pyrogallol are the central intermediates of the sinapic acid and syringic acid metabolic pathways (Fig. 10, 11). In the bacteria Sphingobium sp. strain SYK-6, P. testosteroni and P. putida, gallic acid is converted through intradiol ring cleavage to 4-oxalomesaconate (keto form) catalyzed by the gallate dioxygenase DesB or GalA (Dennis et al., 1973; Kasai et al., 2005; Nogales et al., 2005; Tack et al., 1972). This pathway has also been suggested for the fungi $A$. oryzea, A. flavus and A. japonicus (Guo et al., 2014; Gurujeyalakshmi and Mahadevan, 1987; Milstein et al., 1983). From 4oxalomesaconate the pathway continues as described for the protocatechuic acid 4,5-cleavage pathway.

In the yeast $A$. adeninivorans, pyrogallol is converted to 2-hydroxymuconic acid (Meier et al., 2017) and the pathway continues as described in the catechol extradiol ring cleavage pathway (Fig. 11). This pathway has also been suggested for the fungus $A$. oryzea (Guo et al., 2014).

\subsection{Discussion}

All aromatic metabolic pathways described in this review are summarized in Table S3. Various aromatic metabolic pathways have been described for different species. The reason why so many different aromatic metabolic strategies are observed in nature is currently unknown. However, one 
can speculate that the natural habitat of a microorganism has a major influence on which metabolic pathways are present or activated. Many factors can influence which pathway is present, such as substrate availability, anaerobic or aerobic conditions, and co-factor availability. This will result in selection of the most beneficial pathway for that habitat. In addition, many species have two or more metabolic pathways to convert one single aromatic compound, which indicates that these pathways can have different activators. Most aromatic metabolic pathways have been observed in bacteria, fungi and yeasts (Table S3) however, several pathways were only observed in either bacteria, fungi or yeasts. It appears that most of the unique pathways were observed in bacteria, but this is likely due to the larger amount of research that is performed on these microorganisms. There are also many shared metabolic pathways, such as those presented in the ferulic acid and vanillin pathways (sections 2.2 and 2.3) in which most pathways are observed in both bacteria and fungi. The ferulic acid metabolic pathway is important for many microorganisms due to the interaction of ferulic acid with polysaccharides such as xylan and pectin (Mäkelä et al., 2015), which could explain the overlap between ferulic acid metabolic pathways of bacteria and fungi. However, several pathways also appear to be unique for fungi and yeasts. The decarboxylation of cinnamic acid to styrene (Fig. 5) and the para-hydroxylation of benzoic acid to $p$-hydroxybenzoic acid $(\mathrm{Fig} .6,7)$ have not been observed in bacteria (Table S3). Also between ascomycete and basidiomycete fungi differences were observed. For example, pathways 3 and 4 (section 2.6) in which $p$-coumaric acid is converted to $p$ hydroxybenzoic acid through $\beta$-hydroxy-( $p$-hydroxyphenyl)-propionic acid and 3-( $p$-hydroxyphenyl)propionic acid, and the ferulic acid hydroxylation converting it to 2-hydroxyferulic acid or 5hydroxyferulic acid were only observed in basidiomycetes. This indicates that many different metabolic strategies exist to convert aromatic compounds, which could be a reason for the efficient lignin degradation of basidiomycetes.

Due to the lack of data in fungi, it is not feasible to suggest the main aromatic metabolic pathways for all the mentioned aromatic metabolic pathways. However, several similar strategies were observed for different aromatic compounds. For example, non-oxidative decarboxylation has been observed for ferulic acid, $p$-coumaric acid and sinapic acid and so it is possible to be the main pathway for ferulic acid and $p$-coumaric acid in microorganisms. In most aromatic pathways, the aliphatic chain is first modified from the alcohol towards the aldehyde form, after which they are converted to their acidic form. This was observed for many aromatic alcohols such as coniferyl alcohol, $p$-coumaryl alcohol, benzyl alcohol and vanillyl alcohol (Fig. 2, 3, 6, 8). Thereafter, the compounds are modified through decarboxylation forming $p$-hydroxybenzoic acid, vanillic acid and syringic acid, which are the key compounds of the aromatic metabolic pathways (Fig. 3, 7, 6, 10). All major pathways are funnelled to seven central ring-fission intermediates (Fig. 1, 11). Aromatic compounds derived from the $\mathrm{G}$ and $\mathrm{H}$ subunits of lignin are converted to protocatechuic acid, catechol, hydroxyquinol or gentisic acid, while aromatic compounds derived from the S subunit are converted to gallic acid and pyrogallol. Two catechol ring cleaving pathways have been described. The intradiol cleavage pathway has been well studied in bacteria, while in fungi the enzymes are identified but need to be further characterized. Currently, much research is focused on the production of cis,cis-muconic acid, the cleavage product of catechol, which can be used as precursor for the production of bioplastics such as nylon and polyethylene terephthalate (Becker et al., 2018; Brückner et al., 2018; Curran et al., 2013; Sun et al., 2013; Xie et al., 2014). The increased focus makes it of great interest to study these pathways further in filamentous fungi. The extradiol cleavage pathway of catechol has not been reported for fungi or yeast. Three protocatechuic acid ring cleavage pathways have been described. The intradiol ring cleavage pathway was observed in bacteria and filamentous fungi, which one major difference was observed. Bacteria convert 3-carboxy-cis,cis-muconic acid to $\gamma$-carboxymuconolactone and further to 3-oxoadipate enol-lactone and 3-oxoadipate while filamentous fungi convert 3-carboxy-cis,cismuconic acid to $\beta$-carboxymuconolactone and further to 3-oxoadipate. In yeasts, the ring cleavage has so far been observed for catechol and hydroxyquinol, but not for protocatechuic acid, which instead may be decarboxylated or hydroxylated to form catechol or hydroxyquinol, respectively, prior 
the cleavage (Anderson and Dagley, 1980; Holesova et al., 2011; Meier et al., 2017). The decarboxylation of protocatechuic acid to catechol was also observed in bacteria (Sonoki et al., 2014). Two hydroxyquinol ring cleavage pathways have been described. In the intradiol ring cleavage pathway, bacteria and fungi seem to share similar mechanism. An extradiol ring cleavage of hydroxyquinol has not been observed for fungi. Currently, only one gentisic acid ring cleavage pathway has been described for bacteria and yeasts, whereas no pathway has been observed in filamentous fungi. The cleavage of pyrogallol and gallic acid result in an overlap between the extradiol cleavage of catechol and the 2,3 extradiol cleavage of protocatechuic acid revealing that parts of these pathways are present in fungi. Alternative ring cleavage pathways have been observed on several aromatic compounds such as 2,3-dihydroxybenzoic acid, 2,3,4-trihydroxycinnamic acid and 3,4,5trihydroxycinnamic acid cleavage pathway however these are observed sporadically (Crestini and Sermanni, 1994; Marín et al., 2012). It was suggested that intradiol ring cleavage pathways are the main mechanism found in bacteria (Bugg et al., 2011b). This is presumably the same in filamentous fungi as no extradiol ring cleaving pathway has been reported for these seven central ring-fission intermediates thus far. The cleavage of pyrogallol and gallic acid result in an overlap between the extradiol cleavage of catechol and the 2,3 extradiol cleavage of protocatechuic acid indicating that parts of these pathways are present in fungi.

Most bacterial aromatic metabolic enzymes have been characterized, while only a few of these enzymes are characterized in fungi and yeasts (Tables S1 and S2). Most bacterial genes encoding a set of related enzymes, such as cat, $d m p$, gal, pca, etc. (Tables S1, S2), are clustered on the genome. While currently only a few enzymes are characterized in fungi and yeasts, it appears that these are scattered over the genome. Several BLAST searches using amino acid sequences of bacterial enzymes to find potential homologs in fungi and yeast were performed. These have not been shown in the review since they resulted in no suitable ( $<25 \%$ identity) homologs making them unlikely to be related to the catalytic function. Homology between bacterial and fungal enzymes is low, making it difficult to identify these enzymes in fungi. However, the increasing number of fungal genomes, transcriptomes and proteomes will aid in the identification and characterization of fungal aromatic metabolic enzymes.

\section{Conclusions}

This review compares the similarities and differences in aromatic metabolic pathways, as well as unique aromatic metabolic pathways in bacteria, filamentous fungi and yeasts. In addition, it sheds light on the missing puzzles in particular for the fungal pathways. Understanding the aromatic metabolic pathways can reveal for example, how pathogens evade or suppress the plant defense system and cause diseases. More importantly, discovery of novel aromatic modifying enzymes is of great interest for the valorization of lignin and compounds derived from it. This will offer great opportunities for innovations to produce valuable compounds for many industries, e.g. food, plastics, cosmetics and pharmaceutical industries.

Funding: This project was supported by the European Union's Horizon 2020 research and innovation programme under grant argreement No 720918

\section{References}

Abe, T., Masai, E., Miyauchi, K., Katayama, Y., \& Fukuda, M. (2005). A tetrahydrofolate-dependent Odemethylase, LigM, is crucial for catabolism of vanillate and syringate in Sphingomonas paucimobilis SYK-6. Journal of Bacteriology, 187(6), 2030-2037.

Achterholt, S., Priefert, H., \& Steinbüchel, A. (2000). Identification of Amycolatopsis sp. strain HR167 genes, involved in the bioconversion of ferulic acid to vanillin. Applied Microbiology and Biotechnology, 54(6), 799-807. 
Adeboye, P. T., Bettiga, M., \& Olsson, L. (2014). The chemical nature of phenolic compounds determines their toxicity and induces distinct physiological responses in Saccharomyces cerevisiae in lignocellulose hydrolysates. AMB Express, 4(1), 46.

Adeboye, P. T., Bettiga, M., Aldaeus, F., Larsson, P. T., \& Olsson, L. (2015). Catabolism of coniferyl aldehyde, ferulic acid and $p$-coumaric acid by Saccharomyces cerevisiae yields less toxic products. Microbial Cell Factories, 14(1), 149.

Adeboye, P. T., Bettiga, M., \& Olsson, L. (2017). ALD5, PAD1, ATF1 and ATF2 facilitate the catabolism of coniferyl aldehyde, ferulic acid and p-coumaric acid in Saccharomyces cerevisiae. Scientific Reports, 7, 42635.

Alvarado, I. E., Lomascolo, A., Navarro, D., Delattre, M., Asther, M., \& Lesage-Meessen, L. (2001). Evidence of a new biotransformation pathway of $p$-coumaric acid into $p$-hydroxybenzaldehyde in Pycnoporus cinnabarinus. Applied Microbiology and Biotechnology, 57(5-6), 725-730.

Alvarado, I. E., Navarro, D., Record, E., Asther, M., Asther, M., \& Lesage-Meessen, L. (2003). Fungal biotransformation of $p$-coumaric acid into caffeic acid by Pycnoporus cinnabarinus: an alternative for producing a strong natural antioxidant. World Journal of Microbiology and Biotechnology, 19(2), 157-160.

Álvarez-Rodríguez, M. L., Belloch, C., Villa, M., Uruburu, F., Larriba, G., \& Coque, J. J. R. (2003). Degradation of vanillic acid and production of guaiacol by microorganisms isolated from cork samples. FEMS Microbiology Letters, 220(1), 49-55.

Ander, P., Hatakka, A., \& Eriksson, K. E. (1980). Vanillic acid metabolism by the white-rot fungus Sporotrichum pulverulentum. Archives of Microbiology, 125(3), 189-202.

Anderson, J. J., \& Dagley, S. (1980). Catabolism of aromatic acids in Trichosporon cutaneum. Journal of Bacteriology, 141(2), 534-543.

Arif, T. (2015). Salicylic acid as a peeling agent: a comprehensive review. Clinical, Cosmetic and Investigational Dermatology, 8, 455.

Austin, S., Kontur, W. S., Ulbrich, A., Oshlag, Z., Zhang, W., Higbee, A., Zhang, Y., Coon, J. J., Hodge, D. B., Donahue, T. J. \& Noguera, D. R. (2015). Metabolism of multiple aromatic compounds in corn stover hydrolysate by Rhodopseudomonas palustris. Environmental Science \& Technology, 49(14), 8914.

Bachman, D. M., Dragoon, B., \& John, S. (1960). Reduction of salicylate to saligenin by Neurospora. Archives of Biochemistry and Biophysics, 91, 326-326.

Barton, N., Horbal, L., Starck, S., Kohlstedt, M., Luzhetskyy, A., \& Wittmann, C. (2018). Enabling the valorization of guaiacol-based lignin: Integrated chemical and biochemical production of cis,cis-muconic acid using metabolically engineered Amycolatopsis sp. ATCC 39116. Metabolic Engineering, 45, 200-210.

Baqueiro-Peña, I., Rodríguez-Serrano, G., González-Zamora, E., Augur, C., Loera, O., \& Saucedo-Castañeda, G. (2010). Biotransformation of ferulic acid to 4-vinylguaiacol by a wild and a diploid strain of Aspergillus niger. Bioresource Technology, 101(12), 4721-4724.

Becker, J., Kuhl, M., Kohlstedt, M., Starck, S., \& Wittmann, C. (2018). Metabolic engineering of Corynebacterium glutamicum for the production of cis, cis-muconic acid from lignin. Microbial Cell Factories, 17(1), 115.

Beltrametti, F., Marconi, A. M., Bestetti, G., Colombo, C., Galli, E., Ruzzi, M., \& Zennaro, E. (1997). Sequencing and functional analysis of styrene catabolism genes from Pseudomonas fluorescens ST. Applied and Environmental Microbiology, 63(6), 2232-2239.

Brandt, K., Thewes, S., Overhage, J., Priefert, H., \& Steinbüchel, A. (2001). Characterization of the eugenol hydroxylase genes (ehyA/ehyB) from the new eugenol-degrading Pseudomonas sp. strain OPS1. Applied Microbiology and Biotechnology, 56(5), 724-730. 
Braun-Lüllemann, A., Majcherczyk, A., \& Hüttermann, A. (1997). Degradation of styrene by white-rot fungi. Applied Microbiology and Biotechnology, 47(2), 150-155.

Breese, K., \& Fuchs, G. (1998). 4-Hydroxybenzoyl-CoA reductase (dehydroxylating) from the denitrifying bacterium Thauera aromatica: Prosthetic groups, electron donor, and genes of a member of the molybdenumflavin-iron-sulfur proteins. European Journal of Biochemistry, 251(3), 916-923.

Brown, M. E., \& Chang, M. C. (2014). Exploring bacterial lignin degradation. Current Opinion in Chemical Biology, 19, 1-7.

Brune, A., \& Schink, B. (1992). Phloroglucinol pathway in the strictly anaerobic Pelobacter acidigallici: fermentation of trihydroxybenzenes to acetate via triacetic acid. Archives of Microbiology, 157(5), 417-424.

Brückner, C., Oreb, M., Kunze, G., Boles, E., \& Tripp, J. (2018). An expanded enzyme toolbox for production of cis, cis-muconic acid and other shikimate pathway derivatives in Saccharomyces cerevisiae. FEMS Yeast Research, 18(2), foy017.

Buchan, A., Collier, L. S., Neidle, E. L., \& Moran, M. A. (2000). Key aromatic-ring-cleaving enzyme, protocatechuate 3,4-dioxygenase, in the ecologically important marine Roseobacter lineage. Applied and Environmental Microbiology, 66(11), 4662-4672.

Bugg, T. D. (1993). Overproduction, purification and properties of 2,3-dihydroxyphenylpropionate 1,2dioxygenase from Escherichia coli. Biochimica et Biophysica Acta (BBA)-Protein Structure and Molecular Enzymology, 1202(2), 258-264.

Bugg, T. D., Ahmad, M., Hardiman, E. M., \& Singh, R. (2011a). The emerging role for bacteria in lignin degradation and bio-product formation. Current Opinion in Biotechnology, 22(3), 394-400.

Bugg, T. D., Ahmad, M., Hardiman, E. M., \& Rahmanpour, R. (2011b). Pathways for degradation of lignin in bacteria and fungi. Natural Product Reports, 28(12), 1883-1896.

Bunzel, M., Ralph, J., Kim, H., Lu, F., Ralph, S. A., Marita, J. M., Hatefield, R. D. \& Steinhart, H. (2003). Sinapate dehydrodimers and sinapate-ferulate heterodimers in cereal dietary fiber. Journal of Agricultural and Food Chemistry, 51(5), 1427-1434.

Buraimoh, O. M., Ilori, M. O., Amund, O. O., Isanbor, C., \& Michel, F. C. (2017). The degradation of coniferyl alcohol and the complementary production of chlorogenic acids in the growth culture of Streptomyces albogriseolus KF977548 isolated from decaying wood residues. Process Biochemistry, 52, 22-29.

Buswell, J. A., \& Eriksson, K. E. (1979). Aromatic ring cleavage by the white-rot fungus Sporotrichum pulverulentum. FEBS Letters, 104(2), 258-260.

Cai, R., Yuan, Y., Wang, Z., Guo, C., Liu, B., Liu, L., Wang, Y., \& Yue, T. (2015). Precursors and metabolic pathway for guaiacol production by Alicyclobacillus acidoterrestris. International Journal of Food Microbiology, 214, 4853.

Cao, B., Geng, A., \& Loh, K. C. (2008). Induction of ortho-and meta-cleavage pathways in Pseudomonas in biodegradation of high benzoate concentration: MS identification of catabolic enzymes. Applied Microbiology and Biotechnology, 81(1), 99.

Campillo, T., Renoud, S., Kerzaon, I., Vial, L., Baude, J., Gaillard, V., Bellvert, F., Chamignon, C., Comte, G., Nesme, X., Lavire, C \& Hommais, F. (2014). Analysis of hydroxycinnamic acid degradation in Agrobacterium fabrum reveals a coenzyme A-dependent, beta-oxidative deacetylation pathway. Applied and Environmental Microbiology, 80(11), 3341-3349. 
Cavin, J. F., Barthelmebs, L., Guzzo, J., Van Beeumen, J., Samyn, B., Travers, J. F., \& Diviès, C. (1997a). Purification and characterization of an inducible $p$-coumaric acid decarboxylase from Lactobacillus plantarum. FEMS Microbiology Letters, 147(2), 291-295.

Cavin, J. F., Barthelmebs, L., \& Divies, C. (1997b). Molecular characterization of an inducible p-coumaric acid decarboxylase from Lactobacillus plantarum: gene cloning, transcriptional analysis, overexpression in Escherichia coli, purification, and characterization. Applied and Environmental Microbiology, 63(5), 1939-1944.

Cavin, J. F., Dartois, V., \& Diviès, C. (1998). Gene cloning, transcriptional analysis, purification, and characterization of phenolic acid decarboxylase from Bacillus subtilis. Applied and Environmental Microbiology, 64(4), 1466-1471.

Chakraborty, S., Ortiz-Maldonado, M., Entsch, B., \& Ballou, D. P. (2009). Studies on the mechanism of $p$ hydroxyphenylacetate 3-hydroxylase from Pseudomonas aeruginosa: a system composed of a small flavin reductase and a large flavin-dependent oxygenase. Biochemistry, 49(2), 372-385.

Chang, H. K., \& Zylstra, G. J. (2008). Examination and expansion of the substrate range of $m$-hydroxybenzoate hydroxylase. Biochemical and Biophysical Research Communications, 371(1), 149-153.

Chapman, P. J., \& Ribbons, D. W. (1976). Metabolism of resorcinylic compounds by bacteria: alternative pathways for resorcinol catabolism in Pseudomonas putida. Journal of Bacteriology, 125(3), 985-998.

Chen, C. L., Chang, H. M., \& Kirk, T. K. (1982). Aromatic acids produced during degradation of lignin in spruce wood by Phanerochaete chrysosporium. Holzforschung-International Journal of the Biology, Chemistry, Physics and Technology of Wood, 36(1), 3-9.

Chen, H. P., Chow, M., Liu, C. C., Lau, A., Liu, J., \& Eltis, L. D. (2012). Vanillin catabolism in Rhodococcus jostii RHA1. Applied and Environmental Microbiology, 78(2), 586-588.

Chow, K. T., Pope, M. K., \& Davies, J. (1999). Characterization of a vanillic acid non-oxidative decarboxylation gene cluster from Streptomyces sp. D7. Microbiology, 145(9), 2393-2403.

Clausen, M., Lamb, C. J., Megnet, R., \& Doerner, P. W. (1994). PAD1 encodes phenylacrylic acid decarboxylase which confers resistance to cinnamic acid in Saccharomyces cerevisiae. Gene, 142(1), 107-112.

Clark, J. S., \& Buswell, J. A. (1979). Catabolism of gentisic acid by two strains of Bacillus stearothermophilus. Microbiology, 112(1), 191-195.

Cocaign, M., Wilberg, E., \& Lindley, N. D. (1991). Sequential demethoxylation reactions during methylotrophic growth of methoxylated aromatic substrates with Eubacterium limosum. Archives of Microbiology, 155(5), 496499.

Cox, H. H. J., Houtman, J. H. M., Doddema, H. J., \& Harder, W. (1993). Growth of the black yeast Exophiala jeanselmei on styrene and styrene-related compounds. Applied Microbiology and Biotechnology, 39(3), 372-376.

Crabo, A. G., Singh, B., Nguyen, T., Emami, S., Gassner, G. T., \& Sazinsky, M. H. (2017). Structure and biochemistry of phenylacetaldehyde dehydrogenase from the Pseudomonas putida S12 styrene catabolic pathway. Archives of Biochemistry and Biophysics, 616, 47-58.

Crawford, R. L. (1975). Degradation of 3-hydroxybenzoate by bacteria of the genus Bacillus. Applied Microbiology, 30(3), 439-444.

Crawford, R. L., \& Olson, P. P. (1978). Microbial catabolism of vanillate: decarboxylation to guaiacol. Applied and Environmental Microbiology, 36(4), 539-543.

Crawford, R. L., Bromley, J. W., \& Olson, P. E. (1979). Catabolism of protocatechuate by Bacillus macerans. Applied and Environmental Microbiology, 37(3), 614-618. 
Crestini, C., \& Sermanni, G. G. (1994). Oxidation and aromatic ring cleavage of 4-methoxy and 3,4dimethoxycennamic acid by Lentinus edodes. Biotechnology Letters, 16(9), 995-1000.

Curran, K. A., Leavitt, J. M., Karim, A. S., \& Alper, H. S. (2013). Metabolic engineering of muconic acid production in Saccharomyces cerevisiae. Metabolic Engineering, 15, 55-66.

Darby, J. M., Taylor, D. G., \& Hopper, D. J. (1987). Hydroquinone as the ring-fission substrate in the catabolism of 4-ethylphenol and 4-hydroxyacetophenone by Pseudomonas putida JD1. Microbiology, 133(8), 2137-2146.

Daubaras, D. L., Saido, K., \& Chakrabarty, A. M. (1996). Purification of hydroxyquinol 1,2-dioxygenase and maleylacetate reductase: the lower pathway of 2,4,5-trichlorophenoxyacetic acid metabolism by Burkholderia cepacia AC1100. Applied and Environmental Microbiology, 62(11), 4276-4279.

de Jong, E., Beuling, E. E., van der Zwan, R. P., \& de Bont, J. A. (1990). Degradation of veratryl alcohol by Penicillium simplicissimum. Applied Microbiology and Biotechnology, 34(3), 420-425.

de Jong, E., Van Berkel, W. J., Van Der Zwan, R. P., \& De Bont, J. A. (1992). Purification and characterization of vanillyl-alcohol oxidase from Penicillium simplicissimum. A novel aromatic alcohol oxidase containing covalently bound FAD. European Journal of Biochemistry, 208(3), 651-657.

Defnoun, S., Labat, M., Ambrosio, M., Garcia, J. L., \& Patel, B. K. (2000). Papillibacter cinnamivorans gen. nov., sp. nov., a cinnamate-transforming bacterium from a shea cake digester. International Journal of Systematic and Evolutionary Microbiology, 50(3), 1221-1228.

Dennis, D. A., Chapman, P. J., \& Dagley, S. (1973). Degradation of protocatechuate in Pseudomonas testosteroni by a pathway involving oxidation of the product of meta-fission. Journal of Bacteriology, 113(1), 521-523.

Di Gioia, D., Luziatelli, F., Negroni, A., Ficca, A. G., Fava, F., \& Ruzzi, M. (2011). Metabolic engineering of Pseudomonas fluorescens for the production of vanillin from ferulic acid. Journal of Biotechnology, 156(4), 309316.

Díaz, E., Ferrández, A., \& García, J. L. (1998). Characterization of the hca cluster encoding the dioxygenolytic pathway for initial catabolism of 3-phenylpropionic acid in Escherichia coli K-12. Journal of Bacteriology, 180(11), 2915-2923.

Dilokpimol, A., Mäkelä, M. R., Aguilar-Pontes, M. V., Benoit-Gelber, I., Hildén, K. S., \& Vries, R. P. (2016). Diversity of fungal feruloyl esterases: updated phylogenetic classification, properties, and industrial applications. Biotechnology for Biofuels, 9(1), 231.

Ding, W., Si, M., Zhang, W., Zhang, Y., Chen, C., Zhang, L., Lu, Z., Chen, S., \& Shen, X. (2015). Functional characterization of a vanillin dehydrogenase in Corynebacterium glutamicum. Scientific Reports, 5, 8044.

Donnelly, M. I., \& Dagley, S. (1980). Production of methanol from aromatic acids by Pseudomonas putida. Journal of Bacteriology, 142(3), 916-924.

Drijfhout, F. P., Fraaije, M. W., Jongejan, H., van Berkel, W. J., \& Franssen, M. C. (1998). Enantioselective hydroxylation of 4-alkylphenols by vanillyl alcohol oxidase. Biotechnology and Bioengineering, 59(2), 171-177.

Duggleby, C. J., \& Williams, P. A. (1986). Purification and some properties of the 2-hydroxy-6-oxohepta-2,4dienoate hydrolase (2-hydroxymuconic semialdehyde hydrolase) encoded by the TOL plasmid pWWO from Pseudomonas putida mt-2. Microbiology, 132(3), 717-726.

Dutta, T. K., \& Harayama, S. (2001). Biodegradation of $n$-alkylcycloalkanes and $n$-alkylbenzenes via new pathways in Alcanivorax sp. strain MBIC 4326. Applied and Environmental Microbiology, 67(4), 1970-1974. 
Edlin, D. A., Narbad, A., Dickinson, J. R., \& Lloyd, D. (1995). The biotransformation of simple phenolic compounds by Brettanomyces anomalus. FEMS Microbiology Letters, 125(2-3), 311-315.

Endo, R., Kamakura, M., Miyauchi, K., Fukuda, M., Ohtsubo, Y., Tsuda, M., \& Nagata, Y. (2005). Identification and characterization of genes involved in the downstream degradation pathway of $\mathcal{Y}$-hexachlorocyclohexane in Sphingomonas paucimobilis UT26. Journal of Bacteriology, 187(3), 847-853.

El-Mansi, E. M. T., \& Anderson, S. C. K. (2004). The hydroxylation of vanillate and its conversion to methoxyhydroquinone by a strain of Pseudomonas fluorescens devoid of demethylase and methylhydroxylase activities. World Journal of Microbiology and Biotechnology, 20(8), 827-832.

Entsch, B., Nan, Y., Weaich, K., \& Scott, K. F. (1988). Sequence and organization of pobA, the gene coding for $p$ hydroxybenzoate hydroxylase, an inducible enzyme from Pseudomonas aeruginosa. Gene, 71(2), $279-291$.

Eppink, M. H., Boeren, S. A., Vervoort, J., \& van Berkel, W. J. (1997). Purification and properties of 4hydroxybenzoate 1-hydroxylase (decarboxylating), a novel flavin adenine dinucleotide-dependent monooxygenase from Candida parapsilosis CBS604. Journal of Bacteriology, 179(21), 6680-6687.

Eppink, M. H., Cammaart, E., van Wassenaar, D., Middelhoven, W. J., \& van Berkel, W. J. (2000). Purification and properties of hydroquinone hydroxylase, a FAD-dependent monooxygenase involved in the catabolism of 4hydroxybenzoate in Candida parapsilosis CBS604. The FEBS Journal, 267(23), 6832-6840.

Eriksson, K. E., Gupta, J. K., Nishida, A., \& Rao, M. (1984). Syringic acid metabolism by some white-rot, soft-rot and brown-rot fungi. Microbiology, 130(10), 2457-2464.

Evans, W. C. (1963). The microbiological degradation of aromatic compounds. Microbiology, 32(2), 177-184.

Ewing, T., Van Noord, A., Paul, C., \& van Berkel, W. (2018). A xylenol orange-based screening assay for the substrate specificity of flavin-dependent para-phenol oxidases. Molecules, 23(1), 164.

Falconnier, B., Lapierre, C., Lesage-Meessen, L., Yonnet, G., Brunerie, P., Colonna-Ceccaldi, B., Corrieu, G., \& Asther, M. (1994). Vanillin as a product of ferulic acid biotransformation by the white-rot fungus Pycnoporus cinnabarinus I-937: identification of metabolic pathways. Journal of Biotechnology, 37(2), 123-132.

Fitzgerald, D. J., Stratford, M., \& Narbad, A. (2003). Analysis of the inhibition of food spoilage yeasts by vanillin. International Journal of Food Microbiology, 86(1), 113-122.

Fleige, C., Hansen, G., Kroll, J., \& Steinbüchel, A. (2013). Investigation of the Amycolatopsis sp. strain ATCC 39116 vanillin dehydrogenase and its impact on the biotechnical production of vanillin. Applied and Environmental Microbiology, 79(1), 81-90.

Fleige, C., \& Steinbüchel, A. (2014). Construction of expression vectors for metabolic engineering of the vanillinproducing actinomycete Amycolatopsis sp. ATCC 39116. Applied Microbiology and Biotechnology, 98(14), 63876395.

Fleige, C., Meyer, F., \& Steinbüchel, A. (2016). Metabolic engineering of the actinomycete Amycolatopsis sp. strain ATCC 39116 towards enhanced production of natural vanillin. Applied and Environmental Microbiology, 82(11), 3410-3419.

Fraaije, M. W., Pikkemaat, M., \& Van Berkel, W. (1997). Enigmatic Gratuitous Induction of the Covalent Flavoprotein Vanillyl-Alcohol Oxidase in Penicillium simplicissimum. Applied and Environmental Microbiology, 63(2), 435-439.

Fraser, J. A., Davis, M. A., \& Hynes, M. J. (2002). The genes gmdA, encoding an amidase, and bzuA, encoding a cytochrome P450, are required for benzamide utilization in Aspergillus nidulans. Fungal Genetics and Biology, $35(2), 135-146$. 
Freudenberg, K. (1965). Lignin: its constitution and formation from p-hydroxycinnamyl alcohols. Science, 148(3670), 595-600.

Friedman, M., Henika, P. R., \& Mandrell, R. E. (2003). Antibacterial activities of phenolic benzaldehydes and benzoic acids against Campylobacter jejuni, Escherichia coli, Listeria monocytogenes, and Salmonella enterica. Journal of Food Protection, 66(10), 1811-1821.

Fuenmayor, S. L., Wild, M., Boyes, A. L., \& Williams, P. A. (1998). A gene cluster encoding steps in conversion of naphthalene to gentisate in Pseudomonas sp. strain U2. Journal of Bacteriology, 180(9), 2522-2530.

Fukuda, H., Nakamura, K., Sukita, E., Ogawa, T., \& Fujii, T. (1996). Cytochrome P450rm from Rhodotorula minuta catalyzes 4-hydroxylation of benzoate. The Journal of Biochemistry, 119(2), 314-318.

Furuya, T., \& Kino, K. (2014). Catalytic activity of the two-component flavin-dependent monooxygenase from Pseudomonas aeruginosa toward cinnamic acid derivatives. Applied Microbiology and Biotechnology, 98(3), 1145-1154.

Furuya, T., Miura, M., \& Kino, K. (2014). A coenzyme-Independent decarboxylase/oxygenase cascade for the efficient synthesis of vanillin. ChemBioChem, 15(15), 2248-2254.

Gallage, N. J., Hansen, E. H., Kannangara, R., Olsen, C. E., Motawia, M. S., Jørgensen, K., Holme, I., Hebelstrup, K., Grisoni, M., \& Møller, B. L. (2014). Vanillin formation from ferulic acid in Vanilla planifolia is catalysed by a single enzyme. Nature Communications, 5, 4037.

Gallage, N. J., \& Møller, B. L. (2015). Vanillin-bioconversion and bioengineering of the most popular plant flavor and its de novo biosynthesis in the vanilla orchid. Molecular Plant, 8(1), 40-57.

Gallage, N. J., \& Møller, B. L. (2018). Vanilla: The Most Popular Flavour. In Biotechnology of Natural Products (pp. 3-24). Springer, Cham.

Gasson, M. J., Kitamura, Y., McLauchlan, W. R., Narbad, A., Parr, A. J., Parsons, E. L. H., Rhodes, M. J. C. \& Walton, N. J. (1998). Metabolism of ferulic acid to vanillin. A bacterial gene of the enoyl-SCoA hydratase/isomerase superfamily encodes an enzyme for the hydration and cleavage of a hydroxycinnamic acid SCoA thioester. Journal of Biological Chemistry, 273(7), 4163-4170.

Gao, X., Tan, C. L., Yeo, C. C., \& Poh, C. L. (2005). Molecular and biochemical characterization of the $x \ln D$-encoded 3-hydroxybenzoate 6-hydroxylase involved in the degradation of 2,5-xylenol via the gentisate pathway in Pseudomonas alcaligenes NCIMB 9867. Journal of Bacteriology, 187(22), 7696-7702.

Gérecová, G., Neboháčová, M., Zeman, I., Pryszcz, L. P., Tomáška, L'., Gabaldón, T., \& Nosek, J. (2015). Metabolic gene clusters encoding the enzymes of two branches of the 3-oxoadipate pathway in the pathogenic yeast Candida albicans. FEMS Yeast Research, 15(3), fov006.

Ghosh, R., Nadiminty, N., Fitzpatrick, J. E., Alworth, W. L., Slaga, T. J., \& Kumar, A. P. (2005). Eugenol causes melanoma growth suppression through inhibition of E2F1 transcriptional activity. Journal of Biological Chemistry, 280(7), 5812-5819.

Gibson, J., Dispensa, M., Fogg, G. C., Evans, D. T., \& Harwood, C. S. (1994). 4-Hydroxybenzoate-coenzyme a ligase from Rhodopseudomonas palustris: purification, gene sequence, and role in anaerobic degradation. Journal of Bacteriology, 176(3), 634-641.

Gottardi, M., Knudsen, J. D., Prado, L., Oreb, M., Branduardi, P., \& Boles, E. (2017). De novo biosynthesis of transcinnamic acid derivatives in Saccharomyces cerevisiae. Applied Microbiology and Biotechnology, 101(12), 48834893.

Graf, N., Wenzel, M., \& Altenbuchner, J. (2016). Identification and characterization of the vanillin dehydrogenase YfmT in Bacillus subtilis 3NA. Applied Microbiology and Biotechnology, 100(8), 3511-3521. 
Grant, D. J. W., \& Patel, J. C. (1969). The non-oxidative decarboxylation of $p$-hydroxybenzoic acid, gentisic acid, protocatechuic acid and gallic acid by Klebsiella aerogenes (Aerobacter aerogenes). Antonie van Leeuwenhoek, 35(1), 325-343.

Grbić-Galić, D., \& La Pat-Polasko, L. (1985). Enterobacter cloacae DG-6: a strain that transforms methoxylated aromatics under aerobic and anaerobic conditions. Current Microbiology, 12(6), 321-324.

Grund, E., Knorr, C., \& Eichenlaub, R. (1990). Catabolism of benzoate and monohydroxylated benzoates by Amycolatopsis and Streptomyces spp. Applied and Environmental Microbiology, 56(5), 1459-1464.

Guiraud, P., Steiman, R., Seigle-Murandi, F., \& Benoit-Guyod, J. L. (1992). Metabolism of vanillic acid by micromycetes. World Journal of Microbiology and Biotechnology, 8(3), 270-275.

Guiraud, P., Steiman, R., Seiglemurandi, F., \& Benoitguyod, J. L. (1995). Comparison of the toxicity of various lignin-related phenolic compounds toward selected fungi perfecti and fungi imperfecti. Ecotoxicology and Environmental Safety, 32(1), 29-33.

Gupta, J. K., Jebsen, C., \& Kneifel, H. (1986). Sinapic acid degradation by the yeast Rhodotorula glutinis. Microbiology, 132(10), 2793-2799.

Gupta, V. K., Minocha, A. K., \& Jain, N. (2001). Batch and continuous studies on treatment of pulp mill wastewater by Aeromonas formicans. Journal of Chemical Technology \& Biotechnology: International Research in Process, Environmental \& Clean Technology, 76(6), 547-552.

Guo, D., Zhang, Z., Liu, D., Zheng, H., Chen, H., \& Chen, K. (2014). A comparative study on the degradation of gallic acid by Aspergillus oryzae and Phanerochaete chrysosporium. Water Science and Technology, 70(1), 175181.

Gurujeyalakshmi, G., \& Mahadevan, A. (1987). Degradation of gallic acid by Aspergillus flavus. Zentralblatt für Mikrobiologie, 142(2), 187-192.

Gygli, G., de Vries, R. P., \& van Berkel, W. J. (2018). On the origin of vanillyl alcohol oxidases. Fungal Genetics and Biology, 116, 24-32.

Halsall, B. E., Darrah, J. A., \& Cain, R. B. (1969). The regulation of enzymes of aromatic-ring fission in fungi: organisms using both catechol and protocatechuate pathways. Biochemical Journal, 114(4), 75P.

Hamzah, R. Y., \& Al-Baharna, B. S. (1994). Catechol ring-cleavage in Pseudomonas cepacia: the simultaneous induction of ortho and meta pathways. Applied Microbiology and Biotechnology, 41(2), 250-256.

Hansen, E. H., Møller, B. L., Kock, G. R., Bünner, C. M., Kristensen, C., Jensen, O. R., Okkels, F. T., Olsen, C. E., Motawia, M. S. \& Hansen, J. (2009). De novo biosynthesis of vanillin in fission yeast (Schizosaccharomyces pombe) and baker's yeast (Saccharomyces cerevisiae). Applied and Environmental Microbiology, 75(9), 2765-2774.

Hara, H., Masai, E., Katayama, Y., \& Fukuda, M. (2000). The 4-oxalomesaconate hydratase gene, involved in the protocatechuate 4,5-Cleavage Pathway, is essential to vanillate and syringate degradation in Sphingomonas paucimobilis SYK-6. Journal of Bacteriology, 182(24), 6950-6957.

Hara, H., Masai, E., Miyauchi, K., Katayama, Y., \& Fukuda, M. (2003). Characterization of the 4-carboxy-4hydroxy-2-oxoadipate aldolase gene and operon structure of the protocatechuate 4,5-cleavage pathway genes in Sphingomonas paucimobilis SYK-6. Journal of Bacteriology, 185(1), 41-50.

Harada, A., Kamimura, N., Takeuchi, K., Yu, H. Y., Masai, E., \& Senda, T. (2017). The crystal structure of a new Odemethylase from Sphingobium sp. strain SYK-6. The FEBS Journal, 284(12), 1855-1867. 
Harwood, C. S., Nichols, N. N., Kim, M. K., Ditty, J. L., \& Parales, R. E. (1994). Identification of the pcaRKF gene cluster from Pseudomonas putida: involvement in chemotaxis, biodegradation, and transport of 4hydroxybenzoate. Journal of Bacteriology, 176(21), 6479-6488.

Harwood, C. S., \& Parales, R. E. (1996). The $\beta$-ketoadipate pathway and the biology of self-identity. Annual Reviews in Microbiology, 50(1), 553-590.

Hatakka, A. I. (1985). Degradation of veratric acid and other lignin-related aromatic compounds by the whiterot fungus Pycnoporus cinnabarinus. Archives of Microbiology, 141(1), 22-28.

He, A., Li, T., Daniels, L., Fotheringham, I., \& Rosazza, J. P. (2004). Nocardia sp. carboxylic acid reductase: cloning, expression, and characterization of a new aldehyde oxidoreductase family. Applied and Environmental Microbiology, 70(3), 1874-1881.

Heine, T., Zimmerling, J., Ballmann, A., Kleeberg, S. B., Rückert, C., Busche, T., Winkler, A., Kalinowski, J., Poetsch, A., Scholtissek, A., Oelschlägel, M., Schmidt, G., \& Tischler, D. (2018). On the enigma of glutathione-dependent styrene degradation in Gordonia rubripertincta CWB2. Applied and Environmental Microbiology, 84(9), e0015418.

Henderson, M. E., \& Farmer, V. C. (1955). Utilization by soil fungi of $p$-hydroxybenzaldehyde, ferulic acid, syringaldehyde and vanillin. Microbiology, 12(1), 37-46.

Henderson, M. E. (1961). Isolation, identification and growth of some soil hyphomycetes and yeast-like fungi which utilize aromatic compounds related to lignin. Microbiology, 26(1), 149-154.

Heo, K. T., Kang, S. Y., Jang, J. H., \& Hong, Y. S. (2017). Sam5, a coumarate 3-hydroxylase from Saccharothrix espanaensis: new Insight into the piceatannol Production as a resveratrol 3'-hydroxylase. ChemistrySelect, 2(28), 8785-8789.

Heresztyn, T. (1986). Metabolism of volatile phenolic compounds from hydroxycinnamic acids by Brettanomyces yeast. Archives of Microbiology, 146(1), 96-98.

Higuchi, T. (1986). Catabolic pathways and role of ligninases for the degradation of lignin substructure models by white-rot fungi. Wood Research: Bulletin of the Wood Research Institute Kyoto University, 73: 58-81

Hintner, J. P., Lechner, C., Riegert, U., Kuhm, A. E., Storm, T., Reemtsma, T., \& Stolz, A. (2001). Direct ring fission of salicylate by a salicylate 1,2-dioxygenase activity from Pseudaminobacter salicylatoxidans. Journal of Bacteriology, 183(23), 6936-6942.

Hirakawa, H., Schaefer, A. L., Greenberg, E. P., \& Harwood, C. S. (2012). Anaerobic $p$-coumarate degradation by Rhodopseudomonas palustris and identification of CouR, a MarR repressor protein that binds $p$-coumaroyl coenzyme A. Journal of Bacteriology, 194(8), 1960-1967.

Hogancamp, T. N., Mabanglo, M. F., \& Raushel, F. M. (2018). Structure and reaction mechanism of the LigJ hydratase: An enzyme critical for the bacterial degradation of lignin in the protocatechuate 4,5-cleavage pathway. Biochemistry, 57(40), 5841-5850.

Hogancamp, T. N., \& Raushel, F. M. (2018). Functional annotation of LigU as a 1,3-Allylic Isomerase during the degradation of lignin in the protocatechuate 4, 5-cleavage pathway from the soil bacterium Sphingobium sp. SYK-6. Biochemistry, 57(19), 2837-2845.

Holesova, Z., Jakubkova, M., Zavadiakova, I., Zeman, I., Tomaska, L., \& Nosek, J. (2011). Gentisate and 3oxoadipate pathways in the yeast Candida parapsilosis: identification and functional analysis of the genes coding for 3-hydroxybenzoate 6-hydroxylase and 4-hydroxybenzoate 1-hydroxylase. Microbiology, 157(7), 2152-2163. 
Hopper, D. J., \& Chapman, P. J. (1971). Gentisic acid and its 3-and 4-methyl-substituted homologues as intermediates in the bacterial degradation of $m$-cresol, 3,5-xylenol and 2,5-xylenol. Biochemical Journal, 122(1), 19-28.

Hosokawa, K., \& Stanier, R. Y. (1966). Crystallization and properties of $p$-hydroxybenzoate hydroxylase from Pseudomonas putida. Journal of Biological Chemistry, 241(10), 2453-2460.

Howell, L. G., Spector, T., \& Massey, V. (1972). Purification and properties of $p$-hydroxybenzoate hydroxylase from Pseudomonas fluorescens. Journal of Biological Chemistry, 247(13), 4340-4350.

Huang, Z., Dostal, L., \& Rosazza, J. P. (1993). Mechanisms of ferulic acid conversions to vanillic acid and guaiacol by Rhodotorula rubra. Journal of Biological Chemistry, 268(32), 23954-23958.

Humphreys, J. M., \& Chapple, C. (2002). Rewriting the lignin roadmap. Current Opinion in Plant Biology, 5(3), 224-229.

Inoue, J., Shaw, J. P., Rekik, M., \& Harayama, S. (1995). Overlapping substrate specificities of benzaldehyde dehydrogenase (the $x y / C$ gene product) and 2-hydroxymuconic semialdehyde dehydrogenase (the $x y / G$ gene product) encoded by TOL plasmid pWWO of Pseudomonas putida. Journal of Bacteriology, 177(5), 1196-1201.

Ishiyama, D., Vujaklija, D., \& Davies, J. (2004). Novel pathway of salicylate degradation by Streptomyces sp. strain WA46. Applied and Environmental Microbiology, 70(3), 1297-1306.

Iyayi, C. B., \& Dart, R. K. (1982). The degradation of p-coumaryl alcohol by Aspergillus flavus. Microbiology, 128(7), 1473-1482.

Jayakannan, M., Bose, J., Babourina, O., Rengel, Z., \& Shabala, S. (2015). Salicylic acid in plant salinity stress signalling and tolerance. Plant Growth Regulation, 76(1), 25-40.

Jiménez, N., Curiel, J. A., Reverón, I., de las Rivas, B., \& Muñoz, R. (2013). Uncovering the Lactobacillus plantarum WCFS1 gallate decarboxylase involved in tannin degradation. Applied and Environmental Microbiology, 79(14), 4253-4263.

Jin, J., Mazon, H., van den Heuvel, R. H., Janssen, D. B., \& Fraaije, M. W. (2007). Discovery of a eugenol oxidase from Rhodococcus sp. strain RHA1. The FEBS Journal, 274(9), 2311-2321.

Jones, D. C., \& Cooper, R. A. (1990). Catabolism of 3-hydroxybenzoate by the gentisate pathway in Klebsiella pneumoniae M5a1. Archives of Microbiology, 154(5), 489-495.

Jones, K. H., Trudgill, P. W., \& Hopper, D. J. (1993). Metabolism of p-cresol by the fungus Aspergillus fumigatus. Applied and Environmental Microbiology, 59(4), 1125-1130.

Jones, K. H., Trudgill, P. W., \& Hopper, D. J. (1994). 4-Ethylphenol metabolism by Aspergillus fumigatus. Applied and Environmental Microbiology, 60(6), 1978-1983.

Jung, D. H., Choi, W., Choi, K. Y., Jung, E., Yun, H., Kazlauskas, R. J., \& Kim, B. G. (2013). Bioconversion of $p$ coumaric acid to $p$-hydroxystyrene using phenolic acid decarboxylase from $B$. amyloliquefaciens in biphasic reaction system. Applied Microbiology and Biotechnology, 97(4), 1501-1511.

Jung, D. H., Kim, E. J., Jung, E., Kazlauskas, R. J., Choi, K. Y., \& Kim, B. G. (2016). Production of p-hydroxybenzoic acid from $p$-coumaric acid by Burkholderia glumae BGR1. Biotechnology and Bioengineering, 113(7), 1493-1503.

Kadakol, J. C., \& Kamanavalli, C. M. (2010). Biodegradation of eugenol by Bacillus cereus strain PN24. Journal of Chemistry, 7(S1), S474-S480. 
Kajander, T., Merckel, M. C., Thompson, A., Deacon, A. M., Mazur, P., Kozarich, J. W., \& Goldman, A. (2002). The structure of Neurospora crassa 3-carboxy-cis,cis-muconate lactonizing enzyme, a $\beta$ propeller cycloisomerase. Structure, 10(4), 483-492.

Kälin, M., Neujahr, H. Y., Weissmahr, R. N., Sejlitz, T, Jöhl, R., Fiechter, A., \& Reiser, J. (1992). Phenol hydroxylase from Trichosporon cutaneum: gene cloning, sequence analysis, and functional expression in Escherichia coli. Journal of Bacteriology, 174(22), 7112-7120.

Kamimura, N., \& Masai, E. (2014). The protocatechuate 4,5-cleavage pathway: Overview and new findings. Biodegradative Bacteria, (pp. 207-226). Springer, Tokyo.

Kamimura, N., Takahashi, K., Mori, K., Araki, T., Fujita, M., Higuchi, Y., \& Masai, E. (2017). Bacterial catabolism of lignin-derived aromatics: New findings in a recent decade: Update on bacterial lignin catabolism. Environmental Microbiology Reports, 9(6), 679-705.

Karmakar, B., Vohra, R. M., Nandanwar, H., Sharma, P., Gupta, K. G., \& Sobti, R. C. (2000). Rapid degradation of ferulic acid via 4-vinylguaiacol and vanillin by a newly isolated strain of Bacillus coagulans. Journal of Biotechnology, 80(3), 195-202.

Kasai, D., Masai, E., Miyauchi, K., Katayama, Y., \& Fukuda, M. (2005). Characterization of the gallate dioxygenase gene: three distinct ring cleavage dioxygenases are involved in syringate degradation by Sphingomonas paucimobilis SYK-6. Journal of Bacteriology, 187(15), 5067-5074.

Kasai, D., Masai, E., Katayama, Y., \& Fukuda, M. (2007). Degradation of 3-o-methylgallate in Sphingomonas paucimobilis SYK-6 by pathways involving protocatechuate 4,5-dioxygenase. FEMS Microbiology Letters, 274(2), 323-328.

Kasai, D., Fujinami, T., Abe, T., Mase, K., Katayama, Y., Fukuda, M., \& Masai, E. (2009). Uncovering the protocatechuate 2,3-cleavage pathway genes. Journal of Bacteriology, 191(21), 6758-6768.

Kaschabek, S. R., Kuhn, B., Müller, D., Schmidt, E., \& Reineke, W. (2002). Degradation of aromatics and chloroaromatics by Pseudomonas sp. strain B13: purification and characterization of 3-oxoadipate: succinylcoenzyme A (CoA) transferase and 3-oxoadipyl-CoA thiolase. Journal of Bacteriology, 184(1), 207-215.

Katagiri, M., Maeno, H., Yamamoto, S., Hayaishi, O., Kitao, T., \& Oae, S. (1965). Salicylate hydroxylase, a monooxygenase requiring flavin adenine dinucleotide II. The mechanism of salicylate hydroxylation to catechol. Journal of Biological Chemistry, 240(8), 3414-3417.

Kaur, B., \& Chakraborty, D. (2013). Biotechnological and molecular approaches for vanillin production: a review. Applied Biochemistry and Biotechnology, 169(4), 1353-1372.

Kim, S. I., Leem, S. H., Choi, J. S., Chung, Y. H., Kim, S., Park, Y. M., Park, Y. N. \& Ha, K. S. (1997). Cloning and characterization of two catA genes in Acinetobacter /woffii K24. Journal of Bacteriology, 179(16), 5226-5231.

Kirimura, K., Gunji, H., Wakayama, R., Hattori, T., \& Ishii, Y. (2010). Enzymatic Kolbe-Schmitt reaction to form salicylic acid from phenol: Enzymatic characterization and gene identification of a novel enzyme, Trichosporon moniliiforme salicylic acid decarboxylase. Biochemical and Biophysical Research Communications, 394(2), 279284.

Kirk, T. K., \& Lorenz, L. F. (1973). Methoxyhydroquinone, an intermediate of vanillate catabolism by Polyporus dichrous. Applied Microbiology, 26(2), 173.

Klessig, D. F., Tian, M., \& Choi, H. W. (2016). Multiple targets of salicylic acid and its derivatives in plants and animals. Frontiers in Immunology, 7, 206.

Kocaçalışkan, I., Talan, I., \& Terzi, I. (2006). Antimicrobial activity of catechol and pyrogallol as allelochemicals. Zeitschrift für Naturforschung C, 61(9-10), 639-642. 
Korošec, B., Sova, M., Turk, S., Kraševec, N., Novak, M., Lah, L., Stojan, J., Podobnik, B., Berne, S., Zupanec, N., Bunc, M., Gobec, S., and Komel, R. (2014). Antifungal activity of cinnamic acid derivatives involves inhibition of benzoate 4-hydroxylase (CYP53). Journal of Applied Microbiology, 116(4), 955-966.

Krings, U., \& Berger, R. G. (1998). Biotechnological production of flavours and fragrances. Applied Microbiology and Biotechnology, 49(1), 1-8.

Krings, U., Pilawa, S., Theobald, C., \& Berger, R. G. (2001). Phenyl propenoic side chain degradation of ferulic acid by Pycnoporus cinnabarinus-elucidation of metabolic pathways using [ $\left[-^{2} \mathrm{H}\right]$-ferulic acid. Journal of Biotechnology, 85(3), 305-314.

Kukor, J. J., \& Olsen, R. H. (1991). Genetic organization and regulation of a meta cleavage pathway for catechols produced from catabolism of toluene, benzene, phenol, and cresols by Pseudomonas pickettii PKO1. Journal of Bacteriology, 173(15), 4587-4594.

Kunjapur, A. M., Tarasova, Y., \& Prather, K. L. (2014). Synthesis and accumulation of aromatic aldehydes in an engineered strain of Escherichia coli. Journal of the American Chemical Society, 136(33), 11644-11654.

Kuswandi, K., \& Roberts, C. F. (1992). Genetic control of the protocatechuic acid pathway in Aspergillus nidulans. Microbiology, 138(4), 817-823.

Lah, L., Podobnik, B., Novak, M., Korošec, B., Berne, S., Vogelsang, M., Kraševec, N., Zupanec, N., Stojan, J., Bohlmann. J., \& Komel, R. (2011). The versatility of the fungal cytochrome P450 monooxygenase system is instrumental in xenobiotic detoxification. Molecular Microbiology, 81(5), 1374-1389.

Larroy, C., Fernández, M. R., González, E., Parés, X., \& Biosca, J. A. (2002). Characterization of the Saccharomyces cerevisiae YMR318C (ADH6) gene product as a broad specificity NADPH-dependent alcohol dehydrogenase: relevance in aldehyde reduction. Biochemical Journal, 361(1), 163-172.

Lee, J. W., Lee, S. M., Hong, E. J., Jeung, E. B., Kang, H. Y., Kim, M. K., \& Choi, I. G. (2006). Estrogenic reduction of styrene monomer degraded by Phanerochaete chrysosporium KFRI 20742. The Journal of Microbiology, 44(2), 177-184.

Lee, J. H., \& Wendisch, V. F. (2017). Biotechnological production of aromatic compounds of the extended shikimate pathway from renewable biomass. Journal of Biotechnology, 257, 211-221.

Leisola, M. S., Schmidt, B., Thanei-Wyss, U., \& Fiechter, A. (1985). Aromatic ring cleavage of veratryl alcohol by Phanerochaete chrysosporium. FEBS Letters, 189(2), 267-270.

Lin, F., Ferguson, K. L., Boyer, D. R., Lin, X. N., \& Marsh, E. N. G. (2015). Isofunctional enzymes PAD1 and UbiX catalyze formation of a novel cofactor required by ferulic acid decarboxylase and 4-hydroxy-3-polyprenylbenzoic acid decarboxylase. ACS Chemical Biology, 10(4), 1137-1144.

Linke, D., Riemer, S. J., Schimanski, S., Nieter, A., Krings, U., \& Berger, R. G. (2017). Cold generation of smoke flavour by the first phenolic acid decarboxylase from a filamentous ascomycete Isaria farinosa. Fungal Biology, 121(9), 763-774.

Lima, T. C., Ferreira, A. R., Silva, D. F., Lima, E. O., \& de Sousa, D. P. (2017). Antifungal activity of cinnamic acid and benzoic acid esters against Candida albicans strains. Natural Product Research, 32(5), 572-575.

Loake, G., \& Grant, M. (2007). Salicylic acid in plant defence-the players and protagonists. Current Opinion in Plant Biology, 10(5), 466-472.

Liu, T. T., \& Zhou, N. Y. (2012). Novel L-cysteine-dependent maleylpyruvate isomerase in the gentisate pathway of Paenibacillus sp. strain NyZ101. Journal of Bacteriology, 194(15), 3987-3994. 
Lupa, B., Lyon, D., Gibbs, M. D., Reeves, R. A., \& Wiegel, J. (2005). Distribution of genes encoding the microbial non-oxidative reversible hydroxyarylic acid decarboxylases/phenol carboxylases. Genomics, 86(3), 342-351.

Lupa, B., Lyon, D., Shaw, L. N., Sieprawska-Lupa, M., \& Wiegel, J. (2008). Properties of the reversible nonoxidative vanillate/4-hydroxybenzoate decarboxylase from Bacillus subtilis. Canadian Journal of Microbiology, 54(1), 7581.

Maeda, M., Tokashiki, M., Tokashiki, M., Uechi, K., Ito, S., \& Taira, T. (2018). Characterization and induction of phenolic acid decarboxylase from Aspergillus luchuensis. Journal of Bioscience and Bioengineering, 126(2), 162168.

Mäkelä, M. R., Marinović, M., Nousiainen, P., Liwanag, A. J., Benoit, I., Sipilä, J., Hatakka, A., de Vries, R. P., \& Hildén, K. S. (2015). Aromatic metabolism of filamentous fungi in relation to the presence of aromatic compounds in plant biomass. Advances in Applied Microbiology, 91, 63-137.

Marín, M., Plumeier, I., \& Pieper, D. H. (2012). Degradation of 2,3-dihydroxybenzoate by a novel meta-cleavage pathway. Journal of Bacteriology, JB-00430.

Martins, T. M., Hartmann, D. O., Planchon, S., Martins, I., Renaut, J., \& Pereira, C. S. (2015). The old 3-oxoadipate pathway revisited: new insights in the catabolism of aromatics in the saprophytic fungus Aspergillus nidulans. Fungal Genetics and Biology, 74, 32-44.

Masai, E., Momose, K., Hara, H., Nishikawa, S., Katayama, Y., \& Fukuda, M. (2000). Genetic and biochemical characterization of 4-carboxy-2-hydroxymuconate-6-semialdehyde dehydrogenase and its role in the protocatechuate 4, 5-cleavage pathway in Sphingomonas paucimobilis SYK-6. Journal of Bacteriology, 182(23), 6651-6658.

Masai, E., Harada, K., Peng, X., Kitayama, H., Katayama, Y., \& Fukuda, M. (2002). Cloning and characterization of the ferulic acid catabolic genes of Sphingomonas paucimobilis SYK-6. Applied and Environmental Microbiology, 68(9), 4416-4424.

Masai, E., Sasaki, M., Minakawa, Y., Abe, T., Sonoki, T., Miyauchi, K., Katayama, Y., \& Fukuda, M. (2004). A novel tetrahydrofolate-dependent O-demethylase gene is essential for growth of Sphingomonas paucimobilis SYK-6 with syringate. Journal of Bacteriology, 186(9), 2757-2765.

Masai, E., Katayama, Y., \& Fukuda, M. (2007a). Genetic and biochemical investigations on bacterial catabolic pathways for lignin-derived aromatic compounds. Bioscience, Biotechnology, and Biochemistry, 71(1), 1-15.

Masai, E., Yamamoto, Y., Inoue, T., Takamura, K., Hara, H., Kasai, D., Katayama, Y., \& Fukuda, M. (2007b). Characterization of ligV essential for catabolism of vanillin by Sphingomonas paucimobilis SYK-6. Bioscience, Biotechnology, and Biochemistry, 71(10), 2487-2492.

Matera, I., Ferraroni, M., Bürger, S., Scozzafava, A., Stolz, A., \& Briganti, F. (2008). Salicylate 1,2-dioxygenase from Pseudaminobacter salicylatoxidans: crystal structure of a peculiar ring-cleaving dioxygenase. Journal of Molecular Biology, 380(5), 856-868.

Mathew, S., Abraham, T. E., \& Sudheesh, S. (2007). Rapid conversion of ferulic acid to 4-vinyl guaiacol and vanillin metabolites by Debaryomyces hansenii. Journal of Molecular Catalysis B: Enzymatic, 44(2), 48-52.

Matsuzaki, F., \& Wariishi, H. (2005). Molecular characterization of cytochrome P450 catalyzing hydroxylation of benzoates from the white-rot fungus Phanerochaete chrysosporium. Biochemical and Biophysical Research Communications, 334(4), 1184-1190.

Mazur, P., Henzel, W. J., Mattoo, S., \& Kozarich, J. W. (1994). 3-Carboxy-cis, cis-muconate lactonizing enzyme from Neurospora crassa: an alternate cycloisomerase motif. Journal of Bacteriology, 176(6), 1718-1728. 
McKenna, R., \& Nielsen, D. R. (2011). Styrene biosynthesis from glucose by engineered E. coli. Metabolic Engineering, 13(5), 544-554.

McKenna, R., Pugh, S., Thompson, B., \& Nielsen, D. R. (2013). Microbial production of the aromatic buildingblocks (S)-styrene oxide and (R)-1,2-phenylethanediol from renewable resources. Biotechnology Journal, 8(12), 1465-1475.

McLeod, M. N. (1974). Plant tannins-their role in forage quality. Nutrition Abstracts and Reviews, 44, 803-815.

Meier, A. K., Worch, S., Böer, E., Hartmann, A., Mascher, M., Marzec, M., Scholz, U., Riechen, J., Baronian, K., Schauer, F., Bode, R., \& Kunze, G. (2017). Agdc1p - a gallic acid decarboxylase Involved in the degradation of tannic acid in the yeast Blastobotrys (Arxula) adeninivorans. Frontiers in Microbiology, 8, 1777.

Méndez, V., Agullo, L., Gonzalez, M., \& Seeger, M. (2011). The homogentisate and homoprotocatechuate central pathways are involved in 3- and 4-hydroxyphenylacetate degradation by Burkholderia xenovorans LB400. PLOS One, 6(3), e17583.

Milstein, O., Vered, Y., Shragina, L., Gressel, J., Flowers, H. M., \& Hüttermann, A. (1983). Metabolism of lignin related aromatic compounds by Aspergillus japonicus. Archives of Microbiology, 135(2), 147-154.

Mishra, S., Sachan, A., \& Sachan, S. G. (2013). Production of natural value-added compounds: an insight into the eugenol biotransformation pathway. Journal of Industrial Microbiology \& Biotechnology, 40(6), 545-550.

Miyauchi, K., Adachi, Y., Nagata, Y., \& Takagi, M. (1999). Cloning and sequencing of a novel meta-cleavage dioxygenase gene whose product is involved in degradation of $\gamma$-hexachlorocyclohexane in Sphingomonas paucimobilis. Journal of Bacteriology, 181(21), 6712-6719.

Mohan, K., \& Phale, P. S. (2017). Carbon source-dependent inducible metabolism of veratryl alcohol and ferulic acid in Pseudomonas putida CSV86. Applied and Environmental Microbiology, 83(8), e03326-16.

Monisha, T. R., Mukram, I., Kirankumar, B., Reddy, P. V., Nayak, A. S., \& Karegoudar, T. B. (2017). Utilization of phenylpropanoids by newly isolated bacterium Pseudomonas sp. TRMK1. Applied Biochemistry and Biotechnology, 182(3), 1240-1255.

Montersino, S., \& van Berkel, W. J. (2012). Functional annotation and characterization of 3-hydroxybenzoate 6hydroxylase from Rhodococcus jostii RHA1. Biochimica et Biophysica Acta (BBA)-Proteins and Proteomics, 1824(3), 433-442.

Montiel-González, A. M., Fernández, F. J., Viniegra-González, G., \& Loera, O. (2002). Invertase production on solid-state fermentation by Aspergillus niger strains improved by parasexual recombination. Applied Biochemistry and Biotechnology, 102(1-6), 63-70.

Mukai, N., Masaki, K., Fujii, T., Kawamukai, M., \& lefuji, H. (2010). PAD1 and FDC1 are essential for the decarboxylation of phenylacrylic acids in Saccharomyces cerevisiae. Journal of Bioscience and Bioengineering, 109(6), 564-569.

Mukherjee, G., Sachan, A., Ghosh, S., \& Mitra, A. (2006). Conversion of sinapic acid to syringic acid by a filamentous fungus Paecilomyces variotii. The Journal of General and Applied Microbiology, 52(2), 131-135.

Muthukumar, G., Arunakumari, A., \& Mahadevan, A. (1982). Degradation of aromatic compounds by Rhizobium spp. Plant and Soil, 69(2), 163-169.

Narbad, A., \& Gasson, M. J. (1998). Metabolism of ferulic acid via vanillin using a novel CoA-dependent pathway in a newly-isolated strain of Pseudomonas fluorescens. Microbiology, 144(5), 1397-1405.

Nazareth, S., \& Mavinkurve, S. (1986). Degradation of ferulic acid via 4-vinylguaiacol by Fusarium solani (Mart.) Sacc. Canadian Journal of Microbiology, 32(6), 494-497. 
Neidle, E. L., Hartnett, C., Ornston, L. N., Bairoch, A., Rekik, M., \& Harayama, S. (1991). Nucleotide sequences of the Acinetobacter calcoaceticus ben $A B C$ genes for benzoate 1,2-dioxygenase reveal evolutionary relationships among multicomponent oxygenases. Journal of Bacteriology, 173(17), 5385-5395.

Newby, V. K., Sablon, R. M., Synge, R. L., Casteele, K. V., \& Van Sumere, C. F. (1980). Free and bound phenolic acids of lucerne (Medicago sativa cv Europe). Phytochemistry, 19(4), 651-657.

Nguyen, Q. T., de Gonzalo, G., Binda, C., Rioz-Martínez, A., Mattevi, A., \& Fraaije, M. W. (2016). Biocatalytic properties and structural analysis of eugenol oxidase from Rhodococcus jostii RHA1: a versatile oxidative biocatalyst. ChemBioChem, 17(14), 1359-1366.

Nimura, Y., Tsujiyama, S. I., \& Ueno, M. (2010). Bioconversion of cinnamic acid derivatives by Schizophyllum commune. The Journal of General and Applied Microbiology, 56(5), 381-387.

Nishida, A., \& Fukuzumi, T. (1978). Formation of coniferyl alcohol from ferulic acid by the white rot fungus Trametes. Phytochemistry, 17(3), 417-419.

Noda, S., Kitazono, E., Tanaka, T., Ogino, C., \& Kondo, A. (2012). Benzoic acid fermentation from starch and cellulose via a plant-like $\beta$-oxidation pathway in Streptomyces maritimus. Microbial Cell Factories, 11(1), 49.

Nogales, J., Canales, Á., Jiménez-Barbero, J., García, J. L., \& Díaz, E. (2005). Molecular characterization of the gallate dioxygenase from Pseudomonas putida KT2440 the prototype of a new subgroup of extradiol dioxygenases. Journal of Biological Chemistry, 280(42), 35382-35390.

Nogales, J., Canales, Á., Jiménez-Barbero, J., Serra, B., Pingarrón, J. M., García, J. L., \& Díaz, E. (2011). Unravelling the gallic acid degradation pathway in bacteria: the gal cluster from Pseudomonas putida. Molecular Microbiology, 79(2), 359-374.

Ornston, L. N. (1966). The conversion of catechol and protocatechuate to $\beta$-ketoadipate by Pseudomonas putida III. Enzymes of the catechol pathway. Journal of Biological Chemistry, 241(16), 3795-3799.

Otani, H., Lee, Y. E., Casabon, I., \& Eltis, L. D. (2014). Characterization of p-hydroxycinnamate catabolism in a soil Actinobacterium. Journal of Bacteriology, JB-02247.

Otto, K., Hofstetter, K., Röthlisberger, M., Witholt, B., \& Schmid, A. (2004). Biochemical characterization of StyAB from Pseudomonas sp. strain VLB120 as a two-component flavin-diffusible monooxygenase. Journal of Bacteriology, 186(16), 5292-5302.

Ou, S., \& Kwok, K. C. (2004). Ferulic acid: pharmaceutical functions, preparation and applications in foods. Journal of the Science of Food and Agriculture, 84(11), 1261-1269.

Overhage, J., Priefert, H., Rabenhorst, J., \& Steinbüchel, A. (1999). Biotransformation of eugenol to vanillin by a mutant of Pseudomonas sp. strain HR199 constructed by disruption of the vanillin dehydrogenase ( $v d h)$ gene. Applied Microbiology and Biotechnology, 52(6), 820-828.

Overhage, J., Kresse, A. U., Priefert, H., Sommer, H., Krammer, G., Rabenhorst, J., \& Steinbüchel, A. (1999). Molecular characterization of the genes $p c a G$ and $p c a H$, encoding protocatechuate 3,4-dioxygenase, which are essential for vanillin catabolism in Pseudomonas sp. strain HR199. Applied and Environmental Microbiology, 65(3), 951-960.

Overhage, J., Steinbüchel, A., \& Priefert, H. (2003). Highly efficient biotransformation of eugenol to ferulic acid and further conversion to vanillin in recombinant strains of Escherichia coli. Applied and Environmental Microbiology, 69(11), 6569-6576. 
Palazzolo, M. A., Mascotti, M. L., Lewkowicz, E. S., \& Kurina-Sanz, M. (2015). Self-sufficient redox biotransformation of lignin-related benzoic acids with Aspergillus flavus. Journal of Industrial Microbiology \& Biotechnology, 42(12), 1581-1589.

Parsek, M. R., Shinabarger, D. L., Rothmel, R. K., \& Chakrabarty, A. M. (1992). Roles of CatR and cis,cis-muconate in activation of the catBC operon, which is involved in benzoate degradation in Pseudomonas putida. Journal of Bacteriology, 174(23), 7798-7806.

Pei, K., Ou, J., Huang, J., \& Ou, S. (2016). p-Coumaric acid and its conjugates: dietary sources, pharmacokinetic properties and biological activities. Journal of the Science of Food and Agriculture, 96(9), 2952-2962.

Peng, X., Misawa, N., \& Harayama, S. (2003). Isolation and characterization of thermophilic bacilli degrading cinnamic, 4-coumaric, and ferulic acids. Applied and Environmental Microbiology, 69(3), 1417-1427.

Penn, C. D., \& Daniel, S. L. (2013). Salicylate degradation by the fungal plant pathogen Sclerotinia sclerotiorum. Current Microbiology, 67(2), 218-225.

Plaggenborg, R., Overhage, J., Steinbüchel, A., \& Priefert, H. (2003). Functional analyses of genes involved in the metabolism of ferulic acid in Pseudomonas putida KT2440. Applied Microbiology and Biotechnology, 61(5-6), 528-535.

Plaggenborg, R., Overhage, J., Loos, A., Archer, J. A., Lessard, P., Sinskey, A. J., Steinbüchel, A., \& Priefert, H. (2006). Potential of Rhodococcus strains for biotechnological vanillin production from ferulic acid and eugenol. Applied Microbiology and Biotechnology, 72(4), 745.

Plumridge, A., Stratford, M., Lowe, K. C., \& Archer, D. B. (2008). The weak-acid preservative sorbic acid is decarboxylated and detoxified by a phenylacrylic acid decarboxylase, PadA1, in the spoilage mold Aspergillus niger. Applied and Environmental Microbiology, 74(2), 550-552.

Plumridge, A., Melin, P., Stratford, M., Novodvorska, M., Shunburne, L., Dyer, P. S., Roubos, A. J., Menke, H., Stark, S., Stam, H., \& Archer, D. B. (2010). The decarboxylation of the weak-acid preservative, sorbic acid, is encoded by linked genes in Aspergillus spp. Fungal Genetics and Biology, 47(8), 683-692.

Powlowski, J., \& Shingler, V. (1994). Genetics and biochemistry of phenol degradation by Pseudomonas sp. CF600. Biodegradation, 5(3-4), 219-236.

Pometto III, A. L., Sutherland, J. B., \& Crawford, D. L. (1981). Streptomyces setonii: catabolism of vanillic acid via guaiacol and catechol. Canadian Journal of Microbiology, 27(6), 636-638.

Priefert, H., Rabenhorst, J., \& Steinbüchel, A. (1997). Molecular characterization of genes of Pseudomonas sp. strain HR199 involved in bioconversion of vanillin to protocatechuate. Journal of Bacteriology, 179(8), 25952607.

Priefert, H., Overhage, J., \& Steinbüchel, A. (1999). Identification and molecular characterization of the eugenol hydroxylase genes (ehyA/ehyB) of Pseudomonas sp. strain HR199. Archives of Microbiology, 172(6), 354-363.

Priefert, H., Rabenhorst, J., \& Steinbüchel, A. (2001). Biotechnological production of vanillin. Applied Microbiology and Biotechnology, 56(3-4), 296-314.

Providenti, M. A., O'Brien, J. M., Ruff, J., Cook, A. M., \& Lambert, I. B. (2006). Metabolism of isovanillate, vanillate, and veratrate by Comamonas testosteroni strain BR6020. Journal of Bacteriology, 188(11), 3862-3869.

Rahouti, M., Seigle-Murandi, F., Steiman, R., \& Eriksson, K. E. (1989). Metabolism of ferulic acid by Paecilomyces variotii and Pestalotia palmarum. Applied and Environmental Microbiology, 55(9), 2391-2398. 
Raj, A., Reddy, M. K., \& Chandra, R. (2007). Identification of low molecular weight aromatic compounds by gas chromatography-mass spectrometry (GC-MS) from kraft lignin degradation by three Bacillus sp. International Biodeterioration \& Biodegradation, 59(4), 292-296.

Ravi, K., García-Hidalgo, J., Gorwa-Grauslund, M. F., \& Lidén, G. (2017). Conversion of lignin model compounds by Pseudomonas putida KT2440 and isolates from compost. Applied Microbiology and Biotechnology, 101(12), 5059-5070.

Ravi, K., García-Hidalgo, J., Nöbel, M., Gorwa-Grauslund, M. F., \& Lidén, G. (2018). Biological conversion of aromatic monolignol compounds by a Pseudomonas isolate from sediments of the Baltic Sea. AMB Express, 8(1), 32.

Richard, P., Viljanen, K., \& Penttilä, M. (2015). Overexpression of PAD1 and FDC1 results in significant cinnamic acid decarboxylase activity in Saccharomyces cerevisiae. AMB Express, 5(1), 12.

Rieble, S., Joshi, D. K., \& Gold, M. H. (1994). Aromatic nitroreductase from the basidiomycete Phanerochaete chrysosporium. Biochemical and Biophysical Research Communications, 205(1), 298-304.

Romano, D., Valdetara, F., Zambelli, P., Galafassi, S., De Vitis, V., Molinari, F., Compagno, C., Forschino, R. \& Vigentini, I. (2017). Cloning the putative gene of vinyl phenol reductase of Dekkera bruxellensis in Saccharomyces cerevisiae. Food Microbiology, 63, 92-100.

Rosini, E., D'Arrigo, P., \& Pollegioni, L. (2016). Demethylation of vanillic acid by recombinant LigM in a one-pot cofactor regeneration system. Catalysis Science \& Technology, 6(21), 7729-7737.

Sachan, A., Ghosh, S., \& Mitra, A. (2005). Biotransformation of $p$-coumaric acid by Paecilomyces variotii. Letters in Applied Microbiology, 42(1), 35-41.

Sachan, A., Ghosh, S., Sen, S. K., \& Mitra, A. (2006). Co-production of caffeic acid and p-hydroxybenzoic acid from p-coumaric acid by Streptomyces caeruleus MTCC 6638. Applied Microbiology and Biotechnology, 71(5), 720727.

Sachan, A., Ghosh, S., \& Mitra, A. (2010). Transforming p-coumaric acid into $p$-hydroxybenzoic acid by the mycelial culture of a white rot fungus Schizophyllum commune. African Journal of Microbiology Research, 4(4), 267-273.

Sànchez i Nogué, V., Black, B. A., Kruger, J. S., Singer, C. A., Ramirez, K. J., Reed, M., Cleveland, N. S., Singer, E. R., Yi, X., Yeap, R. Y., Linger, J. G. and Beckham, G. T. (2018) Integrated diesel production from lignocellulosic sugars via oleaginous yeast. Green Chem. 20, 4349-4365.

Santamaría, L., Reverón, I., de Felipe, F. L., de las Rivas, B., \& Muñoz, R. (2018). Ethylphenols formation by Lactobacillus plantarum: Identification of the enzyme involved in the reduction of vinylphenols. Applied and Environmental Microbiology, AEM-01064.

Santha, R., Savithri, H. S., Rao, N. A., \& Vaidyanathan, C. S. (1995). 2,3-Dihydroxybenzoic acid decarboxylase from Aspergillus niger. The FEBS Journal, 230(1), 104-110.

Seo, J. S., Keum, Y. S., \& Li, Q. (2009). Bacterial degradation of aromatic compounds. International Journal of Environmental Research and Public Health, 6(1), 278-309.

Singh, A., Mukhopadhyay, K., \& Ghosh Sachan, S. (2018). Biotransformation of eugenol to vanillin by a novel strain Bacillus safensis SMS1003. Biocatalysis and Biotransformation, 1-13.

Shah, J. (2003). The salicylic acid loop in plant defense. Current Opinion in Plant Biology, 6(4), 365-371. 
Shen, Y., Li, H., Wang, X., Zhang, X., Hou, J., Wang, L., Gao, N., \& Bao, X. (2014). High vanillin tolerance of an evolved Saccharomyces cerevisiae strain owing to its enhanced vanillin reduction and antioxidative capacity. Journal of Industrial Microbiology \& Biotechnology, 41(11), 1637-1645.

Shi, Y., Chai, L., Tang, C., Yang, Z., Zhang, H., Chen, R., Chen, Y. \& Zheng, Y. (2013). Characterization and genomic analysis of kraft lignin biodegradation by the beta-proteobacterium Cupriavidus basilensis B-8. Biotechnology for Biofuels, 6(1), 1.

Shimada, K., Kimura, E., Yasui, Y., Tanaka, H., Matsushita, S., Hagihara, H., Nagakure, M., \& Kawahisa, M. (1992). Styrene formation by the decomposition by Pichia carsonii of trans-cinnamic acid added to a ground fish product. Applied and Environmental Microbiology, 58(5), 1577-1582.

Shin, K. S. (1995). Oxidation of syringic acid by extracellular peroxidase of white-rot fungus, Pleurotus ostreatus. Mycoscience, 36(1), 31-35.

Shingler, V., Powlowski, J., \& Marklund, U. (1992). Nucleotide sequence and functional analysis of the complete phenol/3,4-dimethylphenol catabolic pathway of Pseudomonas sp. strain CF600. Journal of Bacteriology, 174(3), 711-724.

Shu, L., Chiou, Y. M., Orville, A. M., Miller, M. A., Lipscomb, J. D., \& Que Jr, L. (1995). X-ray absorption spectroscopic studies of the Fe(II) active site of catechol 2,3-dioxygenase. Implications for the extradiol cleavage mechanism. Biochemistry, 34(20), 6649-6659.

Sonia, M., Sharma, K. P., \& Johna, P. J. (2017). Characterization of pyrogallol production from gallic acid by Enterobacter spp. Journal of Microbiology and Biotechnology Research, 2(2), 327-336.

Sonoki, T., Masai, E., Sato, K., Kajita, S., \& Katayama, Y. (2009). Methoxyl groups of lignin are essential carbon donors in C1 metabolism of Sphingobium sp. SYK-6. Journal of Basic Microbiology, 49(S1), S98-S102.

Sonoki, T., Morooka, M., Sakamoto, K., Otsuka, Y., Nakamura, M., Jellison, J., \& Goodell, B. (2014). Enhancement of protocatechuate decarboxylase activity for the effective production of muconate from lignin-related aromatic compounds. Journal of Biotechnology, 192, 71-77.

Steele, D. H., Thornburg, M. J., Stanley, J. S., Miller, R. R., Brooke, R., Cushman, J. R., \& Cruzan, G. (1994). Determination of styrene in selected foods. Journal of Agricultural and Food Chemistry, 42(8), 1661-1665.

Stentelaire, C., Lesage-Meessen, L., Oddou, J., Bernard, O., Bastin, G., Ceccaldi, B. C., \& Asther, M. (2000). Design of a fungal bioprocess for vanillin production from vanillic acid at scalable level by Pycnoporus cinnabarinus. Journal of Bioscience and Bioengineering, 89(3), 223-230.

Suárez, R., Suárez-Lepe, J. A., Morata, A., \& Calderón, F. (2007). The production of ethylphenols in wine by yeasts of the genera Brettanomyces and Dekkera: a review. Food Chemistry, 102(1), 10-21.

Sugumaran, M., Ramanarayanan, M., \& Vaidyanathan, C. S. (1973). Involvement of protocatechuic acid in the metabolism of phenylacetic acid by Aspergillus niger. FEBS Letters, 29(1), 69-72.

Sun, X., Lin, Y., Huang, Q., Yuan, Q., \& Yan, Y. (2013). A novel muconic acid biosynthesis approach by shunting tryptophan biosynthesis via anthranilate. Applied and Environmental Microbiology, 79(13), 4024-4030.

Sutherland, J. B., Crawford, D. L., \& Pometto, A. L. (1981). Catabolism of substituted benzoic acids by Streptomyces species. Applied and Environmental Microbiology, 41(2), 442-448.

Sutherland, J. B., Crawford, D. L., \& Pometto III, A. L. (1983). Metabolism of cinnamic, p-coumaric, and ferulic acids by Streptomyces setonii. Canadian Journal of Microbiology, 29(10), 1253-1257.

Suzuki, K., Gomi, T., \& Itagaki, E. (1991). Intermediate and mechanism of hydroxylation of o-iodophenol by salicylate hydroxylase. The Journal of Biochemistry, 109(5), 791-797. 
Tack, B. F., Chapman, P. J., \& Dagley, S. (1972). Metabolism of gallic acid and syringic acid by Pseudomonas putida. Journal of Biological Chemistry, 247(20), 6438-6443.

Taira, J., Toyoshima, R., Ameku, N., Iguchi, A., \& Tamaki, Y. (2018). Vanillin production by biotransformation of phenolic compounds in fungus, Aspergillus luchuensis. AMB Express, 8(1), 40.

Tillett, R., \& Walker, J. R. (1990). Metabolism of ferulic acid by a Penicillium sp. Archives of Microbiology, 154(2), 206-208.

Tischler, D. (2015). Pathways for the degradation of styrene. In Microbial Styrene Degradation (pp. 7-22). Springer, Cham.

Topakas, E., Kalogeris, E., Kekos, D., Macris, B. J., \& Christakopoulos, P. (2003). Bioconversion of ferulic acid into vanillic acid by the thermophilic fungus Sporotrichum thermophile. LWT-Food Science and Technology, 36(6), 561-565.

Torres y Torres, J. L., \& Rosazza, J. P. (2001). Microbial transformations of $p$-coumaric acid by Bacillus megaterium and Curvularia lunata. Journal of Natural Products, 64(11), 1408-1414.

Tran, N. P., Gury, J., Dartois, V., Nguyen, T. K. C., Seraut, H., Barthelmebs, L., Gervais, P., \& Cavin, J. F. (2008). Phenolic acid-mediated regulation of the padC gene, encoding the phenolic acid decarboxylase of Bacillus subtilis. Journal of Bacteriology, 190(9), 3213-3224.

Travkin, V. M., Solyanikova, I. P., \& Golovleva, L. A. (2006). Hydroxyquinol pathway for microbial degradation of halogenated aromatic compounds. Journal of Environmental Science and Health Part B, 41(8), 1361-1382.

Tsai, S. C., \& Li, Y. K. (2007). Purification and characterization of a catechol 1,2-dioxygenase from a phenol degrading Candida albicans TL3. Archives of Microbiology, 187(3), 199-206.

Tsuge, Y., Kawaguchi, H., Sasaki, K., \& Kondo, A. (2016). Engineering cell factories for producing building block chemicals for bio-polymer synthesis. Microbial Cell Factories, 15(1), 19.

Tsujiyama, S. I., \& Ueno, M. (2008). Formation of 4-vinyl guaiacol as an intermediate in bioconversion of ferulic acid by Schizophyllum commune. Bioscience, Biotechnology, and Biochemistry, 72(1), 212-215.

Vaillancourt, F. H., Bolin, J. T., \& Eltis, L. D. (2006). The ins and outs of ring-cleaving dioxygenases. Critical Reviews in Biochemistry and Molecular Biology, 41(4), 241-267.

Van Berkel, W. J., Eppink, M. H., Middelhoven, W. J., Vervoort, J., \& Rietjens, I. M. (1994). Catabolism of 4hydroxybenzoate in Candida parapsilosis proceeds through initial oxidative decarboxylation by a FAD-dependent 4-hydroxybenzoate 1-hydroxylase. FEMS Microbiology Letters, 121(2), 207-215.

Van den Heuvel, R. H., Fraaije, M. W., Ferrer, M., Mattevi, A., \& van Berkel, W. J. (2000). Inversion of stereospecificity of vanillyl-alcohol oxidase. Proceedings of the National Academy of Sciences, 97(17), 9455-9460.

Van den Heuvel, R. H., Fraaije, M. W., Mattevi, A., \& van Berkel, W. J. (2002). Structure, function and redesign of vanillyl-alcohol oxidase. In International Congress Series (Vol. 1233, pp. 13-24). Elsevier.

Van der Brink, J. M., Van Den Hondel, C. A. M. J. J., \& Van Gorcom, R. F. M. (1996). Optimization of the benzoateinducible benzoate $p$-hydroxylase cytochrome P450 enzyme system in Aspergillus niger. Applied Microbiology and Biotechnology, 46(4), 360-364.

Van Duy, N., Mäder, U., Tran, N. P., Cavin, J. F., Tam, L. T., Albrecht, D., Hecker, M., \& Antelmann, H. (2007). The proteome and transcriptome analysis of Bacillus subtilis in response to salicylic acid. Proteomics, 7(5), 698-710.

Van Gorcom, R. F., Boschloo, J. G., Kuijvenhoven, A., Lange, J., van Vark, A. J., Bos, C. J., van Balken J. A. M., Pouwels P. H., \& van den Hondel, C. A. (1990). Isolation and molecular characterization of the benzoate-para- 
hydroxylase gene (bphA) of Aspergillus niger: a member of a new gene family of the cytochrome P450 superfamily. Molecular and General Genetics, 223(2), 192-197.

Varanasi, P., Singh, P., Auer, M., Adams, P. D., Simmons, B. A., \& Singh, S. (2013). Survey of renewable chemicals produced from lignocellulosic biomass during ionic liquid pretreatment. Biotechnology for Biofuels, 6(1), 14.

Vernooij, B., Uknes, S., Ward, E., \& Ryals, J. (1994). Salicylic acid as a signal molecule in plant-pathogen interactions. Current Opinion in Cell Biology, 6(2), 275-279.

Walton, N. J., Mayer, M. J., \& Narbad, A. (2003). Vanillin. Phytochemistry, 63(5), 505-515.

Warhurst, A. M., Clarke, K. F., Hill, R. A., Holt, R. A., \& Fewson, C. A. (1994a). Metabolism of styrene by Rhodococcus rhodochrous NCIMB 13259. Applied and Environmental Microbiology, 60(4), 1137-1145.

Warhurst, A. M., Clarke, K. F., Hill, R. A., Holt, R. A., \& Fewson, C. A. (1994b). Production of catechols and muconic acids from various aromatics by the styrene-degrader Rhodococcus rhodochrous NCIMB 13259. Biotechnology Letters, 16(5), 513-516.

Wu, W., Dutta, T., Varman, A. M., Eudes, A., Manalansan, B., Loqué, D., \& Singh, S. (2017). Lignin valorization: Two hybrid biochemical routes for the conversion of polymeric lignin into value-added chemicals. Scientific Reports, 7(1), 8420.

Xie, N. Z., Liang, H., Huang, R. B., \& Xu, P. (2014). Biotechnological production of muconic acid: current status and future prospects. Biotechnology Advances, 32(3), 615-622.

Xun, L., \& Sandvik, E. R. (2000). Characterization of 4-hydroxyphenylacetate 3-hydroxylase (HpaB) of Escherichia coli as a reduced flavin adenine dinucleotide-utilizing monooxygenase. Applied and Environmental Microbiology, 66(2), 481-486.

Yaegashi, A., Kirby, J., Ito, M., Sun, J., Dutta, T., Mirsiaghi, M., Sundstrom, E. R., Rodriguez, A., Baidoo, E., Tanjore, D., Pray, T., Sale, K., Singh, S., Keasling, J. D., Simmons B. A., Singer, S. W., Magnuson, J. K., Arkin, A. P., Skerker, J. M. \& Gladden, J. M. (2017). Rhodosporidium toruloides: a new platform organism for conversion of lignocellulose into terpene biofuels and bioproducts. Biotechnology for Biofuels, 10(1), 241.

Yajima, Y., Enoki, A., Mayfield, M. B., \& Gold, M. H. (1979). Vanillate hydroxylase from the white rot basidiomycete Phanerochaete chrysosporium. Archives of Microbiology, 123(3), 319-321.

Yaguchi, A., Robinson, A., Mihealsick, E., \& Blenner, M. (2017). Metabolism of aromatics by Trichosporon oleaginosus while remaining oleaginous. Microbial Cell Factories, 16(1), 206.

Yang, W., Tang, H., Ni, J., Wu, Q., Hua, D., Tao, F., \& Xu, P. (2013). Characterization of two Streptomyces enzymes that convert ferulic acid to vanillin. PloS One, 8(6), e67339.

Yoneda, A., Henson, W. R., Goldner, N. K., Park, K. J., Forsberg, K. J., Kim, S. J., Pesesky, M. W., Foston, M., Dantas, G. \& Moon, T. S. (2016). Comparative transcriptomics elucidates adaptive phenol tolerance and utilization in lipid-accumulating Rhodococcus opacus PD630. Nucleic Acids Research, 44(5), 2240-2254.

Zago, A., Degrassi, G., \& Bruschi, C. V. (1995). Cloning, sequencing, and expression in Escherichia coli of the Bacillus pumilus gene for ferulic acid decarboxylase. Applied and Environmental Microbiology, 61(12), 4484-4486.

Zapanta, L. S., \& Tien, M. (1997). The roles of veratryl alcohol and oxalate in fungal lignin degradation. Journal of Biotechnology, 53(2-3), 93-102.

Zhao, H., Xu, Y., Lin, S., Spain, J. C., \& Zhou, N. Y. (2018). The molecular basis for the intramolecular migration (NIH shift) of the carboxyl group during para-hydroxybenzoate catabolism. Molecular Microbiology, 110(3), 411424. 
Zhou, N. Y., Fuenmayor, S. L., \& Williams, P. A. (2001). nag genes of Ralstonia (formerly Pseudomonas) sp. strain U2 encoding enzymes for gentisate catabolism. Journal of Bacteriology, 183(2), 700-708.

Zhu, D., Zhang, P., Xie, C., Zhang, W., Sun, J., Qian, W. J., \& Yang, B. (2017). Biodegradation of alkaline lignin by Bacillus ligniniphilus L1. Biotechnology for Biofuels, 10(1), 44. 


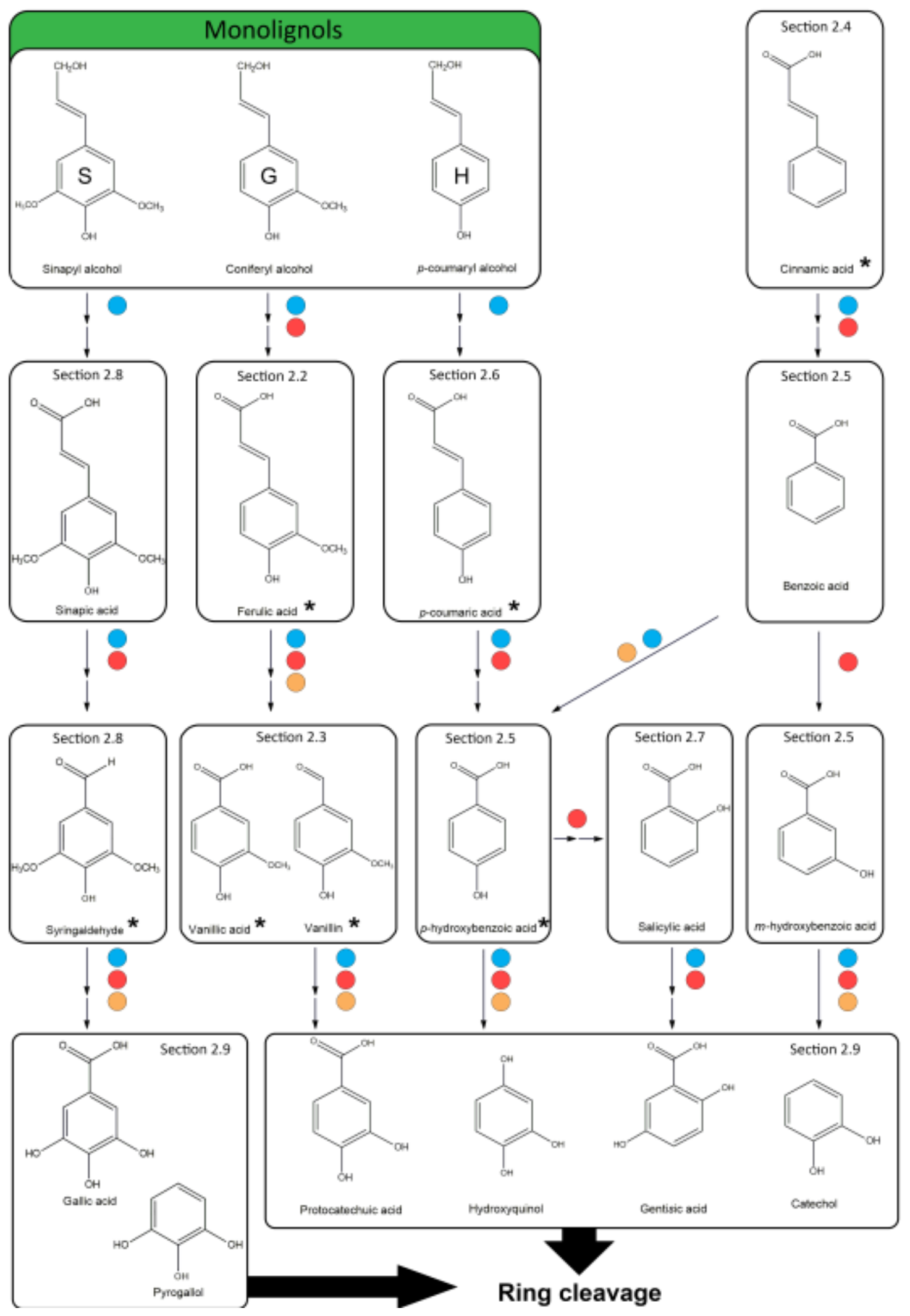

Figure 1. Roadmap of the main aromatic metabolic pathways in bacteria, fungi and yeast. Arrows indicate in which species these aromatic metabolic pathways are observed. Species are marked with a red dot for bacteria, blue for fungi and orange for yeast. Aromatic compounds marked with an asterisk are released during lignin degradation. 


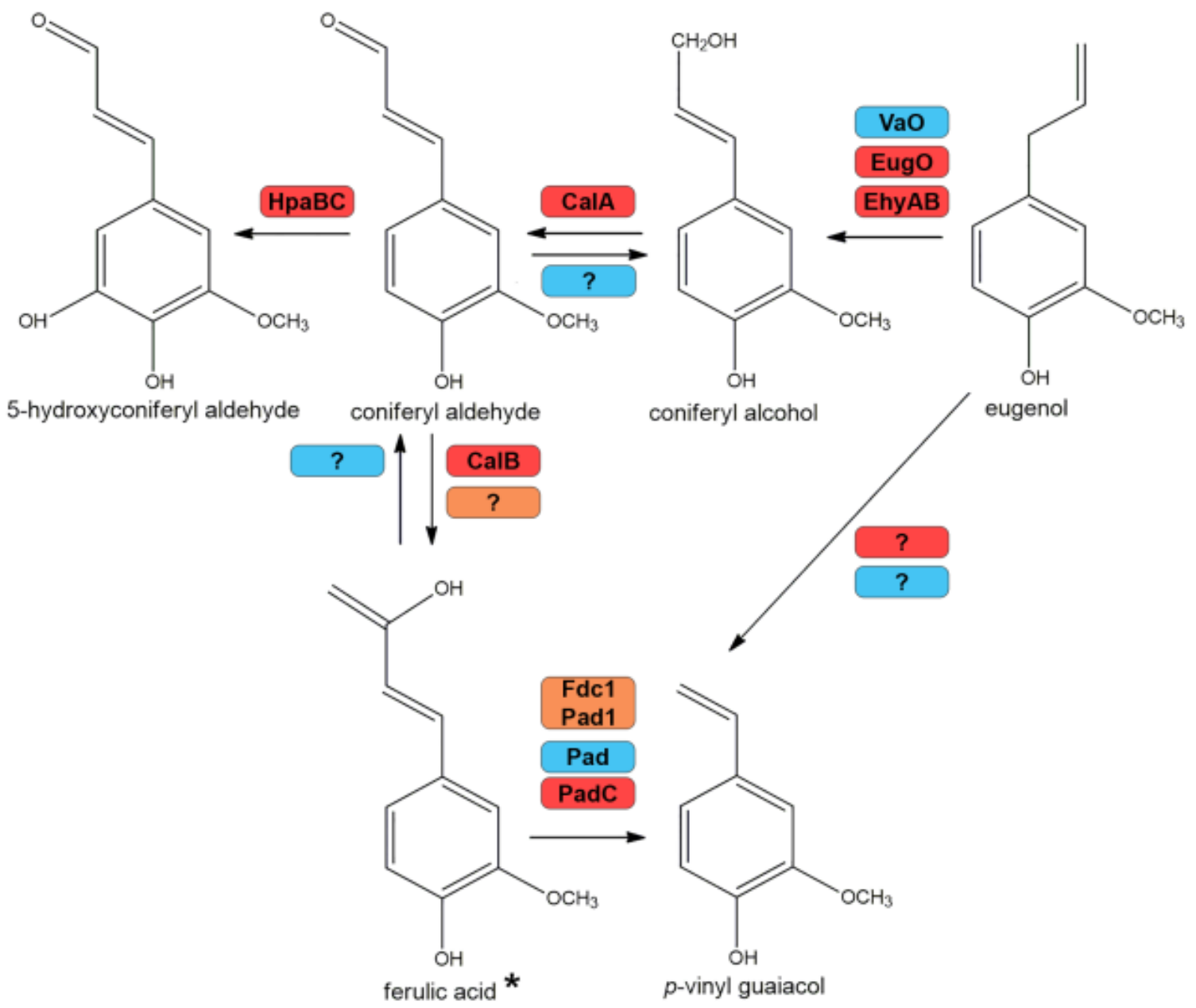

Figure 2. Bacterial, fungal and yeast aromatic metabolic pathways of coniferyl alcohol, eugenol and related aromatic compounds. The aromatic converting enzymes of bacteria (red), filamentous fungi (blue) and yeast (orange) are boxed next to the corresponding pathway. Question marks indicate that the enzyme is not identified. Aromatic compounds marked with an asterisk are released during lignin degradation. 


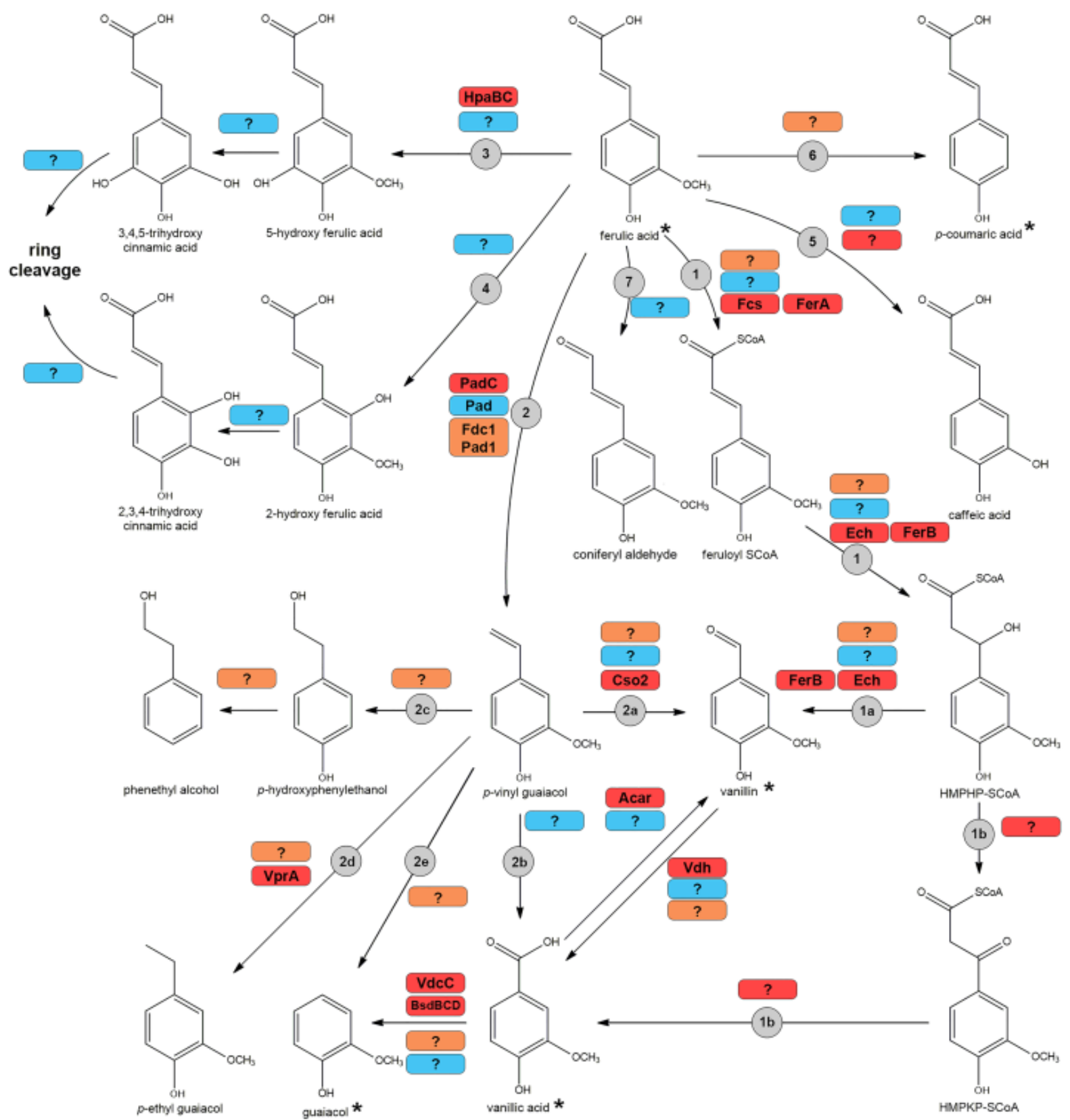

Figure 3. Bacterial, fungal and yeast aromatic metabolic pathways of ferulic acid and related aromatic compounds. The aromatic converting enzymes of bacteria (red), filamentous fungi (blue) and yeast (orange) are boxed next to the corresponding pathway. Question marks indicate that the enzyme is not identified. Pathway numbers corresponds with the numbers given in section 2.2. Aromatic compounds marked with an asterisk are released during lignin degradation. 


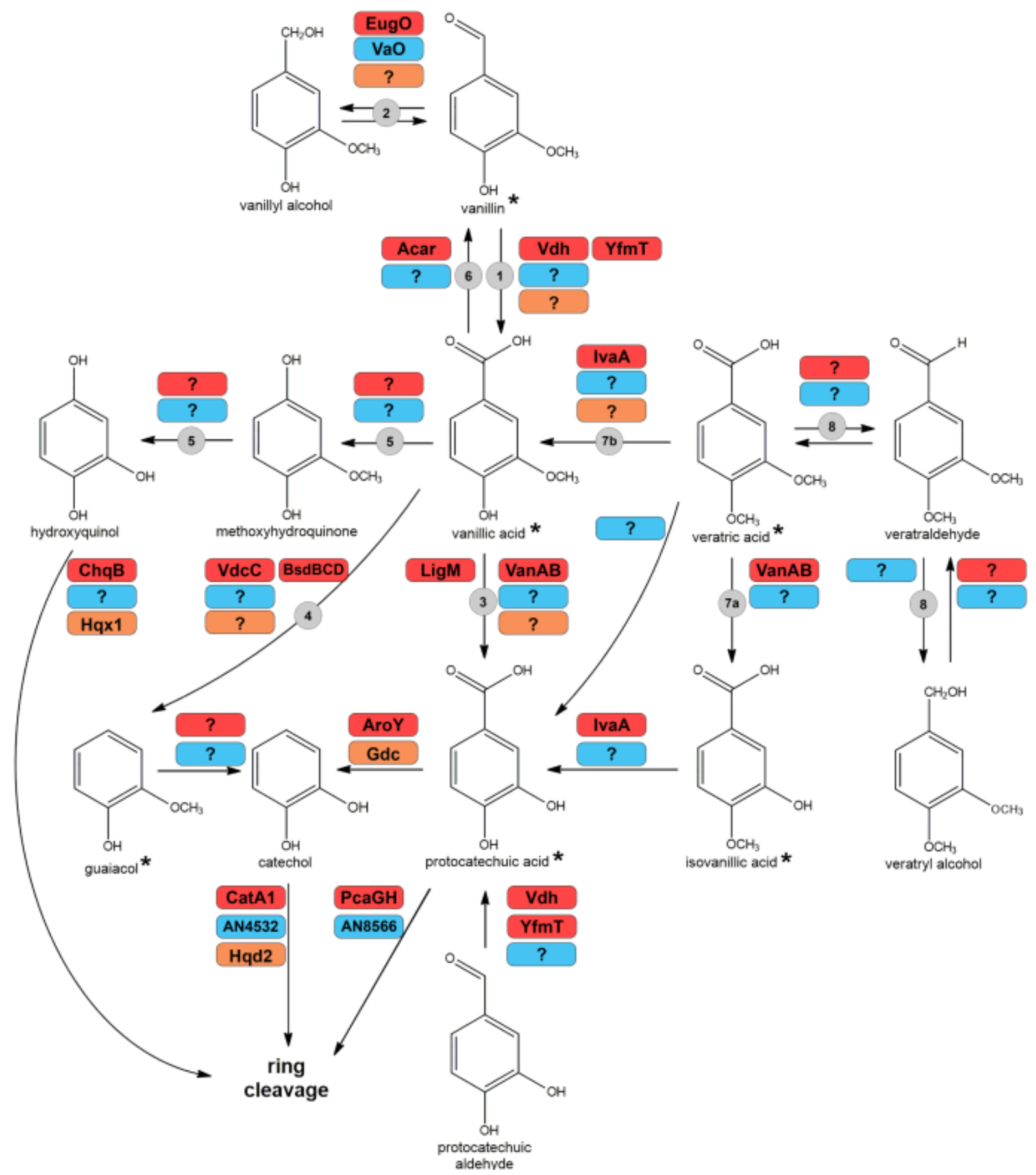

Figure 4. Bacterial, fungal and yeast aromatic metabolic pathways of vanillin, vanillic acid and related aromatic compounds. The aromatic converting enzymes of bacteria (red), filamentous fungi (blue) and yeast (orange) are boxed next to the corresponding pathway. Question marks indicate that the enzyme is not identified. Pathway numbers corresponds with the numbers given in section 2.3. Aromatic compounds marked with an asterisk are released during lignin degradation. 


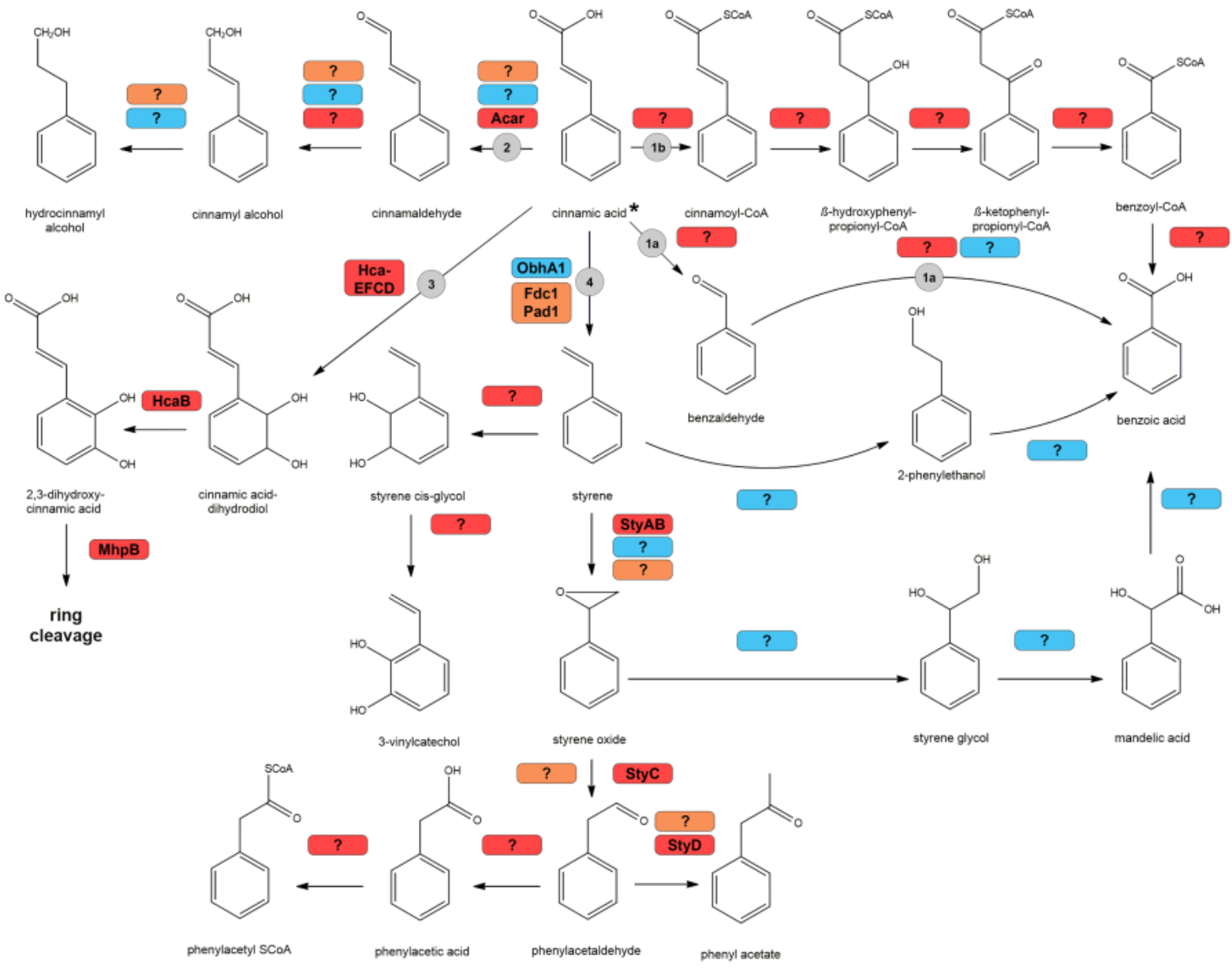

Figure 5. Bacterial, fungal and yeast metabolic pathways of cinnamic acid and related aromatic compounds. The aromatic converting enzymes of bacteria (red), filamentous fungi (blue) and yeast (orange) are boxed next to the corresponding pathway. Question marks indicate that the enzyme is not identified. Pathway numbers corresponds with the number given in section 2.4. Aromatic compounds marked with an asterisk are released during lignin degradation. 


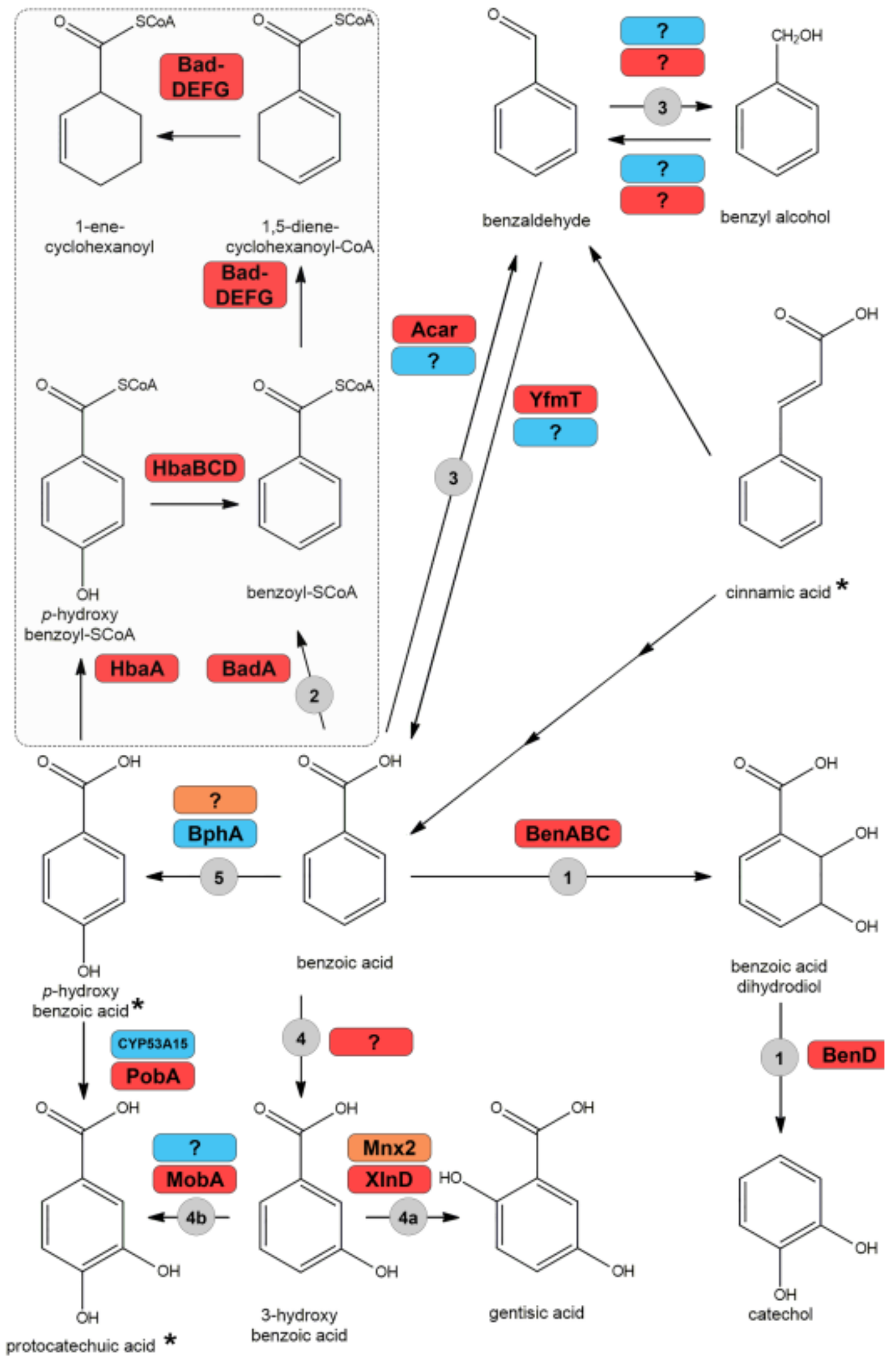

Figure 6. Bacterial, fungal and yeast aromatic metabolic pathways of benzoic acid and related aromatic compounds. The aromatic converting enzymes of bacteria (red), filamentous fungi (blue) and yeast (orange) are boxed next to the corresponding pathway. Question marks indicate that the enzyme is not identified. Pathway numbers corresponds with the numbers given in section 2.5. Compounds within the dashed box are obtained through anaerobic conversion. Aromatic compounds marked with an asterisk are released during lignin degradation. 


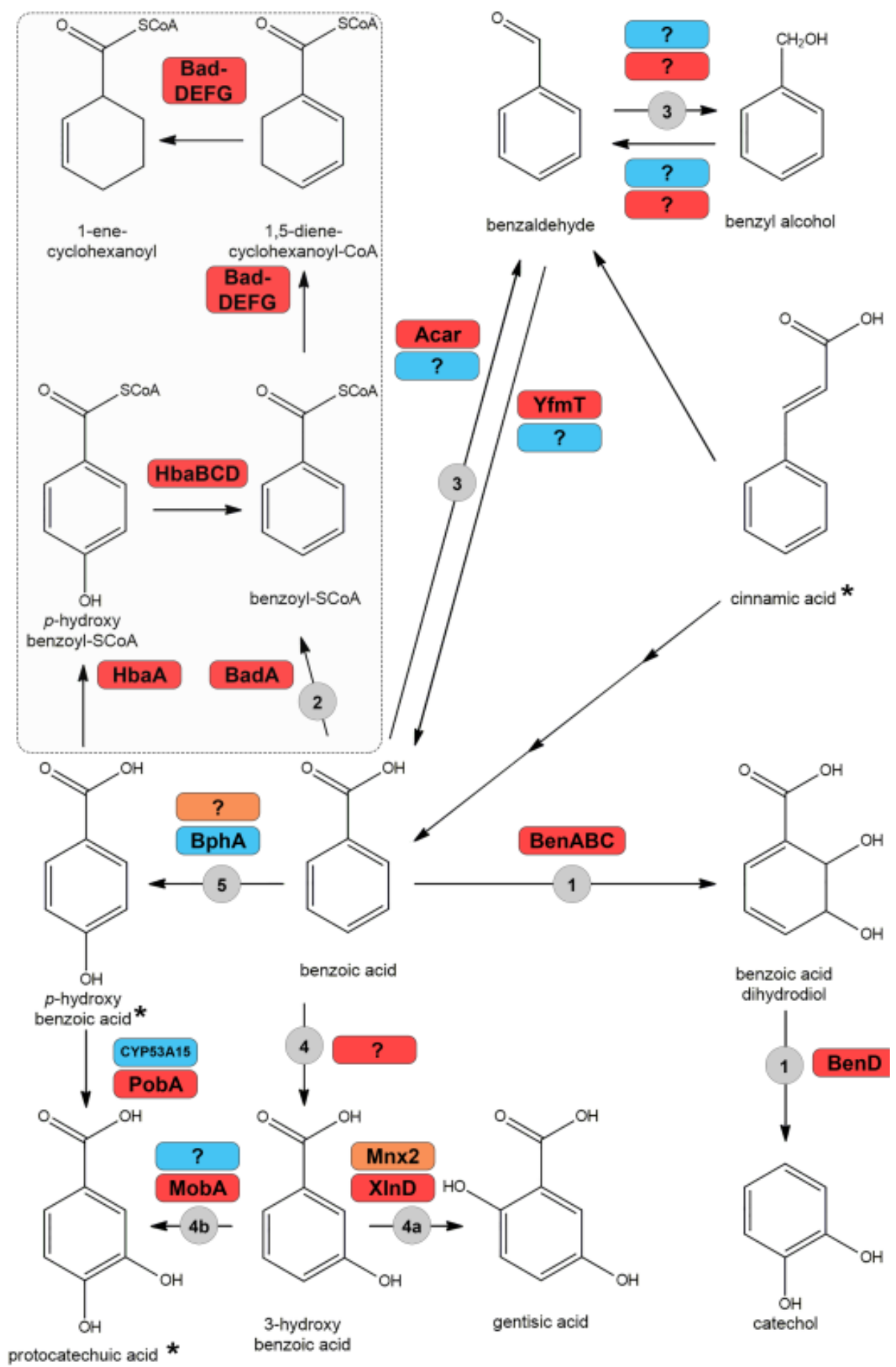

Figure 7. Bacterial, fungal and yeast aromatic metabolic pathways $p$-hydroxybenzoic acid and related aromatic compounds. The aromatic converting enzymes of bacteria (red), filamentous fungi (blue) and yeast (orange) are boxed next to the corresponding pathway. Question marks indicate that the enzyme is not identified. Pathway numbers corresponds with the numbers given in section 2.5. Compounds within the dashed box are obtained through anaerobic conversion. Aromatic compounds marked with an asterisk are released during lignin degradation. 


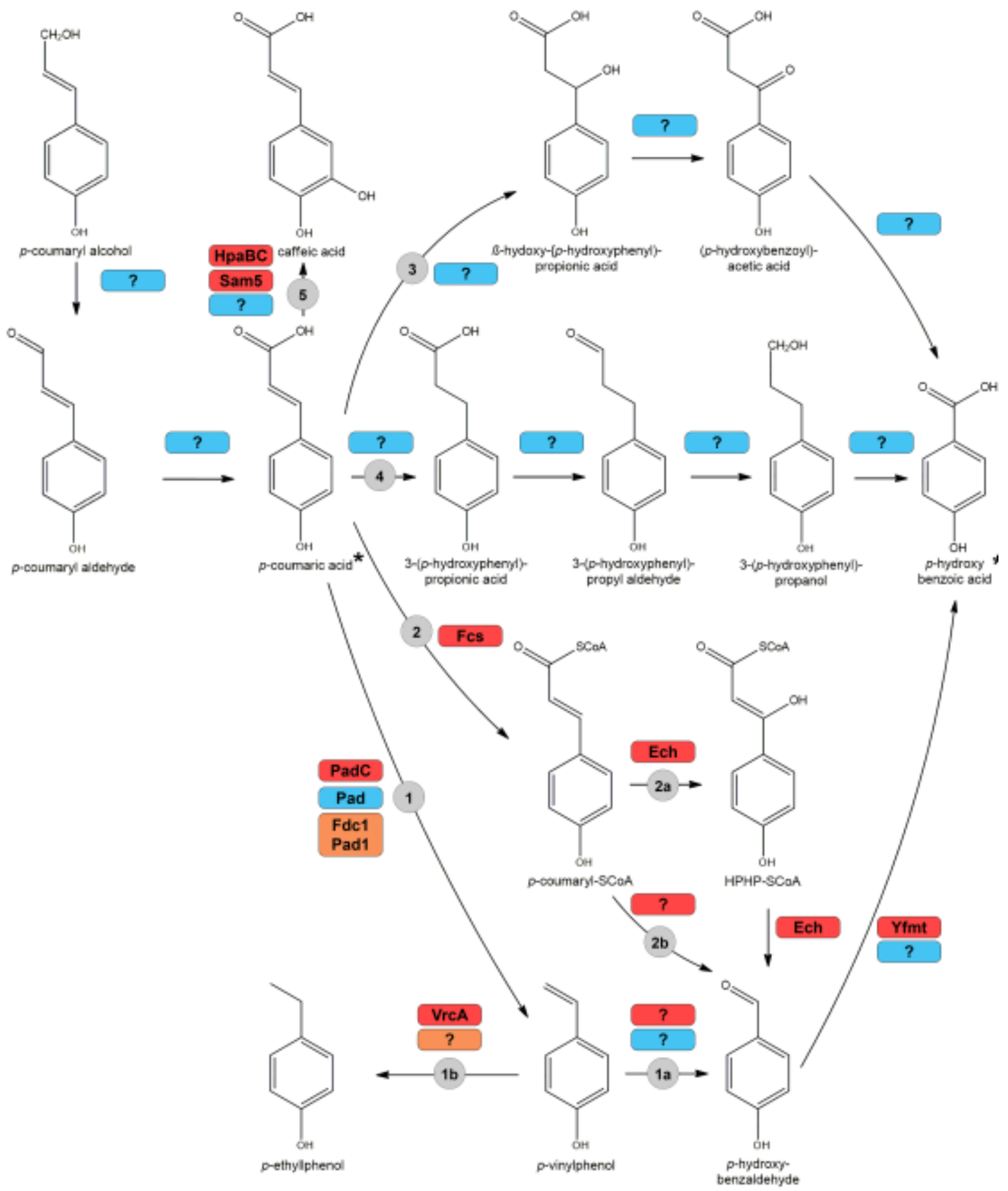

Figure 8. Bacterial, fungal and yeast aromatic metabolic pathways of $p$-coumaric acid and related aromatic compounds. The aromatic converting enzymes of bacteria (red), filamentous fungi (blue) and yeast (orange) are boxed next to the corresponding pathway. Question marks indicate that the enzyme is not identified. Pathway numbers corresponds with the numbers given in section 2.6. Aromatic compounds marked with an asterisk are released during lignin degradation. 


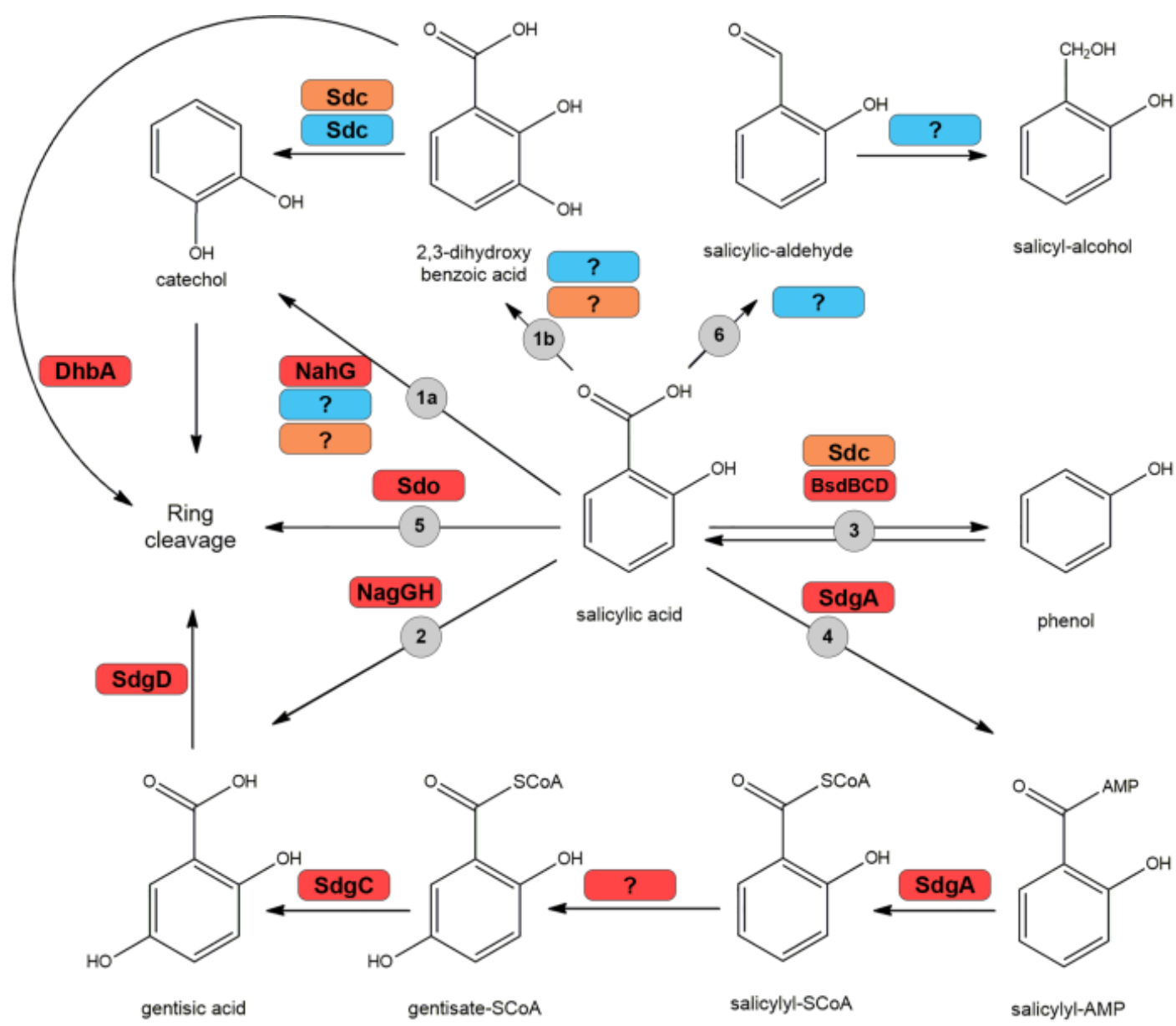

Figure 9. Bacterial, fungal and yeast aromatic metabolic pathways of salicylic acid. The aromatic converting enzymes of bacteria (red), filamentous fungi (blue) and yeast (orange) are boxed next to the corresponding pathway. Question marks indicate that the enzyme is not identified. Pathway numbers corresponds with the numbers given in section 2.7. Aromatic compounds marked with an asterisk are released during lignin degradation. 

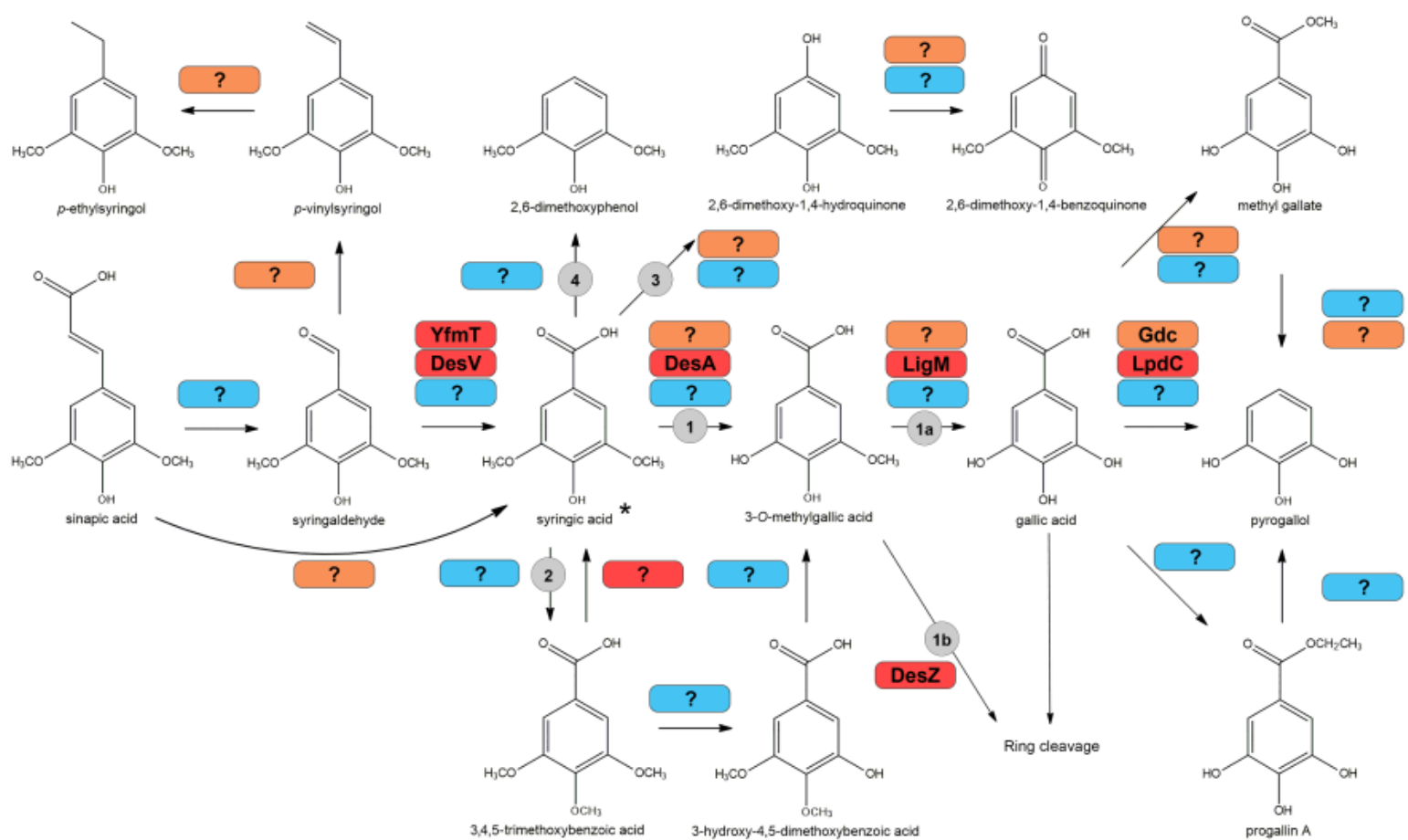

Figure 10. Bacterial, fungal and yeast aromatic metabolic pathways of sinapic acid, syringic acid and related aromatic compounds. The aromatic converting enzymes of bacteria (red), filamentous fungi (blue) and yeast (orange) are boxed next to the corresponding pathway. Question marks indicate that the enzyme is not identified. Pathway numbers corresponds with the numbers given in section 2.8. Aromatic compounds marked with an asterisk are released during lignin degradation. 


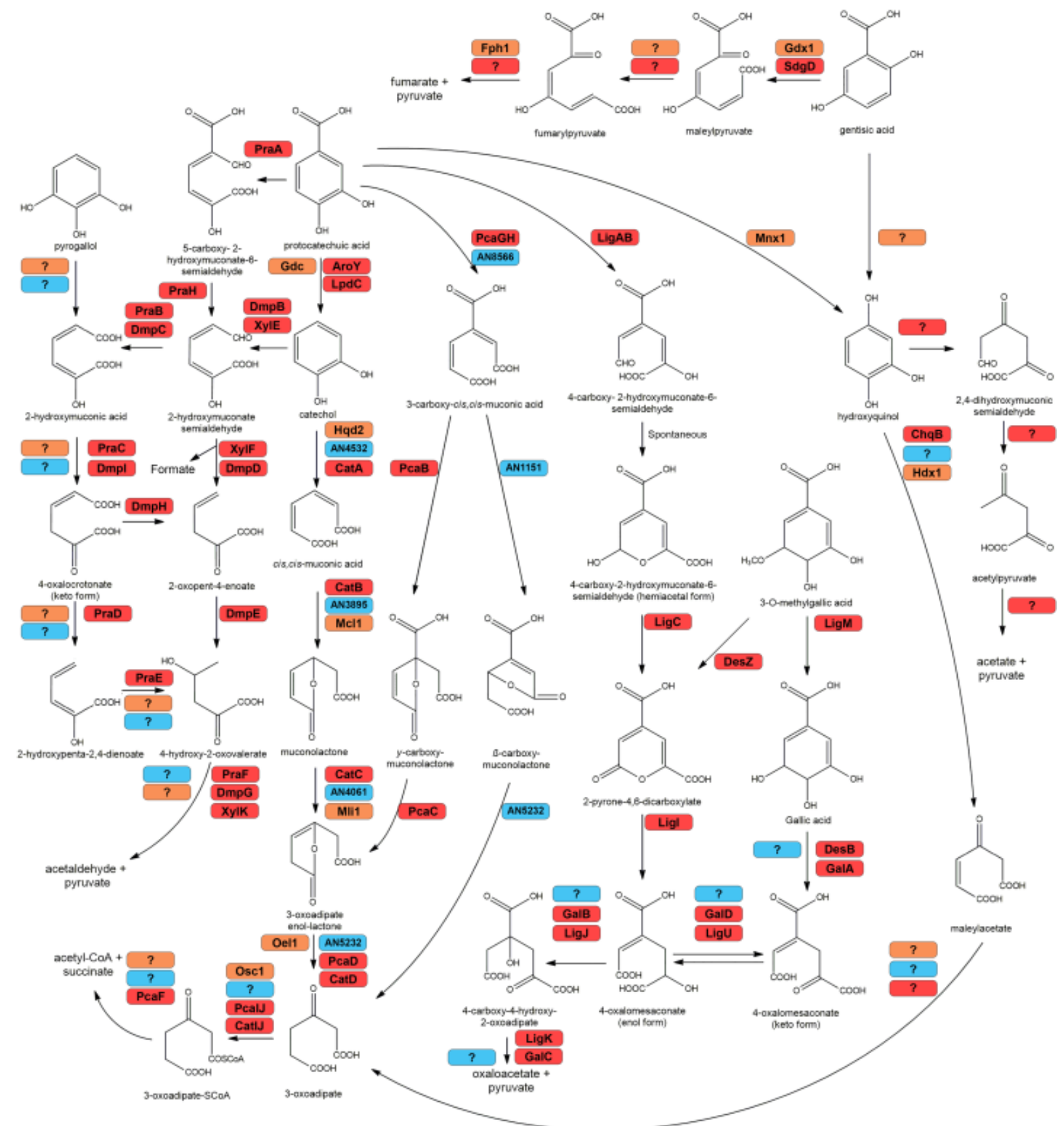

Figure 11. Bacterial, fungal and yeast aromatic ring cleavage pathways. The aromatic converting enzymes of bacteria (red), filamentous fungi (blue) and yeast (orange) are boxed next to the corresponding pathway. Question marks indicate that the enzyme is not identified. 